\author{
Universidade de São Paulo \\ Faculdade de Educação \\ Programa de Pós-Graduação em Educação \\ Nível: Doutorado
}

\title{
A construção/negociação de significados no curso universitário inicial de Cálculo Diferencial e Integral
}

Maria Cristina Bonomi Barufi 


\author{
Universidade de São Paulo \\ Faculdade de Educação \\ Programa de Pós-Graduação em Educação \\ Nível: Doutorado
}

\title{
A construção/negociação de significados no curso universitário inicial de Cálculo Diferencial e Integral
}

Maria Cristina Bonomi Barufi

Tese apresentada como exigência parcial para obtenção do título de Doutor em Educação - Área de Didática, sob a orientação do Prof. Dr. Nilson José Machado

São Paulo março/1999 
aos meninos que nunca me deixaram desistir 
Agradecimentos

Minha gratidão é total.

Ao Professor Nilson, pelo exemplo, dedicação e estímulo; por todo seu apoio e amizade fraterna.

Aos membros da douta Banca, em particular à Professora Elza e ao Professor Scipione, professores de sempre, que me ensinaram a trilhar por este caminho tão frutífero em inquietações e retornos inesquecíveis.

À Professora Ausônia, Diretora Pedagógica do Colégio Equipe, por sua humanidade e pela metodologia problematizadora de ensino.

À Professora lole, pelos cursos de Cálculo, repensados em diferentes tempos, sempre com o mesmo envolvimento.

Aos amigos, e estes são tantos, no IME, na FE, no Equipe, no Oswald de Andrade, na E.E. Mauá, e por aí afora: com eles dividi ansiedades e momentos de grande felicidade. 


\section{A construção/negociação de significados no curso universitário inicial de Cálculo Diferencial e Integral}

\section{Resumo}

As dificuldades existentes com o ensino do Cálculo Diferencial e Integral nos cursos iniciais da Universidade constituíram a grande motivação para este trabalho. À luz do referencial teórico da rede de conhecimentos e significados, buscou-se a compreensão dessas dificuldades a partir dos livros didáticos, por constituírem um instrumento sempre presente no trabalho do professor na sala de aula. Uma vez que conhecer é conhecer o significado, o enfoque principal residiu na negociação dos significados, para esclarecer em que medida a abordagem do Cálculo realizada é uma simples revelação ou uma construção significativa. A análise dos livros didáticos selecionados baseou-se em um modelo construído a partir do referencial teórico proposto e mostrou que a dificuldade não reside na falta de bons livros. A diversidade dos percursos nos livros analisados se traduz numa maior ou menor adequação à construção/negociação de significados no Cálculo.

No trabalho discute-se o papel fundamental do professor na sala de aula, tendo como potencial aliado o computador, como instrumento facilitador, que abre novos horizontes, possibilita o estabelecimento de múltiplas relações e a negociação de significados.

Palavras-chave: Negociação de significados no Cálculo; Ensino de Cálculo; Conhecimento significativo no Cálculo; Computador no ensino de Cálculo. 


\section{The construction/negotiation of the meanings in the beginner's courses of Calculus at the University}

Abstract

The existing difficulties of teaching Calculus in the beginner's courses at the University were the main motivation for this work. In the light of the theoretical referential of the net of knowledge and meanings, one looked for the understanding of these difficulties from textbooks, for they are always present in the work of teachers in classrooms. Since knowing is knowing the meaning, the main focus of this work became the negotiation of meanings, in order to make clear in which measure the chosen approach to the Calculus is a simple revelation or a significant construction. The analysis of the selected textbooks according to a model that was constructed from the proposed theoretical referential, showed that the difficulty is not in the absence of good books. The diversity of paths in the examined books translates into a greater or smaller adequacy to the construction/negotiation of meanings in Calculus.

In this work, one discusses the fundamental role of the teacher in the classroom, having as a potential ally the computer, as an instrument to facilitate work, which opens new horizons, makes possible the setting of multiple relationships and the negotiation of meanings.

Key-words: Negotiation of meanings in Calculus; Teaching of Calculus; Significant knowledge in Calculus; Computer in Calculus teaching. 


\section{La construction/négociation des significations dans le cours univérsitaire initial de Calcul Différentiel et Intégral.}

Résumé

Les difficultés constatées dans l'enseignement du Calcul Différentiel et Intégral dans les cours iniciaux de l'Université sont la grande motivation pour ce travail. À la lumière du repère théorique du réseau de connaissances et significations, on a poursuivit la comprehension de ces difficultés à partir des livres didactiques, puisqu'ils constituent un instrument toujours présent dans le travail de l'instructeur avec ses étudiants. Étant donné que connaître c'est connaître la signification, le focus principal du travail est la négociation des significations, pour éclaircir la mesure dans laquelle la façon d'aborder le Calcul Différentiel et Intégral est une simple revélation ou une construction avec signification. L'analyse des livres didactiques sélectionnés, faite selon un modèle construit à partir du repère théorique proposé, a montré que les difficultés ne se trouvent pas dans l'absence de bons livres. La diversité des parcours utilisés par les livres analysés reflète le degré d'adéquation, plus ou moins grand, à la construction/négociation des significations dans le Calcul Différentiel et Intégral.

Dans ce travail on discute le rôle fondamental du maître dans sa classe, ayant comme allié potential l'ordinateur, lequel peut être un instrument pour faciliter le travail et ouvrir des nouveax horizons, en permettant l'etablissement de relations multiples et aussi la négociation des significations. 
Mots-clés: Négociation des significations dans le Calcul Différentiel et Intégral; Enseignement du Calcul Différentiel et Intégral; Connaissance significative dans le Calcul Différentiel et Intégral; L'ordinateur dans I'enseignement du Calcul Différentiel et Intégral. 
Índice

Introdução

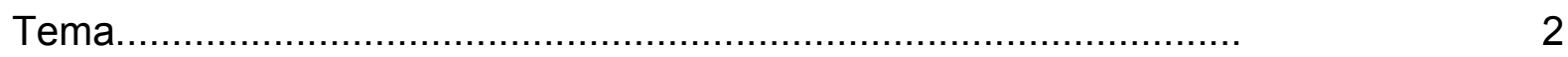

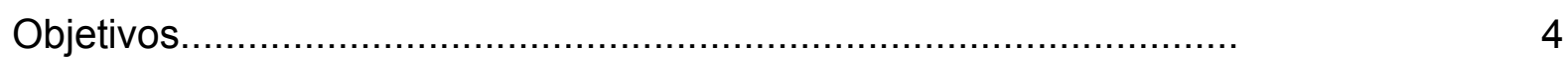

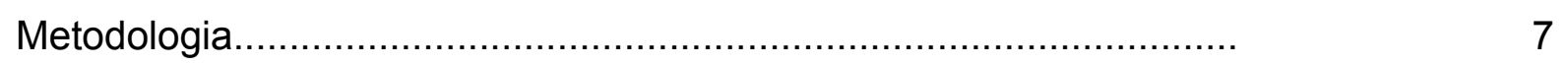

Capítulo 1: O pano de fundo: o conhecimento

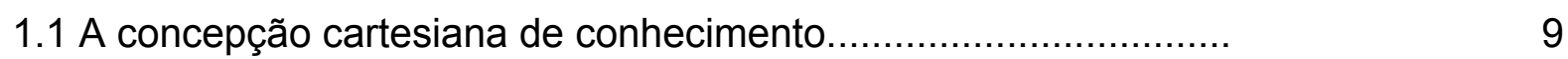

1.2 A rede de conhecimentos e significados.............................. 12

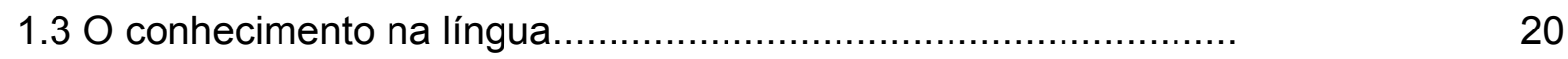

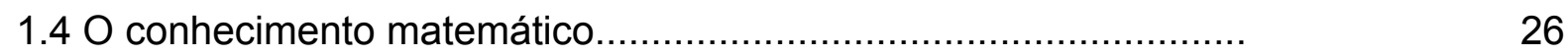

Capítulo 2: A construção do conhecimento matemático e a negociação dos significados na sala de aula

2.1 O trabalho do professor de Matemática................................... 33

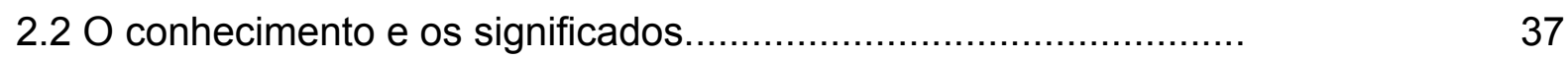

$2.3 \mathrm{O}$ discurso na sala de aula........................................... 40

2.4 A negociação dos significados.......................................... 43 


\section{Capítulo 3: O foco da pesquisa}

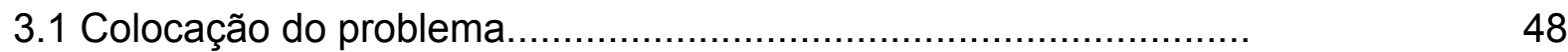

3.2 A análise ........................................................................

3.3 Os livros didáticos selecionados.............................................

Alexander H. W. et alii: A Programed Course In Calculus - Vol I, II, III, IV e V

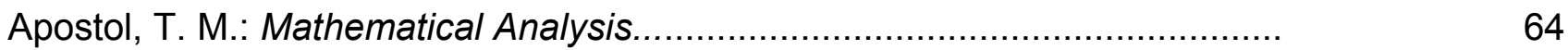

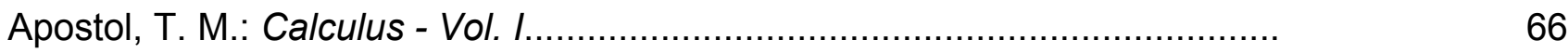

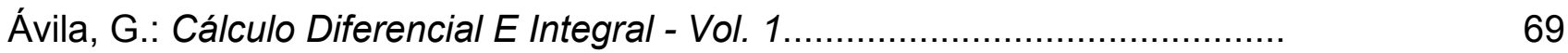

Bartkovich, K. G. et alii: Contemporary Calculus Through Applications............ 71

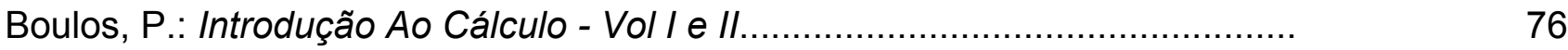

Bruckheimer, M. et alii: Introducción Al Cálculo Y Al Álgebra - Vol. I e II.......... 78

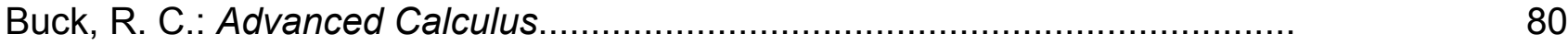

Courant, R.: Differential And Integral Calculus - Vol. I..................................

Courant, R. and John, F.: Introduction To Calculus And Analysis - Vol. I........... 89

Greenspan, H. P. and Benney, D. J.: Calculus - An Introduction To Applied

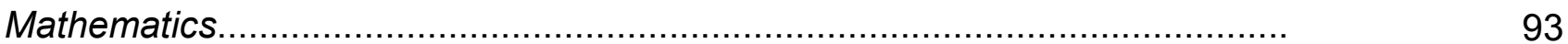

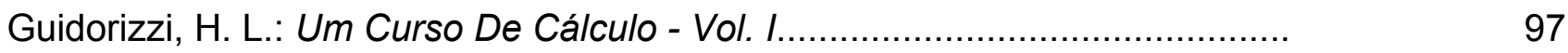

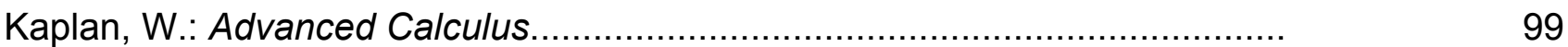

Kaplan, W e Lewis, D. J.: Cálculo E Álgebra Linear - Vol. I.......................... 101

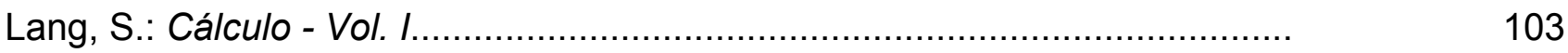

Leithold, L.:O Cálculo Com Geometria Analítica - Vol. I................................ 106

Moise, E. E.: Cálculo - Um Curso Universitário - Vol. I.............................. 108 
Piskounov, N.: Calcul Différentiel et Integral........................................ 111

Rudin, W.: Principles Of Mathematical Analysis .....................................

Simmons, G. F.: Cálculo Com Geometria Analítica - Vol. I........................... 114

Spivak, M.: Cálculo Infinitesimal - Vol. I e II........................................ 116

Swokowski, E. W.: Cálculo Com Geometria Analítica - Vol. I.......................... 118

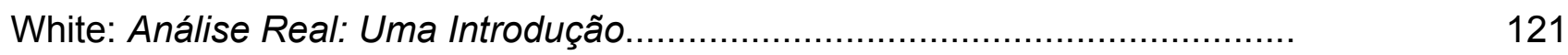

Willcox, A. B. et alii: Introduction To Calculus - Vol. I..................................

\section{Capítulo 4: A análise dos resultados}

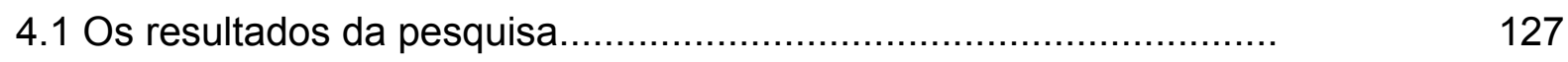

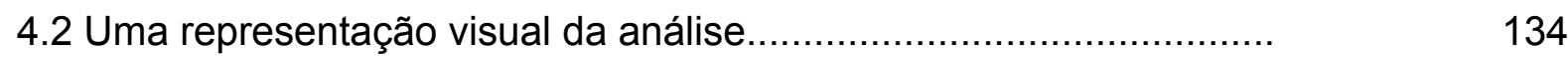

\section{Capítulo 5: Comentários finais e perspectivas}

$5.1 \mathrm{O}$ conhecimento significativo........................................... 148

5.2 A abordagem que respeita a gênese das idéias e a abordagem lógico-formal.

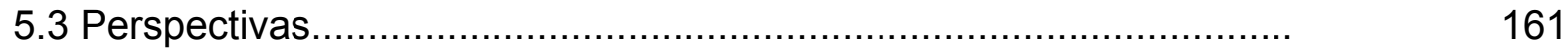

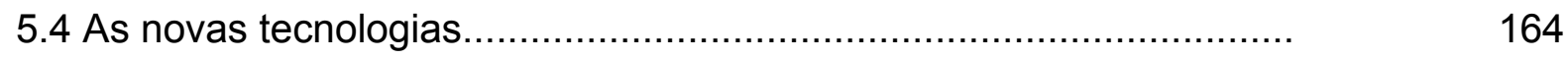

5.5 Novos tempos, novos instrumentos, novos olhares...................... 167

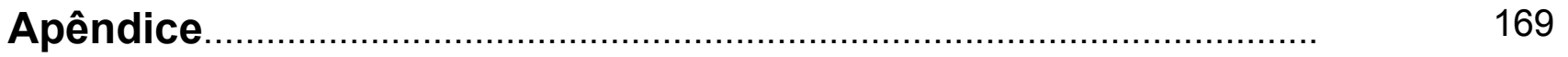

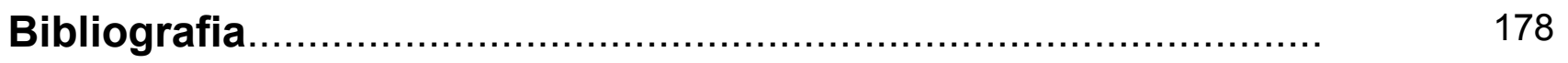


Existe uma verdadeira alegria em fazer matemática, em aprender maneiras de pensar que explicam, organizam e simplificam. Pode-se sentir esta alegria descobrindo novos resultados em matemática, redescobrindo resultados antigos, aprendendo um modo de pensar com alguém ou em um texto, ou encontrando nova maneira de explicar ou de olhar para uma estrutura matemática conhecida. (Thurston, 1994) 


\section{Introdução}

\section{Tema}

$\mathrm{Na}$ Universidade, os cursos introdutórios de Cálculo aparecem como disciplinas do primeiro ano, nas diferentes especificidades dos cursos de Engenharia, nos cursos de Matemática, Física, Química, Ciências Econômicas, Administração, Contabilidade, Arquitetura, Geociências, Biociências. São cursos básicos, ministrados para alunos recém-egressos da escola secundária, de todas as áreas denominadas "exatas" e de algumas classificadas como "humanas" ou "biológicas".

Os diferentes cursos de Cálculo I ministrados na Universidade pretendem levar os alunos a estudar, com maior ou menor profundidade, de acordo com sua área de concentração, o que seja uma função de uma variável real. A construção desse conceito pretende ser sólida, chegando normalmente à visualização através de gráficos, e conseqüente análise do comportamento das funções em seu domínio. Posteriormente, no curso de Cálculo II, trabalha-se o conceito de função de mais de uma variável real, a valores reais, que, aliás descreve situações muito mais realistas no campo, por exemplo, da Economia, Biologia, Engenharia, etc.

Além disso, uma das especificidades do Cálculo, ao desenvolver o estudo de funções, é a de estudar a taxa de variação de uma função, ou seja diferentes maneiras pela qual uma função cresce ou decresce num intervalo ou num determinado ponto de um intervalo. A idéia fundamental é a de que uma curva, localmente, pode ser bem aproximada por uma reta, onde as características de 
proporcionalidade constituem um elemento facilitador na análise e compreensão dos processos envolvidos.

Nessa perspectiva, o Cálculo é uma ferramenta extremamente útil, pois a variação de grandezas e a necessidade de aproximações locais é uma problemática presente em praticamente todas as áreas do conhecimento.

Outro grande objetivo dos cursos iniciais de Cálculo é o de propiciar condições de base para o estudo de equações diferenciais, equações essas que são modelos para problemas relevantes da Física, Química, Engenharia, Economia, Biologia, e etc.

Assim sendo, o Cálculo aparece como um curso básico, amplo e integrador, de caráter fundamental, envolvendo, ano após ano, milhares de alunos e várias dezenas de professores.

Entretanto, ao examinar os resultados obtidos entre 1990 a 1995, na Universidade de São Paulo, observamos médias de aproveitamento muitas vezes sofríveis e elevados números referentes a alunos que não foram aprovados, caracterizando uma situação que, no mínimo, pode ser considerada problemática.

É possível observar esta realidade, por exemplo, no IME, onde, mesmo a mudança da periodicidade dos cursos de Cálculo, transformando os dois cursos semestrais num único curso anual, não trouxe uma significativa melhoria da situação. De fato, verificamos que no ano de 1995, a taxa de não aprovação isto é, reprovação por nota ou por falta, ou desistência - em MAT 135 (Cálculo para Funções de uma Variável Real) foi de 66,9\%, e, em MAT 131 (Cálculo Diferencial e Integral), de 43,8\%. De modo geral, o mesmo se observa fora do IME, como na Escola Politécnica, com dados que, embora denotando uma condição um pouco mais confortável, com médias relativamente mais altas, ainda mostram elevados números de alunos não aprovados. Tais índices se 
mantêm mesmo nos cursos de re-oferecimento, como é o caso de $46,9 \%$ de não aprovação no primeiro semestre de 1994, no curso inicial de Cálculo Diferencial e Integral, para alunos que não foram aprovados no ano anterior.

Em outras Unidades, a conclusão é semelhante, mesmo naquelas em que os cursos de Cálculo são mais adaptados à realidade local, como por exemplo, no Instituto de Geociências, onde, em 1995, a taxa de aprovação na disciplina foi de apenas $35,1 \%$.

Em situações isoladas aparecem resultados melhores, deixando transparecer uma realidade que talvez seja fruto do trabalho de tal ou qual professor, ou do enfoque particular que imprimiu ao seu curso.

Algumas tabelas explicitando mais dados relativos a essa situação, no período de 1990 a 1995, podem ser encontradas no Apêndice.

\section{Objetivos}

No presente trabalho de investigação, estamos interessados em examinar o conhecimento matemático que é trabalhado na sala de aula, especificamente no curso introdutório de Cálculo, na Universidade de São Paulo, no que diz respeito a alguns aspectos que consideramos fortemente relevantes.

Especificamente, espera-se, no curso de Cálculo I, propiciar aos alunos, uma primeira visão mais ampla e global de como o conhecimento matemático pode ser articulado, resolvendo um grande número de problemas reais. 
Considerando que, no curso secundário, a maioria dos alunos não trabalhou com nenhuma das noções do Cálculo, e que os novos conceitos lhe são apresentados segundo uma abordagem que está muito pouco relacionada com a maneira pela qual o Cálculo foi sendo historicamente estruturado, surge uma primeira questão fundamental. Para a maioria dos alunos, o conhecimento matemático, desenvolvido anteriormente, na escola secundária, pouco ou nada tem a ver com o que lhe é apresentado no curso de Cálculo, e o caráter de análise com o qual passa a se defrontar parece constituir uma grande dificuldade. Isto ocorre principalmente quando as questões do Cálculo são apresentadas dentro de um contexto formal, logicamente bem estruturado, no qual o conceito de número real é preponderante e o estudo das funções de variável real aparece como um fim em si mesmo, baseado nas propriedades dos números reais (enquanto corpo ordenado, arquimediano e completo).

Nesse sentido, será interessante observar como é que os novos significados são construídos, como as novas relações são estabelecidas, como, enfim, o Cálculo é articulado à rede de conhecimentos dos estudantes ingressantes na Universidade. Assim, de que maneira é feita a "ponte" entre o conhecimento matemático desenvolvido na escola secundária e aquele abordado no curso de Cálculo? 0 Cálculo é apresentado como algo pronto, ou apresenta-se seu caráter heurístico que possibilitou, ao longo da história, diversas formulações para finalmente se chegar à atual?

Observamos também que os cursos de Cálculo fazem parte de um currículo que, de modo geral, segundo concepções mais atuais, é entendido de uma forma flexível, aberta, reformulável no decorrer da ação, integrando as diferentes disciplinas, através de múltiplas relações inter e transdiciplinares, e que tem por objetivo não apenas a aprendizagem dos alunos, como também o desenvolvimento profissional da equipe de professores. Este conceito difere da 
concepção tradicional, que considera o currículo como um conjunto estático de prescrições a cumprir, estabelecidas a priori, independentemente de qualquer negociação e interação que ocorra em sala de aula.

No sentido da moderna concepção, a socialização das informações obtidas através dos professores das diferentes disciplinas do currículo é de importância crucial para que o processo de investigação-reflexão-ação de toda a equipe responsável venha a se desenrolar de maneira eficiente e produtiva.

Assim, temos outras questões também muito importantes: como, e quanto, o caráter interdisciplinar do Cálculo é explicitado nos diferentes cursos universitários? O conteúdo dos cursos passa por processos de adequação dependendo do que ocorre na sala de aula?

Finalmente, uma questão, que nos desperta grande interesse, refere-se ao processo de negociação didática que se desenrola na sala de aula. Em Hariki, encontramos que o conceito de negociação saiu do âmbito da esfera econômica ou comercial, passando a ter um significado muito mais amplo, especificamente no ambiente da sala de aula. Dessa forma,

The negotiation teacher-learners is a face-to-face interaction: they negotiate meanings, behaviour and values in the classroom. Negotiation does not mean that there is equilibrium of forces between the participants. The imbalance of forces between teacher and learners is indeed one of the principal characteristics of the pedagogic process. The mutual interaction between learners is nowadays very important for this process; it can be done in cooperation or in competition. (Hariki, 1992, p. 18) ${ }^{1}$

Nos diferentes cursos de Cálculo, observamos preocupações diferentes

\footnotetext{
${ }^{1}$ A negociação professor-alunos é uma interação face a face: eles negociam significados, comportamentos e valores na sala de aula. Negociação não significa que haja um equilíbrio de forças entre os participantes. O desequilíbrio de forças entre professor e alunos é uma das características principais do processo pedagógico. A interação mútua entre os alunos é, hoje em dia, muito importante para este processo; ela pode ocorrer em situações de cooperação ou de competição.
} 
relativamente ao enfoque dado, em alguns casos, mais teórico, em outros, mais técnico. De qualquer forma, a construção dos significados, por parte dos alunos, deveria ser um objetivo primordial de todos os cursos. A consecução desse objetivo depende do processo de negociação didática que necessariamente ocorre na sala de aula.

Nesse contexto, será interessante investigar de que maneira é feita a negociação de significados nos cursos de Cálculo I, a fim de possibilitar a construção do conhecimento desejável por parte dos alunos.

Nessa questão, que, na realidade, engloba todas as outras, acreditamos estar o ponto nevrálgico, o verdadeiro nó do problema a ser enfrentado, no que diz respeito ao ensino-aprendizagem do Cálculo. Esperamos, com este trabalho, fazer brilhar alguma luz, que possibilite um melhor entendimento da problemática enfrentada por professores e alunos de alguns dos primeiros cursos da Universidade.

\section{Metodologia}

Para realizar este trabalho de investigação, buscaremos respostas, a nossas perguntas, num conjunto de livros didáticos de Cálculo Diferencial e Integral, juntamente com alguns de Análise Real, que se constituem em modelos da abordagem do conteúdo que é realizada na sala de aula. Entendemos que o livro didático, escolhido pelo professor para suporte ou apoio ao seu trabalho, constitui um forte indício do tratamento que será dado ao curso. O livro preferido faz transparecer muitas das preocupações do professor, suas crenças, suas escolhas metodológicas. No grande espectro de livros que desenvolvem o 
Cálculo Diferencial e Integral, do qual selecionamos uma pequena parte, entendemos que a escolha do professor é importante e significativa.

Evidentemente, a proposta deste trabalho não é a de estabelecer um ranking dos livros didáticos existentes, nem construir qualquer tipo de classificação, com a atribuição de estrelas. A idéia não é a de concluir qual livro é melhor ou qual é pior, mas compreender os fatores determinantes dos problemas enfrentados pelo ensino de Cálculo nos cursos básicos da Universidade, particularmente aqueles relacionados ao importante papel desempenhado pelos livros didáticos. Subsidiariamente, pretende-se desenvolver um modelo de análise dos livros que, à luz dos paradigmas teóricos, nos permita encontrar explicações para as nossas inquietações e assim chegar a um diagnóstico esclarecedor da problemática do Cálculo na Universidade de São Paulo. 


\section{Capítulo 1. O pano de fundo: o conhecimento}

\subsection{A concepção cartesiana de conhecimento}

Penso, logo existo.

A máxima de Descartes permaneceu durante muito tempo como uma verdade tão firme e tão certa que todas as extravagantes suposições dos céticos não eram capazes de a abalar (Descartes, p. 107). A apologia da razão, do racionalmente concebido, foi transparente em Descartes, para o qual era quase impossível que os nossos juízos sejam tão puros e tão sólidos como seriam se tivéssemos todos, desde o nascimento, o uso inteiro de nossa razão e apenas nos tivéssemos conduzido por ela. (íd., p. 77)

A filosofia cartesiana norteou por muito tempo, e, em alguns ambientes, talvez continue norteando, as concepções vigentes de conhecimento em geral, e especificamente do conhecimento matemático. As pressuposições de seu acalentado método de bem conduzir a razão e descobrir a verdade nas ciências são as seguintes:

- nunca aceitar por verdadeira, coisa nenhuma que não se conhecesse como evidente, isto é, evitar cuidadosamente a precipitação e a prevenção;

- dividir cada uma das dificuldades que examinasse em tantas parcelas quantas pudessem ser e fossem exigidas para melhor compreendê-las;

- conduzir por ordem os pensamentos, começando pelos objetos mais simples e mais fáceis de serem conhecidos, para subir, pouco a pouco, 
como por degraus, até o conhecimento dos mais compostos, e, supondo mesmo certa ordem entre os que não se precedem naturalmente uns aos outros;

- fazer sempre enumerações tão completas e revisões tão gerais, que ficasse certo de nada omitir. (Descartes, 1969, p. 85)

Nesse sentido, as considerações a respeito tanto do conhecimento em si, como sobre aquilo que ocorre no campo educacional, especificamente, na sala de aula, e, portanto, no que se refere ao trabalho do professor, tinham por base implícita, quando não realmente explicitada, reflexões que revelavam a rigidez do pensamento do filósofo francês.

\section{Segundo essas concepções,}

(...) el hombre se pensaba radicalmente separado de la naturaleza; observador y observado eran términos rigurosamente separados. En un universo domesticado de esencias estables, de procesos reversibles, de leyes universales, reglado y predictible en el que el hombre se concebía separado de la naturaleza, se sentia ajeno, creía poder observar desde una perspectiva exterior independiente $y$ arrancar al mundo-objecto sus secretos para dominarlo a su arbitrio, sólo un proyecto era possible: conocer para dominar. (Dabas y Najmanovich, 1995 , p. 53) ${ }^{2}$

Nesse contexto, o conhecimento era fundamental para atingir um pedestal de onde o homem poderia exercer seu domínio sobre a natureza, com um caráter de conquista e controle. Além disso, o conhecimento era considerado como algo a ser perseguido, ou transmitido, de maneira linear, obedecendo a uma ordem hierárquica, partindo do mais simples, que se constituía sempre num pré-requisito para se chegar ao mais complexo, mais elaborado.

\footnotetext{
2 (...) o homem se imaginava radicalmente separado da natureza: observador e observado eram termos rigorosamente separados. Em um universo domesticado, de essências estáveis, de processos reversíveis, de leis universais, sujeito a regras e previsível, no qual o homem se concebia separado da natureza, se sentia alheio, acreditava poder observar a partir de uma perspectiva exterior independente e arrancar os segredos do mundo-objeto para arbitrariamente dominá-lo, apenas um projeto era possível: conhecer para dominar.
} 
Tal hierarquização contribuía assim, de certa maneira, para caracterizar o papel do professor, como detentor de um saber que, paulatinamente, deveria ser repassado aos alunos, receptores passivos, esperançosos apenas de atingir aquele degrau altíssimo onde estava o conhecimento imenso do professor.

A crise, cada vez mais evidente, particularmente no campo educacional, tem feito estremecer as bases do pensamento cartesiano e, embora ainda sejam múltiplos os indícios da permanência daquelas concepções, podemos encontrar inúmeros focos que revelam a busca de novos paradigmas. Muito embora a imagem cartesiana seja fortemente hegemônica e ainda constitua um paradigma que norteia o processo de ensino/aprendizagem, reflexões e discussões teóricas têm-se desenrolado em diferentes âmbitos, na busca de uma fundamentação válida que possa viabilizar a construção do conhecimento significativo.

Em Porlán, encontramos que

(...) pretender conocer el conocimiento es quizás uno de los retos más ambiciosos que se pueda imaginar. La doble vertiente del ser humano como sujeto que conoce y como posible objeto de conocimiento plantea un conjunto de problemas filosóficos, científicos $y$ metodológicos que están presentes de forma destacada en la historia del pensamiento humano. De manera especial, el intento de comprender la relación entre el ser y el conocer, ha sido el centro de innumerables debates teóricos entre diferentes paradigmas epistemológicos. (Porlán, 1995, p. 23) ${ }^{3}$

${ }^{3}$ (...) pretender conhecer o conhecimento é talvez um dos desafios mais ambiciosos que se possa imaginar. A dupla caracterização do ser humano como sujeito que conhece e como possível objeto de conhecimento coloca um conjunto de problemas filosóficos, científicos e metodológicos que estão presentes de maneira destacada na história do pensamento humano. De modo especial, a tentativa de compreender a relação entre o ser e o conhecer, tem sido o centro de inumeráveis debates teóricos entre diferentes paradigmas epistemológicos. 


\subsection{A rede de conhecimentos e significados}

Inicialmente, para falarmos a respeito de conhecimento, precisamos esclarecer que a nossa concepção é a de que conhecer algo é conhecer o seu significado.

Segundo Machado, observamos que, de modo geral:

- compreender é aprender o significado;

- aprender o significado de um objeto ou de um acontecimento é vê-lo em suas relações com outros objetos ou acontecimentos;

- os significados constituem, pois, feixes de relações;

- as relações entretecem-se, articulam-se em teias, em redes, construídas social e individualmente, e em permanente estado de atualização;

- em ambos os níveis - individual e social - a idéia de conhecer assemelha-se à de enredar. (Machado, 1995, p.138)

De acordo com essa visão, a compreensão não pode simplesmente ser fruto da transmissão. Ela decorre da apreensão do significado do objeto do conhecimento. Quando falamos em significado de um dado conhecimento, estamos nos referindo a todas as relações que dizem respeito a esse conhecimento. Assim sendo, o significado não é algo material que se transfere de um indivíduo a outro. Constitui-se num feixe de relações, analógicas, metafóricas, que podem ser estabelecidas, envolvendo aquilo que se pretende conhecer, enredando-o ao que já é conhecido. Os significados podem emergir das experiências individual ou coletivamente vivenciadas, a partir da interação dos indivíduos com objetos ou com outros indivíduos. Em vez de afirmar estar "de posse de determinado conhecimento", devemos procurar compreender seu 
significado, por meio das relações que são percebidas. Assim é que conhecer é conhecer o significado.

A idéia subjacente, para a colocação dessa questão, é a de que o conhecimento não é algo que materialmente se acumula, mas que continuamente se constrói, constituindo uma imensa rede de relações. Tal rede é constituída por nós e relações que interligam os diversos nós. Cada nó é um feixe de relações. Não é possível isolar um nó, nem mesmo uma relação. O conjunto todo tem sentido, não há partes que possam ser isoladamente consideradas.

A rede, é dinâmica, em constante transformação, e nela os feixes de relações vão sendo enriquecidos, como também vão sendo estabelecidas sempre mais e novas relações entre os nós.

Se fosse possível retratarmos a rede de significações de um indivíduo, em instantes pontuais sucessivos, veríamos uma série de imagens, onde a malha da rede apresenta configurações sucessivas diferentes, sendo que as relações entre os nós tanto podem ir se tornando mais numerosas, complexas, como serem substituídas por outras, em novas configurações. Essa transformação é fruto das mais diversas experiências vivenciadas, onde cada novo conhecimento significativo, isto é, repleto de significado para o indivíduo, é assimilado à rede como um novo nó ou através de uma ou várias articulações estabelecidas na configuração anterior, conduzindo a uma reconfiguração da rede inteira. Também perceberíamos que a rede, como um todo, não é estática, cada feixe pode ser alterado, ampliado, substituído, e os próprios nós podem mudar sua caracterização.

Além disso, em termos de significações coletivas, percebemos a existência de uma grande rede cuja constituição, transformação e fortalecimento constante é viabilizada pela contribuição das diversas redes individuais, não em termos de somas, mas de entrelaçamentos. 
Finalmente, podemos pensar na imensa rede universal, sem limites, onde todos estão inseridos, imagens, pessoas, objetos, valores, problemas, ... De fato,

Todo el universo físico es visto hoy como una inmensa "red de interacciones" donde nada puede definirse de manera absolutamente independiente, y en el que se enseñorea el "efecto mariposa" (cuja versión popular dice que cuando una mariposa aletea en el Mar de la China puede "causar" un tornado en Nueva York). (...) Hemos pasado de una concepción estática - el átomo como una bola de billar - a una descripción dinámica que nos habla de una red o patrón de interacciones. (Dabas y Najmanovich, 1995, p. 59) ${ }^{4}$

A concepção mecanicista do universo que, durante séculos resolveu diversos problemas enfrentados pela humanidade, teve suas bases estremecidas, com rachaduras profundas, que não puderam ser controladas. 0 ideal de tudo ser mensurável e quantificável não conseguiu mais permanecer intacto. As idéias mais simples, de linearidade, causa e efeito, com resultados previsíveis decorrentes de determinadas ações, tiveram que ser revistas e, paulatinamente, substituídas.

Assim sendo, segundo a metáfora da rede, o conhecimento não pode ser fruto de um simples ato de transmissão de informações, onde quem sabe, ou conhece, expõe para quem não sabe, que, naturalmente, apreende. A aprendizagem, como vimos, ocorre quando o aprendiz conseguiu estabelecer significados para o objeto de conhecimento - nó - em questão, quando, portanto, conseguiu estabelecer novas relações - feixes - em sua própria rede, articulando assim o novo aos diversos nós já existentes. É dessa maneira que os novos conhecimentos constituem enredamentos.

\footnotetext{
4 Todo o universo físico é visto hoje como uma imensa "rede de interações", de modo que nada pode ser definido de maneira absolutamente independente, e no qual domina o "efeito borboleta" (cuja versão popular diz que quando uma borboleta bate as asas sobre o Mar da China pode "causar" um tornado em New York). (...) Passamos de uma concepção estática - o átomo como uma bola de bilhar - a uma descrição dinâmica que nos fala de uma rede ou padrão de interações.
} 
Nas palavras de Machado,

(...) o conhecimento não se reduz a informações: ele exige a capacidade de estabelecer conexões entre elementos informacionais aparentemente desconexos, de processar informações, analisá-las, armazená-las, avaliá-las segundo critérios de relevância, organizá-las em sistemas. A cada instante, a cada nova relação percebida, a cada nova interpretação de uma relação já configurada, alteram-se os feixes que compõem os nós/significados, atualiza-se o desenho de toda a rede. (Machado, 1995, p.145)

Lévy, em As Tecnologias da Inteligência, examina as novas maneiras de pensar e conviver decorrentes das mudanças tecnológicas da atualidade. A passagem da oralidade para a escrita e daí para a informática se dá, segundo ele, por complexificação e mudança dos centros de gravidade. A elaboração de um hipertexto, com todas as variações possíveis, conexões nunca antes imaginadas entre elementos aparentemente desconexos, através do processamento das mais diversas informações, nos sugere uma liberdade tão grande, comparável à liberdade de transformação da própria rede de significações vivenciadas pelos indivíduos:

Cada um em sua escala, os atores da comunicação ou os elementos de uma mensagem constróem e remodelam universos de sentidos. (...) chamaremos esses mundos de significação de hipertextos. (Lévy, 1995, p. 25)

No plano individual, cada indivíduo, em particular cada aluno, é responsável pelo seu processo de mudança e evolução, isto é, pela ampliação, refinamento ou complexificação de uma rede de conhecimentos e significados. Em relação a isto, tenderá a transformar suas propostas e crenças pessoais se se encontrar insatisfeito com elas, e se considerar as idéias selecionadas e construídas por si mesmo, ou coletivamente, em dado momento, mais poderosas e úteis que as anteriores. Desse modo, a rede adquire novos feixes mais significativos, que substituem outros anteriormente estabelecidos. 
Para Lévy, no contexto das novas tecnologias,

O hipertexto é talvez uma metáfora válida para todas as esferas da realidade em que significações estejam em jogo.(id., p. 25)

O autor caracteriza a rede hipertextual através de seis princípios conformadores: metamorfose, heterogeneidade, multiplicidade e de encaixe das escalas, exterioridade, topologia e mobilidade dos centros.

O princípio da metamorfose caracteriza o dinamismo da rede, o constante processo de transformação e evolução, a impossibilidade de ser considerada pronta, acabada, podendo apenas apresentar estabilidade temporária. O princípio da metamorfose nos faz entender a importância da História que apresenta justamente a evolução, a transformação das relações estabelecidas ao longo do tempo. Nas palavras de Lévy,

O princípio da metamorfose - A rede hipertextual está em constante construção e renegociação. Ela pode permanecer estável durante um certo tempo, mas esta estabilidade é em si mesma fruto de um trabalho. Sua extensão, sua composição e seu desenho estão permanentemente em jogo para os atores envolvidos, sejam eles humanos, palavras, imagens ou de contexto, objetos técnicos, componentes destes objetos. etc. (id., p. 25)

Outra característica da rede é o fato de seus diferentes nós não apresentarem, a priori, características de homogeneidade, podendo ter consistências diversas, assim como os feixes de relações estabelecidas entre eles. Assim, ao pensarmos na rede do indivíduo, os nós não são todos de uma mesma categoria - tudo faz parte da rede: pessoas, objetos, imagens, emoções, e as inúmeras relações que podem ser estabelecidas.

O princípio da heterogeneidade - Os nós e as conexões de uma rede hipertextual são heterogêneos. Na memória serão encontradas imagens, sons, palavras, diversas sensações, modelos, etc., e as conexões serão lógicas, afetivas, etc. Na comunicação, as mensagens 
serão multimídias, multimodais, analógicas, digitais, etc. O processo sociotécnico colocará em jogo pessoas, grupos, artefatos, forças naturais de todos os tamanhos, com todos os tipos de associações que pudermos imaginar entre estes elementos. (id., p. 25)

Consideremos agora o princípio da multiplicidade e de encaixe das escalas, que nos leva à imagem do conhecimento como mapeamento, no sentido de que conhecemos o que conseguimos mapear. Nas palavras de Lévy,

O princípio de multiplicidade e de encaixe das escalas - O hipertexto se organiza de modo "fractal", ou seja, qualquer nó ou conexão, quando analisado, pode revelar-se como sendo composto por toda uma rede, e assim por diante, indefinidamente, ao longo da escala dos graus de precisão. Em algumas circunstâncias críticas, há efeitos que podem propagar-se de uma escala a outra: a interpretação de uma vírgula em um texto (elemento de uma microrrede de documentos), caso se trate de um tratado internacional, pode repercutir na vida de milhões de pessoas (na escala da macrorrede social).(id., p. 25)

Quando examinamos uma imagem fractal podemos ter a idéia do que o autor quer significar. Se nos concentramos numa pequena região é como se ali estivesse o todo, com as características do global.

Para caracterizar o universo de significações recorrendo à imagem do hipertexto, uma nova questão se apresenta, qual seja a das relações entre o sujeito e o objeto. A rede não tem um interior e um exterior nitidamente definidos. Lévy caracteriza o hipertexto como inserido num ambiente sem limites rígidos, no qual pode haver movimento em qualquer direção, a evolução pode ocorrer segundo qualquer mecanismo, com ampla liberdade. Não há limites para a evolução das relações sujeito-objeto ou sujeito-sujeito. Segundo esse autor,

O princípio da exterioridade - A rede não possui unidade orgânica, nem motor interno. Seu crescimento e sua diminuição, sua composição e sua recomposição permanente dependem de um exterior indeterminado: adição de novos elementos, conexões com outras 
redes, excitação de elementos terminais, etc. Por exemplo, para a rede semântica de uma pessoa escutando um discurso, a dinâmica dos estados de ativação resulta de uma fonte externa de palavras e imagens. Na constituição da rede sociotécnica intervêm o tempo todo elementos novos que não Ihe pertenciam no instante anterior: elétrons, micróbios, raios $X$, macromoléculas, etc. (id., p. 26)

Assim, o professor não se apresenta como um elemento externo à rede de significações vivenciadas pelos estudantes: ele faz parte dela.

A noção de espaço topológico revela-se fundamental para entender a rede hipertextual, onde as vizinhanças assumem papel preponderante, caracterizando a formação da própria rede. Na rede de significações tudo funciona por proximidade: construímos significados conforme nos aproximamos do objeto do conhecimento. Para Lévy,

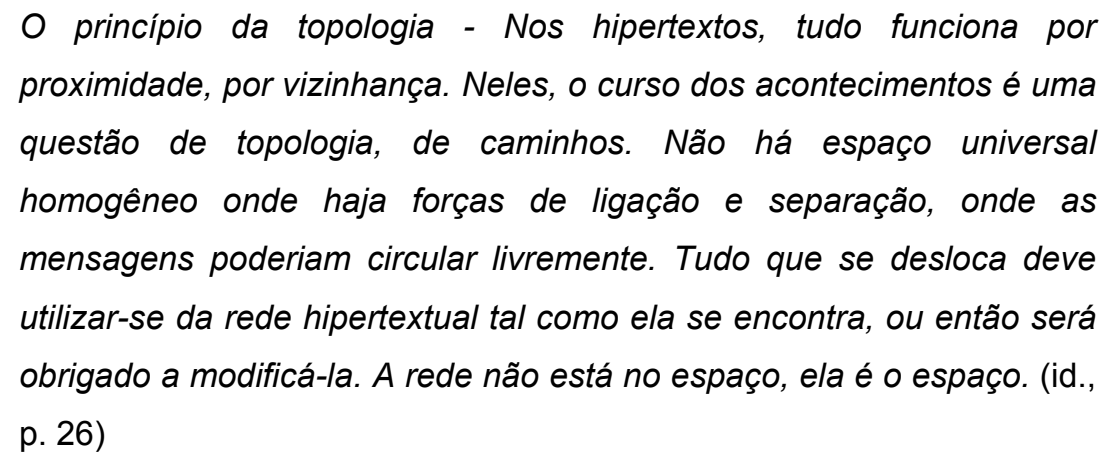

Em outras palavras, o significado sempre se constrói em um sistema de proximidades, de vizinhanças. Muda-se a noção de distância, mas o fato não se altera.

Finalmente, a fractalidade, a heterogeneidade, a constante mobilidade e transformação, culminam na caracterização da rede hipertextual como acentrada, pois ela não evolui necessariamente em qualquer direção, nem em todas as direções, nem da mesma maneira. A evolução da rede se dá segundo os centros de interesse, que são diversos, variáveis, e promovem o aparecimento de novos feixes de relações. Segundo Lévy, 
O princípio de mobilidade dos centros - A rede não tem centro, ou melhor, possui permanentemente diversos centros que são como pontas luminosas perpetuamente móveis, saltando de um nó a outro, trazendo ao redor de si uma ramificação infinita de pequenas raízes, de rizomas, finas linhas brancas esboçando por um instante um mapa qualquer com detalhes delicados, e depois correndo para desenhar mais à frente outras paisagens do sentido. (id., p. 26)

Deste modo, a rede hipertextual de Lévy nos oferece uma metáfora riquíssima e extremamente consistente para os universos de significações. Os princípios conformadores do hipertexto se transferem, por analogia, como característicos da rede de conhecimentos e significados, individual ou coletivamente considerada. Voltamos a frisar que é preciso ter claro que, ao olharmos para um grupo de indivíduos, como numa sala de aula, ou para toda uma sociedade, as diversas redes individuais não são disjuntas, mas se entrelaçam. É como se existisse uma grande rede coletiva, do grupo encarado como um todo, da qual todas as redes individuais participam, alimentando-se simbioticamente. $\mathrm{O}$ individual e o coletivo, numa relação de reciprocidade, são responsáveis pela construção do conhecimento. Dessa forma,

Há comenzado a gestarse una cultura que no piensa el universo como un reloj sino como "archipiélagos de orden en un mar de caos": la cultura de la complejidad. La civilización que creyó en las certezas definitivas, en el conocimiento absoluto y el progresso permanente se derrumba y están abriendo-se pasos nuevos modos de pensar, de sentir, de actuar y vivir en el mundo. (Dabas y Najmanovich, 1995, p. $61)^{5}$

\footnotetext{
${ }^{5}$ Começou a nascer uma cultura que não pensa o universo como um relógio, mas como "arquipélagos de ordem em um mar de caos": a cultura da complexidade. A civilização que acreditou nas certezas definitivas, no conhecimento absoluto e progresso permanente, está caindo e estão surgindo novos modos de pensar, de sentir, de atuar e viver no mundo.
} 


\title{
1.30 conhecimento na língua
}

Desde os primeiros anos de vida, o eixo lingüístico-lógico-matemático merece toda a atenção, devido à interdependência natural e às inúmeras relações. A língua materna veiculando a comunicação interpessoal, possibilita a integração do indivíduo ao meio e, conseqüentemente, a sua interação, na busca de compreensão e transformação. De fato,

\begin{abstract}
Reconhecendo-se que os fatos são sujeitos à interpretação e que a língua, na medida em que é constituída pela falha, pelo deslize, pela ambigüidade, faz lugar para a interpretação, pode-se perceber que não há como regulamentar o uso dos sentidos embora não se deixe nunca de tentá-lo. Assim, talvez fosse melhor acatar essa impossibilidade e ao mesmo tempo reconhecer a necessidade desse controle, vendo no processo das diferentes leituras uma reorganização do trabalho intelectual e a propensão a novas divisões no trabalho social da leitura. O que não descaracteriza a especificidade do discurso científico, mas repõe o conhecimento produzido como parte de um processo. Inacabado. Ou como dizemos em linguagem: incompleto. E, por isso mesmo, possível. Porque é isso mesmo que nos ensina o discurso: o lugar da falha, da incompletude, é também o lugar do possível, da transformação. (Orlandi, 1997, p. 33)
\end{abstract}

A língua abre assim espaço para a existência de uma característica essencial no âmbito da comunicação humana, ou seja, a flexibilidade, enquanto possibilita diferentes maneiras, mais ou menos eficazes de aproximação ao essencial.

Por outro lado, a matemática, logo de início, faz parte do currículo, em todos os países do mundo. Ela viabiliza a compreensão de esquemas operacionais, raciocínios, uma lógica interna que pode ser transferida para outras esferas da comunicação humana. É fundamental, entretanto, mesmo no contexto da matemática, considerar e valorizar a abordagem discursiva. Através 
da língua materna torna-se possível o estabelecimento de relações novas, articulações mais frutíferas cujo entrelaçamento promove o refinamento da rede de conhecimentos e significados.

De Machado, retiramos o seguinte comentário a respeito da colaboração entre a Matemática e a Língua Materna:

\begin{abstract}
Entre a Matemática e a Língua Materna existe uma relação de impregnação mútua. Ao considerarem-se estes dois temas enquanto componentes curriculares, tal impregnação se revela através de um paralelismo nas funções que desempenham, uma complementaridade nas metas que perseguem, uma imbricação nas questões básicas relativas ao ensino de ambas. É necessário reconhecer a essencialidade dessa impregnação e tê-la como fundamento para a proposição de ações que visem à superação das dificuldades com o ensino da Matemática. (Machado, 1990, p. 10)
\end{abstract}

Em "Seis propostas para o próximo milênio", Calvino apresenta-nos sua visão a respeito do conhecimento traduzido num texto literário: exatidão, leveza, rapidez, visibilidade, multiplicidade, consistência (esta última, infelizmente, não foi descrita por ele, deixando-a para a nossa imaginação), são características fundamentais e imprescindíveis. As propostas conformadoras de Calvino parecem caracterizar de maneira brilhante a rede de significados, traduzida através do uso da língua materna, num texto literário, mas que também poderiam referir-se ao conhecimento em geral, incluindo o conhecimento matemático.

Em primeiro lugar, examinemos a questão da exatidão. O senso comum atribui, quase que exclusivamente, essa característica à Matemática, por imaginar que as considerações realizadas em seu interior primam pela exatidão.

A exatidão, para Calvino, significa principalmente três coisas: 
- a evocação de imagens visuais, nítidas, incisivas, memoráveis;

- uma linguagem que seja a mais precisa possível como léxico e em sua capacidade de traduzir as nuanças do pensamento e da imaginação. (id., p. 71)

Também é sua a crítica feroz à situação em que se encontra, segundo ele, a comunicação entre os homens, onde a necessidade da exatidão se faz cada vez mais presente, no espaço de dimensões infinitas, sem limites.

Às vezes me parece que uma epidemia pestilenta tenha atingido a humanidade inteira em sua faculdade mais característica, ou seja, no uso da palavra, consistindo essa peste da linguagem numa perda de força cognoscitiva e de imediaticidade, como um automatismo que tendesse a nivelar a expressão em fórmulas mais genéricas, anônimas, abstratas, a diluir os significados, a embotar os pontos expressivos, a extinguir toda centelha que crepite no encontro das palavras com novas circunstâncias. (id., p. 72)

Quando Calvino mostra a necessidade de exatidão nos textos, ele o faz de maneira eloqüente e fundamental, esclarecendo que a expressão lingüística necessita dessa característica, propondo então a busca incessante e cuidadosa da melhor forma de traduzir o pensamento. No campo da Matemática, entretanto, embora haja diversas situações em que os cálculos são exatos, há inúmeras outras em que, para se chegar à resolução do problema proposto, o cálculo é simplesmente aproximado.

A proposta seguinte de Calvino é a leveza, e, nesse sentido,

"Il faut être léger comme l'oiseau, et non comme la plume." (Paul Valéry) ${ }^{6}$

Segundo Calvino, a leveza pode ser caracterizada por:

\footnotetext{
6 "É preciso ser leve como o pássaro, não como a pluma."
} 
- um despojamento da linguagem, por meio do qual os significados são canalizados por um tecido verbal quase imponderável, até assumirem essa mesma rarefeita consistência;

- a narração de um raciocínio ou de um processo psicológico, no qual interferem elementos sutis e imperceptíveis, ou qualquer descrição que comporte um grau de abstração. (Calvino, p. 28)

A leveza, como característica essencial da rede, permite-lhe ser como um pássaro, muito mais do que como uma pluma, a qual, por mais leve, cai, sem possibilidade de alçar vôo. A leveza num texto matemático ou literário possibilita penetrar em novos mundos através de constantes vôos e conseqüentes processos de reequilibração da própria rede.

Para Calvino, a noção de rapidez está relacionada às idéias de Galileu Galilei.

"Discorrer", "discurso", para Galileu quer dizer raciocínio, e quase sempre raciocínio dedutivo. "O discorrer é como o correr": esta afirmação é como o programa estilístico de Galileu, o estilo como método de pensamento e como gosto literário - a rapidez, a agilidade do raciocínio, a economia de argumentos, mas igualmente a fantasia dos exemplos são para Galileu qualidades decisivas do bem pensar. (id., p. 56)

O raciocínio rápido, leve, que permite desenvolver o pensamento, enquanto movimento de análise, crítica, reflexão, aprofundamento, generalização. O raciocínio não travado, livre, com constante mobilidade, sem objetivo de chegar a um estado terminal, mas, ao contrário com possibilidade de novos vôos, novas relações, buscando novos horizontes, sem limites...

Segundo Calvino, a metáfora do cavalo para designar a velocidade da mente, foi usada pela primeira vez por Galileu Galilei, que em Saggiatore, escreve: 
Se il discorrere circa un problema difficile fosse come il portar pesi, dove molti cavalli porteranno più sacca di grano che un caval solo, io acconsentirei che $i$ molti discorsi facessero più che uno solo; ma il discorrere è come il correre e non come il portare, ed un caval barbero solo correrà più che cento frisoni. (apud Calvino, 1994, p. 56) ${ }^{7}$

Em seguida, encontramos a proposta da visibilidade, com a qual o autor nos esclarece sobre a importância da visualização na construção de significados. Assim,

podemos distinguir dois tipos de processos imaginativos: o que parte da palavra para chegar à imagem visiva e o que parte da imagem visiva para chegar à expressão verbal. (id., p. 99)

Desse modo, em qualquer das duas direções move-se o pensamento: seja do concreto, visível, para o abstrato, na expressão da língua ou da matemática, ou na direção contrária, traduzindo as palavras através de imagens. O pensamento interage com o exterior visível, perceptível, imediatamente ou através de um novo movimento. Essa interação promove possíveis ampliações, aprofundamentos, generalizações, articulações novas.

A variedade de pontos de vista, os diferentes ângulos segundo os quais é possível encarar o problema proposto, tornam seu enfrentamento mais rico e desafiador. Decisões, caminhos escolhidos, podem ter consequências as mais variadas, com propagações imprevisíveis, dando à rede de conhecimentos e significados uma sua característica fundamental: a multiplicidade de formas, de configurações possíveis.

Segundo Calvino,

(...) cada texto (referindo-se ao escritor Jorge Luis Borges) contém um modelo do universo ou de um atributo do universo - o infinito, o

\footnotetext{
7 Se o discorrer sobre um problema difícil fosse como o transportar pesos, caso em que muitos cavalos podem transportar mais sacos de trigo do que um só cavalo, admitiria então que uma pluralidade de discursos valesse mais que apenas um; mas o discorrer é como o correr, e não como o transportar, e um só cavalo árabe há de correr mais do que cem cavalos frísios. (Trad. in Calvino, 1994, p.56)
} 
inumerável, o tempo, eterno ou compreendido simultaneamente ou cíclico, (...) obras que correspondem à rigorosa geometria do cristal e à abstração de um raciocínio dedutivo.(id., p. 133)

Finalmente, com relação à consistência, não temos como nos referir a Calvino, mas podemos imaginar facilmente o quanto o texto literário ou matemático precisa ser consistente e articulado. Num universo onde a heterogeneidade possibilita o estabelecimento das mais diversas relações, a consistência se torna uma característica fundamental, na qualidade de referencial que determina escolhas e decisões.

As propostas para o terceiro milênio foram escritas no contexto da literatura; entretanto a caracterização e a abrangência as tornam extremamente relevantes para a construção de significações em todas as áreas, podendo inclusive orientar o professor de Matemática em seu trabalho diário na sala de aula.

Essa pertinência se torna mais significativa quando pensamos na distância existente entre os cientistas e os literatos, representantes de duas culturas que, trinta anos atrás já haviam cessado de falar uma com a outra, mas pelo menos trocavam um sorriso amarelo através do fosso. (Snow, 1995, p.36)

Os preconceitos recíprocos existentes na comunidade dos que trabalham com as diversas ciências, matemáticos, físicos, biólogos, ou outros, e daqueles que trabalham com literatura ou humanidades têm originado distorções profundas e separações estranhas, que, no contexto atual, precisam ser revistas e mesmo superadas para não encontrarmos mais

\footnotetext{
Num polo os literatos; no outro os cientistas e, como os mais representativos, os físicos. Entre os dois, um abismo (particularmente entre os jovens) hostilidade e aversão, mas, principalmente, falta de compreensão. Cada um tem uma imagem curiosamente distorcida do outro. Suas atitudes são tão diferentes, que, mesmo ao nível da emoção, não encontram muito terreno comum. (Snow, 1995, p. 21)
} 
O que provavelmente constitui o grande elo de comunicação que precisa ser reconstruído, reformulado e novamente compreendido é justamente o discurso realizado através da língua materna e da leitura que dele se faz. Esse elo fornece a possibilidade de mútua compreensão, visto que

Quando me refiro à pluralidade das leituras não estou pensando apenas na leitura de vários textos, mas, sobretudo, na possibilidade de se ler um mesmo texto de várias maneiras. Este é um aspecto fundamental do processo de significação que a leitura estabelece. (Orlandi, 1996, p.87)

Finalmente, então, no conjunto dos múltiplos significados produzidos, poderá haver a compreensão enquanto a busca por ela se realiza no campo em que os indivíduos conseguem se comunicar.

\subsection{0 conhecimento matemático}

Consideramos que a Matemática se constitui numa das áreas do conhecimento mais aptas a desempenhar um papel interdisciplinar e básico, comparável talvez somente à língua materna.

No contexto de rede de conhecimentos e significados, vamos encarar, com mais detalhe, a questão do conhecimento matemático. Nas palavras de Galileu,

A Ciência está escrita neste imenso livro que continuamente se abre diante dos olhos (refiro-me ao Universo), livro este que só pode ser entendido, entretanto, se aprendermos antes sua língua e a conhecer os caracteres nos quais está escrito. Ele está escrito em linguagem matemática e os caracteres são triângulos, círculos e outras figuras 
geométricas sem cujos meios é humanamente impossivel entender-se uma só palavra; sem eles, é um vagar inútil por um obscuro labirinto. (apud Machado, 1995, p. 142).

Assim, o universo não precisa ser novamente criado, mas precisa ser compreendido, isto é, apreendido, e, para isso, é fundamental conhecer a linguagem matemática.

Basicamente, existem dois tipos de personalidades que trabalham diária e constantemente com a Matemática e que, portanto, estão preocupadas com esse campo do saber humano: o matemático profissional e o professor de matemática.

O matemático profissional, a priori, não precisa ser um eficiente professor de matemática, como também este último não necessariamente é um matemático profissional competente e de sucesso. São pessoas diferentes, cujos trabalhos são diferentes; desempenham papéis distintos, porque não possuem os mesmos objetivos. Nesse sentido, os dois profissionais não podem ser confundidos, embora, evidentemente, possam existir pessoas que têm competência para o desempenho de ambas as funções.

De modo geral, o matemático profissional tem por objetivo a construção do conhecimento matemático, enquanto que o professor de matemática está preocupado com a construção de conhecimento matemático por parte de outros: os seus alunos.

Segundo o matemático Hyman Bass, Adrain Professor at Columbia University,

(...) knowing something for oneself or for communication to an expert colleague is not the same as knowing it for explanation to a student. 
Further, the experience of a mathematical scientist as a learner may not be the best model for the learning of his/her student. (Bass, 1997 p.19) ${ }^{8}$

A citação acima, retirada de um artigo publicado na Notices of the AMS, importante revista da comunidade dos matemáticos profissionais, mostra a preocupação do autor com o ensino de Matemática, confirmando não ser uma simples transferência do conhecimento. Bass defende a existência da Educação Matemática como responsável para proporcionar conhecimento matemático apropriado, compreensão e habilidades aos estudantes dos mais variados tipos.

Entendemos assim, que há uma grande diferença que é fundamental: o matemático que produz Matemática, realiza pesquisa num campo restrito e profundo, descobre novos resultados, reorganiza-os da maneira mais geral possível, descontextualizada, despersonalizada, atemporal. Dessa forma, o matemático estabelece comunicação com uma comunidade restrita, dentro da qual os resultados que encontrou são reconhecidos, e portanto validados, constituindo-se em conhecimento matemático. O conhecimento construído pelo matemático profissional provém de situações com as quais ele trabalha, tem sua marca pessoal que lhe é própria e particular, mas que, em seguida, para ser validado pela comunidade científica, precisa ser despersonalizado, perdendo as características do autor, e descontextualizado, perdendo as características do contexto no qual foi construído. São poucas as pessoas que se comunicam sobre esse conhecimento, numa linguagem peculiar, técnica, exclusiva.

No diagrama a seguir podemos visualizar esquemática e resumidamente o papel do matemático profissional:

\footnotetext{
8 (...) conhecer algo para si mesmo ou para se comunicar com um colega experiente, não é a mesma coisa do que conhecer para explicar a um estudante. Mais ainda, a experiência de um matemático quando aprendiz pode não ser o melhor modelo para a aprendizagem de seu/sua estudante.
} 


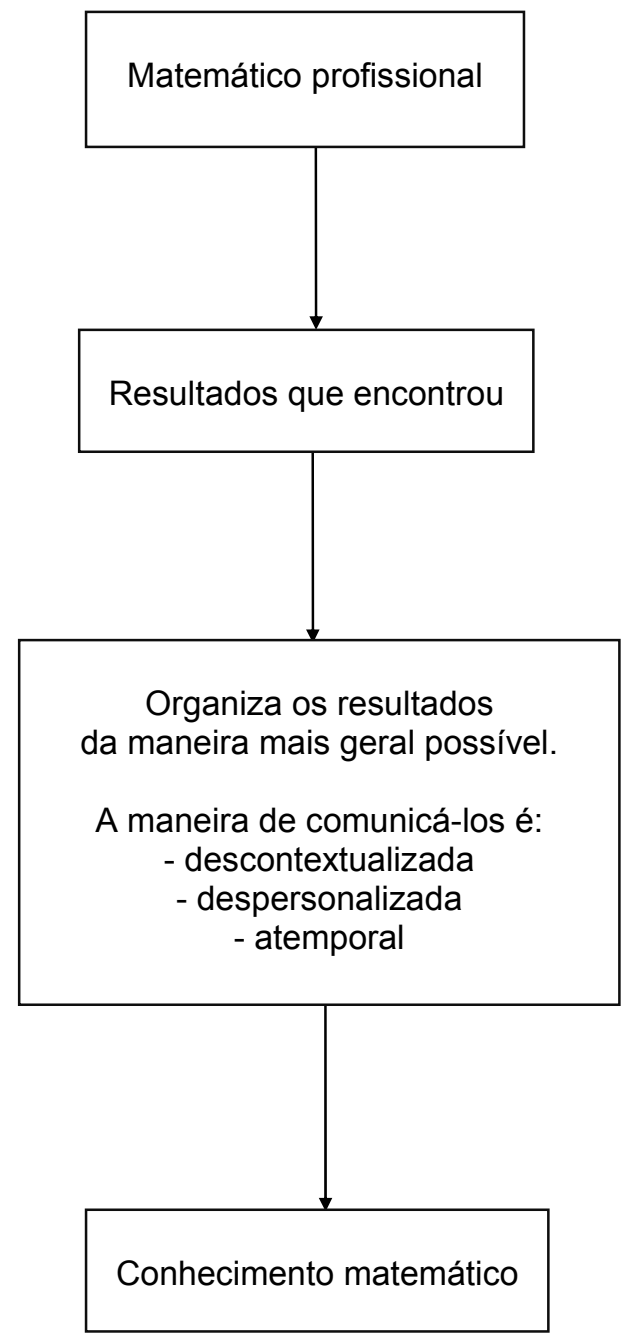

Fig. 1: O papel do matemático profissional 
Por outro lado, o professor de Matemática executa uma tarefa muito diferente, na medida em que ele precisa recontextualizar e repersonalizar o conhecimento que seus alunos necessitam articular, isto é, realiza um processo que é contrário, em certo sentido, ao dos matemáticos que produziram o conhecimento.

Para isso, precisa encontrar situações significativas e motivadoras, com problemas interessantes, a fim de que seus alunos, tentando dar respostas adequadas a esses problemas, consigam estabelecer significados para o conhecimento desejado, compreendendo-o e, portanto, articulando-o à própria rede. Nessa busca, o professor é essencialmente um pesquisador, pois estará formulando suas hipóteses pessoais a respeito da possibilidade que seus alunos têm de construir significados através das situações e problemas propostos por ele.

O processo de problematização é fundamental, se o professor pretende que o aluno construa os significados para daí ser possível a compreensão do conhecimento desejado. Sem uma metodologia problematizadora o professor corre o risco de tentar apenas transmitir seu próprio conhecimento, pronto estruturado, que o aluno não conseguirá articular se não tiver significado para ele, se não responder a algum problema que seja seu, especial, desafiador, interessante.

Quando a fase de personalização e contextualização teve sucesso e os alunos conseguiram respostas adequadas para os problemas colocados, aparece uma nova questão importante, pois os alunos não sabem que produziram conhecimento que poderá ser utilizado em outras situações. Para isso, faz-se necessária uma nova descontextualização e despersonalização, processo este que precisa ser realizado pelo aluno, com a ajuda do professor.

Segundo Brousseau, 
(...) para el docente, es grande la tentación de saltar estas dos fases y enseñar directamente el saber como objeto cultural evitando este doble movimiento. En ese caso, se presenta el saber y el alumno se lo apropria como puede. (apud Parra et alii, 1994, p. 65) ${ }^{9}$

Num diagrama podemos ter uma visão sintética do trabalho do professor:

Professor de Matemática

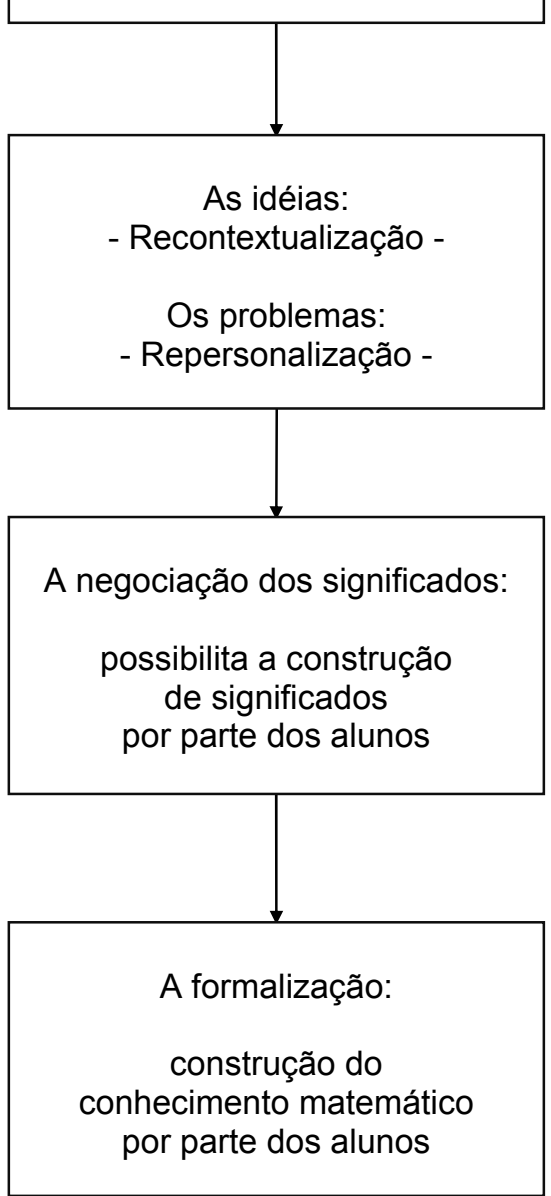

Fig. 2: O papel do professor de matemática

9 (...) para o docente é grande a tentação de pular estas duas fases e ensinar diretamente o saber como objeto cultural, evitando esse duplo movimento. Nesse caso, apresenta-se o saber ao aluno e este apropria-se dele como pode. 
Dessa forma, o professor viabiliza a construção de conhecimento matemático por parte de seus alunos, de maneira tal que, em certo sentido, os alunos realizam um trabalho semelhante ao dos matemáticos profissionais. 


\section{Capítulo 2. A construção do conhecimento matemático e a negociação dos significados na sala de aula}

\subsection{0 trabalho do professor de Matemática}

Tendo claro que a construção do conhecimento por parte dos alunos não ocorre por simples transposição, através da exposição por parte do professor, de seu próprio conhecimento estruturado e articulado, podemos perceber que o trabalho do professor situa-se num patamar muito diferente daquele preconizado por uma concepção cartesiana do conhecimento.

Dessa maneira, o professor em geral, e em particular, o professor de Matemática, é, essencialmente, um pesquisador que realiza um trabalho que se constitui num processo de investigação-reflexão-ação.

Esse processo ocorre em diversos níveis.

Em primeiro lugar, o questionamento por ele próprio formulado a respeito do conhecimento matemático que deseja ver construído por seus alunos: quando e como foi construído, em qual contexto histórico, segundo quais avanços e recuos. Conhecer as dificuldades vivenciadas pela humanidade para alcançar a compreensão, com a evolução das relações inicialmente estabelecidas, poderão auxiliá-lo, uma vez que os alunos, de alguma forma, precisarão repetir um processo cujos obstáculos são muitas vezes, em certo sentido, previsíveis.

Em segundo lugar, o trabalho do professor precisará se voltar para a busca de situações-problemas interessantes e adequadas para o grupo de 
alunos com o qual está trabalhando, uma vez que, novamente a história fornece o modelo da construção do conhecimento a partir dos desafios enfrentados. Para gerar o interesse dos estudantes pelas idéias que deseja desenvolver, o professor pode buscar aqueles problemas importantes que, historicamente, deram origem ao desenvolvimento dos conceitos, ou mesmo buscar problemas relevantes na atualidade. Certamente, ele precisa ter uma boa visão histórica para poder entender o contexto no qual o conhecimento desejado foi construído e, mais ainda, conhecer a epistemologia para então poder criar situações adequadas para que a recontextualização em sua sala de aula seja viável. Todo o processo de reflexão concomitante está voltado para sua ação na sala de aula, onde o seu papel não será o de um mero transmissor de conhecimento, mas o de um orientador dos alunos, inicialmente, na busca das respostas às situações criadas ou problemas colocados, e, em seguida, no processo de formalização do conhecimento construído, que é, desse modo, redescontextualizado e redespersonalizado.

Visando a construção do conhecimento significativo na sala de aula, e o estabelecimento de uma situação de poder compartilhado,

(...) fazer o aluno falar é uma prática louvável na qual a escola francesa de Educação Matemática está se iniciando. Certamente, suspender os malabarismos com o saber que os catedráticos europeus exibem nos enormes anfiteatros gelados, para escutar os alunos, é um procedimento político de louvável atrevimento, quase impensável em círculos matemáticos. Sabemos que, segundo Lacan, "seria totalmente utópico acreditar que uma tal montagem didática vá deslanchar subitamente uma forte paixão científica nos anfiteatros" Porém, com vários anos de experiência que acumulamos tentando fazer o aluno falar, sabemos também que, nos anfiteatros, jamais falarão mais que uma parcela ínfima dos alunos e que, dependendo das circunstâncias, essa prática pode ser tão discriminatória quanto a aula expositiva dirigida apenas aos poucos que podem manter o diálogo com 0 professor. (Baldino, 1995, p.11) 
Também em Polya, para o qual o estudante deve adquirir tanta experiência pelo trabalho independente o quanto Ihe for possível, encontramos suporte para nossas considerações:

Se o aluno for deixado sozinho, sem ajuda ou com auxílio insuficiente, é possivel que não experimente qualquer progresso. Se o professor ajudar demais, nada restará para o aluno fazer. O professor deve auxiliar, nem demais, nem de menos, mas de tal modo que ao estudante caiba uma parcela razoável de trabalho. Se o aluno não for capaz de fazer muita coisa, o mestre deverá deixar-lhe pelo menos alguma ilusão de trabalho independente. Para isto, deve auxiliá-lo discretamente, sem dar na vista. O melhor é, porém, ajudar o estudante com naturalidade. O professor deve colocar-se no lugar do aluno, perceber o ponto de vista deste, procurar compreender o que se passa em sua cabeça e fazer uma pergunta ou indicar um passo que poderia ter ocorrido ao próprio estudante. (Polya, 1978, p.2)

Assim o professor enfrenta o seu problema: propondo problemas aos seus alunos e guiando-os na busca da solução. Ainda segundo Polya,

A resolução de problemas é uma habilitação prática como, digamos, o é a natação. Adquirimos qualquer habilitação por imitação e prática. Ao tentarmos nadar, imitamos o que os outros fazem com as mãos e os pés para manterem suas cabeças fora d'água e, afinal, aprendemos a nadar pela prática da natação. Ao tentarmos resolver problemas, temos de observar e imitar o que fazem outras pessoas quando resolvem os seus e, por fim, aprendemos a resolver problemas, resolvendo-os. $O$ professor que deseja desenvolver nos estudantes a capacidade de resolver problemas deve incutir em suas mentes algum interesse por problemas e proporcionar-Ihes muitas outras oportunidades de imitar e de praticar. (id., p.3)

Conforme podemos observar, o trabalho do aluno na sala de aula, é, de certa forma, semelhante ao do matemático profissional, enquanto busca de solução do seu problema que promoverá a construção de um novo conhecimento. Para cada aluno, a descoberta da solução do problema colocado 
pelo professor deve ocasionar tamanha alegria e satisfação, pois, para ele, o problema era tão próprio e promoveu a construção de conhecimento no seu ambiente, onde poderá compartilhá-lo.

A produção de conhecimento constitui-se num ato de criação que Moles, em A Criação Científica, considera

como um proceder do espírito numa rede emalhada, uma espécie de labirinto de múltiplas vias, tipo de labirinto até agora muito pouco estudado experimentalmente. No plano desta rede, ele dispõe apenas de um campo de visão muito estreito: este é limitado por trás pela memória, e de frente, pela capacidade intuitiva. (Moles, 1998, p. 203)

Quando se gera interesse, e a estrutura de poder está relativamente compartilhada, as possibilidades de criação conceitual e de crítica reflexiva por parte dos alunos, diante de determinados problemas, aumentam extraordinariamente. Não é um processo marcado pelo empirismo ingênuo de investigar a realidade para encontrar nela o conhecimento, mas um processo aberto e circular no qual, partindo de problemas concretos, interessantes e próximos aos alunos, estes coloquem em jogo suas propostas pessoais, reestruturando-as e re-significando-as.

O conhecimento desejável para os alunos desenhar-se-á como uma síntese integradora de diferentes âmbitos. Há de levar-se em conta a análise histórica e epistemológica dos conceitos e modelos disciplinares; a análise da problemática sócio-ambiental e cultural mais relevante; a análise das concepções dos alunos e a análise dos procedimentos e valores desejáveis. 


\subsection{0 conhecimento e os significados}

Uma vez que conhecer é conhecer o significado, a construção do conhecimento na sala de aula baseia-se na negociação de significados, num processo onde todas as pessoas envolvidas têm as mesmas possibilidades de emitir idéias críticas sobre as questões colocadas. Através do envolvimento gerado pela análise e discussão, o conhecimento é construído de forma significativa, com o estabelecimento de diferentes relações, incorporando-se ao que se poderia chamar de memória ou estrutura semântica do indivíduo, isto é, aquele conjunto de significações que já foram vivenciadas. Quando isso não ocorre, a nova informação utiliza códigos indecifráveis e fica armazenada, de maneira instrumental, na memória episódica. No primeiro caso, há incorporação na rede de significações; no segundo, não.

Na sala de aula, o processo de negociação de significados é detonado e controlado pelo professor. Nesse sentido, podemos perceber o quão fundamental é o papel do professor, pois é essencialmente ele quem realiza a mediação entre o saber matemático cultural, descontextualizado e despersonalizado, e os estudantes que querem construir esse conhecimento, enquanto pessoas enfrentando problemas desafiadores, cada uma com suas características pessoais. Dessa forma,

Onde situar, com relação ao intervalo metodológico, o que chamamos de intervalo semântico, isto é, estas relações do locutor ao destinatário que constituem o próprio sentido de nossos enunciados, e que lhes dão uma organização fundamentalmente comparativa? (Ducrot in Vogt, 1977, p. 7)

Levar o aluno à construção do conhecimento é algo, no mínimo, não trivial. O professor não tem nem mesmo garantia, a priori, de que a adesão e o resultado sejam positivos, e, conseqüentemente, faz-se necessária uma 
cuidadosa investigação a respeito. Nesse instante, a problematização do novo conhecimento tem um papel fundamental, pois, através da colocação de problemas importantes para os estudantes, a curiosidade deverá ser gerada, mas também deverá surgir um certo desconforto e insatisfação, uma vez que as pré-concepções, individuais ou coletivas, não são suficientes para encontrar a solução desejada. A necessidade de buscar a resposta ao desafio colocado propiciará então o envolvimento do aluno que, através da orientação do professor, trilhará pelo caminho da solução.

A aula constitui um sistema de comunicação formado por uma rede de emissores, receptores e canais pelos quais flui todo tipo de informação, através de mensagens e ruídos, utilizando diferentes códigos e programas de expressão. A negociação de significados é o conteúdo da interação e da organização completa da aula. A produção do conhecimento compartilhado depende de diversos fatores, como, por exemplo: a estrutura semântica de cada aluno; a estrutura semântica do professor; o grau de adequação entre as tarefas propostas e os interesses potenciais dos alunos; o grau de adequação entre as mensagens didáticas do professor e os esquemas de conhecimento dos alunos; as características físicas do contexto: material didático, espaço, tempo, etc.

O professor precisa ter bastante clareza sobre as características do conhecimento desejado, de quais diferentes relações podem ser estabelecidas, a fim de possibilitar articulações, mais ou menos estáveis, até por aproximações sucessivas possibilitar a construção de significados importantes.

Entendemos então o caráter social da construção do conhecimento, e como as diferentes interações entre os indivíduos possibilitam o crescimento do coletivo. A transposição do individual para o coletivo, e vice-versa, possibilita o estabelecimento de relações de mútua responsabilidade, extremamente favoráveis para o trabalho na sala de aula. 
Segundo Granger, a idéia de significação pode ser traduzida da seguinte maneira:

Denominamos experiência um momento vivido como totalidade, por um sujeito ou por sujeitos formando uma coletividade. Totalidade não deve ser aqui compreendida de modo místico; o caráter de totalidade de uma experiência não se erige de modo algum num absoluto; é simplesmente um certo fechamento, circunstancial e relativo, comportando horizontes, primeiros planos, lacunas. Fechamento, no entanto, radicalmente diferente do buscado pela estruturação: sem horizontes, completamente dominado, claro e distinto. Toda prática poderia ser descrita como uma tentativa de transformar a unidade da experiência em unidade de uma estrutura, mas esta tentativa comporta sempre um resíduo. A significação nasceria das alusões a este resíduo, que a consciência laboriosa apreende na obra estruturada e introduz como imperfeições da estrutura. (Granger,1974, p.134)

Pensando na totalidade e nos resíduos, podemos ter uma imagem do conhecimento e das significações - estas são atributos que vão sendo aprimorados, burilados, em tentativas constantes de chegar realmente ao âmago, completo, total. Este processo de aproximação nos faz perceber o quanto é infrutífera a tentativa de buscar a apreensão imediata do todo, sem passar por etapas anteriores nas quais aquilo que é significativo e importante para o sujeito, e mais ainda, responde a necessidades, problemas e sentimentos seus, é incorporado, passando a fazer parte de sua rede. Entendemos assim a característica do imediatismo das respostas, das soluções inicialmente perseguidas pelos alunos, embora, em geral, isso não satisfaça o professor em sua busca de propiciar a construção de um conhecimento mais profundo e global.

Não podemos esquecer que somos todos pescadores e, se nossa rede não apresentar uma constituição adequada ao que desejamos pescar, nosso tempo e trabalho serão perdidos. Dependendo das lacunas, as finuras, as características sutis, serão inicialmente desperdiçadas e deveremos nos 
contentar com o que é mais grosseiro, mas que a nossa rede consegue reter. Posteriormente, poderemos conseguir um resultado mais satisfatório.

\subsection{0 discurso na sala de aula}

A ferramenta fundamental do professor para chegar à consecução de seu objetivo, não é o giz e o apagador, e nem mesmo uma tecnologia mais avançada. O que torna uma aula muito especial, diferente de um livro, ou mesmo de um CD-rom interativo, é a própria presença do professor, com suas características pessoais, semelhantes, em certo sentido, às de um ator, de um diretor de orquestra, mas principalmente às de um coordenador de pensamentos. A batuta é o seu discurso.

Em Hariki, encontramos que

- Discourse means social interaction through messages.

- Discourse is a negotiation of messages between speaker and hearer. (Hariki, 1992, p. 7) ${ }^{10}$

ampliando, assim, o conceito de discurso, considerado não apenas em relação ao seu possível enfoque lingüístico, mas num âmbito muito maior, referindo-se a tudo aquilo que ocorre numa atividade interativa, interpessoal, como é a de uma aula.

O discurso do professor é o grande e poderoso instrumento que the permite exercer o papel de coordenação no processo que se desenrola com 0

\footnotetext{
10 - Discurso significa uma interação social através de mensagens.
}

- Discurso é uma negociação de mensagens entre orador e ouvinte. 
seu grupo de alunos. Através dele, várias características, muitas vezes apenas implícitas, são explicitadas e, portanto, manifestas. Não é apenas do discurso específico, matemático, que estamos falando, mas de toda uma gama extremamente variada de ações e reações que ocorrem na sala de aula, tanto por parte do professor como dos estudantes.

Num estudo realizado na Universidade da Califórnia aparecem cinco tipos diferentes de professores, que resumimos a seguir:

A. O professor de autômatos: procura ajudar o aluno a adquirir a capacidade de responder imediatamente sem necessidade de pensar. Os estudantes pouco mais fazem do que recitar definições, explicações e generalizações que memorizam a partir de exposições do professor, ou de um texto ou apostila dados por ele. O instrutor é a autoridade máxima e o aluno tem poucas alternativas oferecidas ou exigidas.

B. O professor que se concentra no conteúdo: afirma que sua primeira tarefa consiste em cobrir sistematicamente as matérias de sua disciplina para assim ajudar os alunos a dominá-las. Ele tem plena certeza das matérias que devem ser ensinadas e aprendidas. Considera uma tolice a opinião de que o processo de ensinar e de aprender deva consistir numa pesquisa conjunta. (...) Este professor dá menos importância à originalidade que ao fato de o aluno aprender toda a matéria que já foi descoberta no passado. A idéia de que o professor possa aprender algo discutindo com os alunos é para ele completamente estranha ao objetivo de ensinar ou aprender.

C. O professor que se concentra no processo de instrução: assim como o do tipo anterior se concentra no domínio da matéria, este tipo se concentra em conseguir que seus alunos tratem a matéria com os mesmos métodos e processos com que ele os trata. Preocupa-se em impor um modelo de raciocínio e exige de seus alunos que demonstrem, nos exercícios, exames e discussões, que podem imitar seus métodos, perspectivas, formulações, bem como sua maneira de usar os dados.(...) Se se analisa bem o seu papel, observa-se que todas as suas conversas começam sempre com ele e suas idéias e, 
mais cedo ou mais tarde, acabam sempre voltando a ele e suas idéias. (...) Distingue-se do tipo anterior, pois enquanto $B$ se interessa pelo saber como produto, o tipo $C$ se interessa pelo saber como processo.

D. O professor que se concentra no intelecto do aluno: Para este tipo, o processo de ensinar e de aprendizagem deve concentrar-se na própria atividade racional. Para ele deve-se dar muito mais importância ao como e ao porquê do saber, que ao que. Preocupa-se sobretudo em desenvolver as capacidades intelectuais do aluno. Utiliza a análise e a solução de problemas como o principal artifício do ensino, porém dá mais importância ao intelecto que às atitudes e emoções do estudante. O problema é, para ele, apenas um recurso para a tarefa didática, e não um assunto com o qual se compromete como pessoa.

E. O professor que se concentra na pessoa total: tem muito a ver com o tipo $D$, pois ambos concentram-se no estudante. A diferença é que o professor $E$ não acredita que o desenvolvimento intelectual deva ou possa ser desligado dos outros aspectos da personalidade humana, tais como os fatores afetivos e não-racionais da identidade e da intimidade. ... considera o ensino como um desafio global à pessoa do estudante, que o obriga a buscar respostas ainda não aprendidas e a experimentá-las. (...) Acha que o estudante deve ser tratado como pessoa integral, pois separando-se o mundo intelectual do resto, o processo de crescimento do estudante na direção de um ser adulto torna-se seriamente comprometido. (Bordenave et alii, 1989, p. 59)

Nessa caracterização, apresentada pela universidade americana, encontramos paradigmas detalhados, que confirmam a existência de diferentes tipos de posturas dos professores no exercício da profissão, o que, evidentemente, tem influência marcante na consecução dos objetivos perseguidos na sala de aula. 


\subsection{A negociação dos significados}

Conforme vimos, o trabalho desenvolvido na sala de aula visa levar à construção individual e, ao mesmo tempo, coletiva e compartilhada do conhecimento.

Quando conscientes de que nem uma simples exposição nem uma imposição acarretam a construção do conhecimento por parte dos alunos, encontramos o professor totalmente preocupado com a escolha e definição de quais mecanismos de negociação poderá dispor para possibilitar a apropriação, por parte dos alunos, daqueles significados do conhecimento desejado que são seus, particulares, incorporados à sua própria rede. Nesse sentido, o professor necessita ser aberto e extremamente flexível, a fim de poder interagir com o grupo de alunos. Essa flexibilidade, como característica fundamental do professor, poderá apontar para necessárias mudanças de enfoque no curso, dependendo do grupo de alunos.

Observamos também que no processo pedagógico não há equilíbrio de forças, o que é aliás fundamental para a eficácia do próprio processo. E aqui é importante salientar que o "poder" do professor provém de sua maior experiência, da vivência e da percepção das relações que conseguiu estabelecer. Essa condição gera respeito por parte dos estudantes, mas não significa o direito ao exercício arbitrário do poder na sala de aula, pois este precisa ser compartilhado.

Para a negociação poder acontecer na sala de aula, o professor dispõe de alguns mecanismos de atuação. Como já salientamos, estabelecida a fase inicial da colocação de idéias e problemas, o aluno, sentindo-se desafiado, assume os problemas como sendo seus, pessoais, e busca resolvê-los. As tentativas podem ser inicialmente infrutíferas e o professor poderá utilizar 
trabalhos grupais para promover a interação entre os estudantes; esses trabalhos, normalmente, funcionam como estímulos recíprocos propiciando a discussão e a troca de informações.

A necessidade da introdução de novos conceitos surge a partir dos problemas e questionamentos colocados. Precisamos esclarecer que:

\begin{abstract}
Cuando la gente se habla no comparte la misma cultura, conocimientos, valores y presuposiciones, la comprensión mutua puede ser especialmente difícil. Esta comprensión es posible a través de la negociación del significado. Para negociar el significado com alguien, uno tiene que darse cuenta de las diferencias de fondo, y respetarlas, así como saber cuando son importantes. Es necesaria una diversidad suficiente de experiencias personales y culturales para darse cuenta de que existen visiones del mundo distintas, divergentes, $y$, para darse cuenta de cómo pueden ser. También se requiere paciencia, una cierta flexibilidad en la visión del mundo y una tolerancia generosa para los errores, así como cierto talento para dar com la metáfora correcta que comunique las partes relevantes de las experiencias que no son compartidas, o para destacar las experiencias comunes mientras se quita énfasis a las otras. La imaginación metafórica es una habilidad crucial para crear relaciones y comunicar la naturaleza de las experiencias que no son comunes. (Lakoff y Johnson, 1986, p. 276) ${ }^{11}$
\end{abstract}

Essa citação nos oferece, de maneira brilhante, uma visão de algumas das características do professor, fundamentais para possibilitar a construção dos significados por parte de seus alunos, viabilizando a compreensão e, portanto, a apreensão dos novos conhecimentos.

\footnotetext{
11 Quando as pessoas que falam não compartilham da mesma cultura, conhecimentos, valores e pressupostos, a compreensão mútua pode ser particularmente difícil. Esta compreensão é possível através da negociação do significado. Para negociar o significado com alguém é preciso dar-se conta das diferenças de fundo, e respeitá-las, como também saber quando são importantes. É necessária uma diversidade suficiente de experiências pessoais e culturais para dar-se conta de que existem visões de mundo distintas, divergentes, e para perceber como podem ser. Requer-se também paciência, uma certa flexibilidade na visão de mundo e uma generosa tolerância para com os erros, assim como certo talento para encontrar a metáfora correta que comunique as partes relevantes das experiências que não são compartilhadas, ou para destacar as experiências que são comuns, tirando a ênfase das outras. A imaginação metafórica é uma habilidade crucial para criar relações e comunicar a natureza das experiências que não são comuns.
} 
(...) la comprensión emerge de la interacción, de la negociación constante com el ambiente y con las otras personas. (...) Entendemos las experiencias metafóricamente cuando usamos una gestalt de un dominio de la experiencia para estructurar la experiencia en outro dominio. (Lakoff y Johnson, 1986, p. 275) ${ }^{12}$

A língua materna, como já salientamos, é um instrumento eficaz para possibilitar a consecução dos objetivos do professor. De fato,

Nos termos de Granger, a linguagem é condição transcendental para o conhecimento, o que significa que sem linguagem não há conhecimento, de tipo nenhum. Nem o científico, nem o não científico. (Possenti, 1997, p.16)

Através da linguagem é possível viabilizar a construção dos significados por parte dos alunos, uma vez que relações de proximidade podem ser estabelecidas com maior facilidade através de um veículo tão presente e relevante no processo de comunicação entre as pessoas, e, em particular, no universo dos estudantes. $E$ não podemos esquecer que

O mote fundamental é que a ciência não passa de um discurso. (Possenti, 1997, p. 9)

Outro mecanismo útil para propiciar uma frutífera negociação de significados é a utilização de imagens pictóricas, esquemas, desenhos, percebendo-se a característica de visibilidade como facilitador do processo de significação. De fato,

A imagem não constitui um império autônomo e cerrado, um mundo fechado sem comunicação com o que o rodeia. As imagens - como as palavras, como todo o resto - não poderiam deixar de ser consideradas nos jogos do sentido, nos mil movimentos que vêm regular a significação no seio das sociedades. (Metz et alii, 1974, p.10)

\footnotetext{
${ }^{12}$ (...) a compreensão emerge a partir da interação, da negociação constante com o ambiente e com outras pessoas. (...) Entendemos as experiências metaforicamente quando usamos uma gestalt de um domínio da experiência para estruturar a experiência em outro domínio.
} 
A negociação estabelecida pretende levar à produção de conhecimento contextualizado, pessoal de cada aluno, individualmente considerado, e do conhecimento coletivo compartilhado. Conforme Brousseau, o passo seguinte é realizado, com a ajuda do professor, para promover a descontextualização e despersonalização e o aluno descobrir assim que poderá usar esse conhecimento em outras situações-problema.

O crescimento dos alunos, propiciado dessa maneira, é evidente. O professor, entretanto, a priori, não tem uma previsão clara de como vai se dar esse crescimento. Cada novo grupo de alunos é uma nova realidade; cada novo conhecimento que deseja ver construído constitui-se num desafio, e, a busca de novas, ou mais adequadas, negociações promove o enfrentamento de dificuldades necessário para o crescimento profissional do professor.

Resumindo, vamos representar num diagrama a questão da construção do conhecimento em sala de aula: 
Trabalho dos alunos sob a orientação do professor

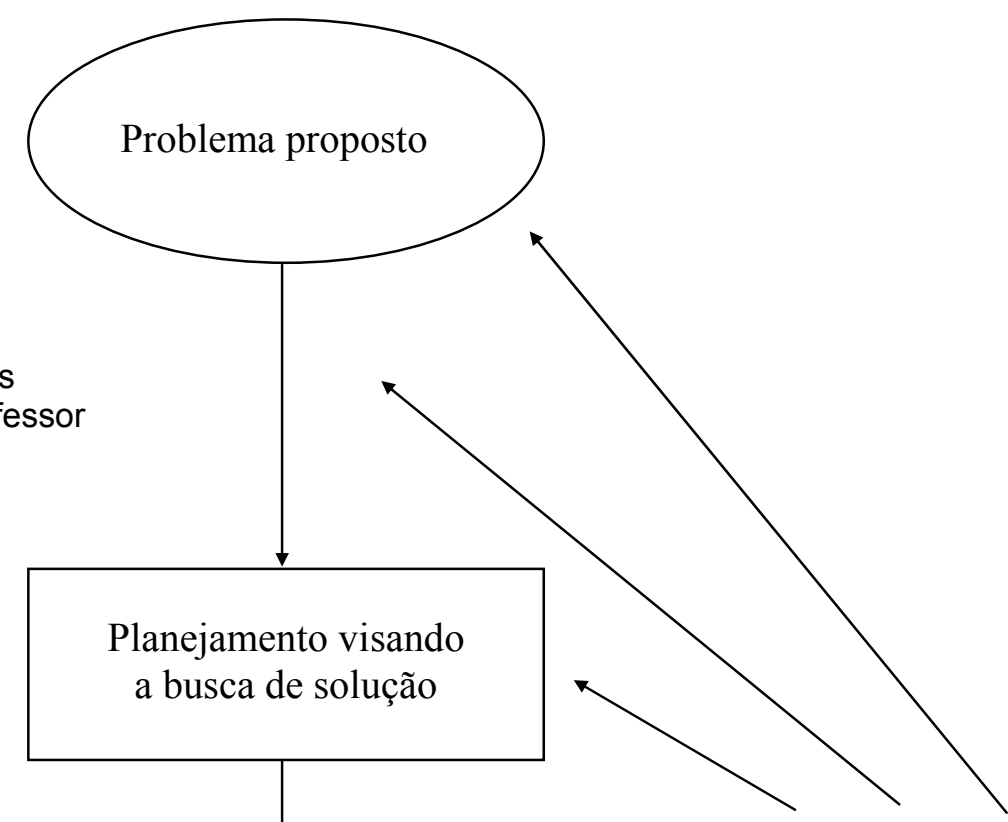

Negociação no processo de interação professor - alunos sob a orientação do professor

Formalização e generalização sob a orientação do professor

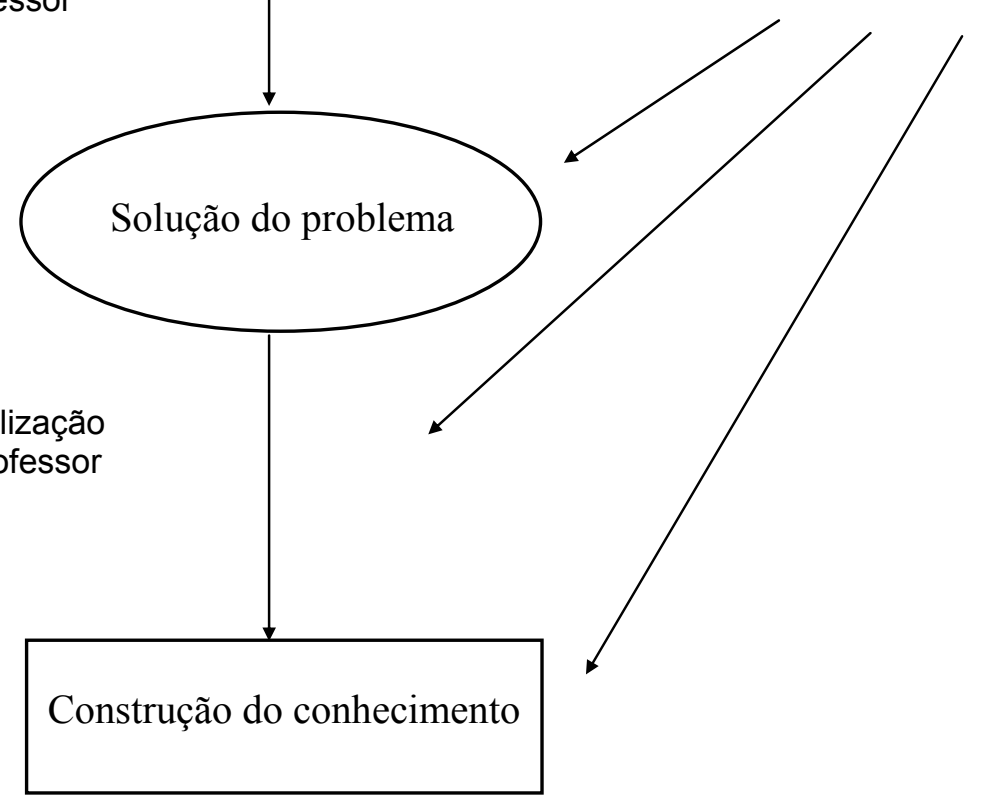

Fig. 3: A construção do conhecimento em sala de aula 


\section{Capítulo 3. O foco da pesquisa}

\subsection{Colocação do problema}

No contexto de rede de conhecimentos e significados, diferentemente da perspectiva cartesiana de construção do conhecimento, estamos interessados, neste trabalho, em examinar a maneira segundo a qual o Cálculo Diferencial e Integral é apresentado nos diferentes cursos. Nesse sentido, buscamos descobrir a forma de organização pela qual o conhecimento é comunicado, revelado, ou pela qual os significados são construídos. Há muitos modos para concretizar tal projeto, e, dentre os vários caminhos possíveis, escolhemos aquele que nos parece mais isento, menos sujeito a ruídos de comunicação, ou seja, aquele que consiste em examinar um instrumento normalmente presente e que desempenha um importante papel nos diversos cursos: o livro didático, adotado ou sugerido pelo professor.

O livro didático revela-se um suporte para o curso, seja para leitura prévia por parte dos alunos, seja para complemento das aulas ministradas pelo professor, ou para pesquisa dos alunos, mais ou menos aprofundada, ou mesmo como coleção de exercícios propostos.

O livro didático é um "porto seguro" onde o professor ancora o curso, evitando desvios de rota em demasia. Constitui-se num referencial sempre presente para ele e para os alunos. É claro que, no decorrer da viagem por mares nunca d'antes navegados, pequenas incursões em ilhas desconhecidas são permitidas, até mesmo podem ser estimulantes para tornar a viagem mais interessante. Entretanto, o rumo não pode ser esquecido. 
Um texto para um curso inicial de Cálculo não pode apresentar o mesmo tipo de abordagem que é encontrada num paper produzido por um matemático profissional, onde é fundamental apenas o resultado encontrado, sendo que os problemas que motivaram a busca desse resultado, normalmente pouco importam. Os passos necessários, o caminho percorrido, têm pequena relevância, tão somente para garantir que o resultado é correto, e, nesse sentido, sequer são detalhados. É claro que o objetivo de um artigo é muito diferente daquele de um livro didático, pois, enquanto o primeiro visa à comunicação de resultados para um número muito restrito de leitores da comunidade científica, o segundo objetiva viabilizar a construção do conhecimento, sendo examinado por um número relativamente grande de pessoas: os que ensinam, isto é, os professores, e os que apreendem, ou seja, os alunos. Poderíamos dizer que o trabalho do matemático profissional está para o paper assim como o trabalho do professor está para o seu curso e, nesse sentido, a abordagem apresentada num livro, reveladora de indícios de como o conhecimento em Cálculo pode ser construído, é muito diferente da de um artigo.

A escolha do livro revela uma primeira compatibilidade entre a proposta a do autor e a proposta do professor que ministra o curso. Essa premissa nos parece razoável diante do grande número de livros didáticos de Cálculo existentes e das escolhas normalmente realizadas. O professor não escolhe qualquer texto. A opção por um determinado livro, revela sua maior identificação com o trabalho nele desenvolvido, em contraposição daquele realizado nos outros textos disponíveis. Essa identificação, evidentemente, é relativa, podendo sempre acontecer de o professor realizar complementos, textos ou coleções de exercícios, para ampliar ou modificar partes em que ele gostaria de fazer de outra maneira. Não podemos esquecer dos desvios na rota préestabelecida, mesmo porque neles, muitas vezes, revela-se a criatividade em potencial que cada professor possui. Assim, o curso não se desenvolve necessariamente de modo idêntico ao livro, mas, de modo geral, a organização 
do Cálculo, apresentada no texto, fornece fortes indícios das intenções do professor, de suas crenças em relação a como deverá ocorrer a construção do conhecimento por parte de seus alunos, no decorrer de seu curso.

O livro didático mostra um caminho proposto por seu autor, para viabilizar a sua concepção de como o conhecimento no Cálculo pode ou deve ser construído. A rota, muitas vezes, foi inicialmente estabelecida em apostilas, que foram sendo aprimoradas através dos cursos que o próprio autor ministrou, para finalmente serem transformadas no livro, editado, re-editado, num processo de aperfeiçoamento contínuo. Essa é a rota definitiva, pelo menos até que novas modificações sejam eventualmente propostas numa posterior edição.

Evidentemente, o uso do livro depende muito do leitor, mas é claro que a proposta nele contida é fruto de um intenso trabalho e de profunda reflexão por parte do autor. É sua sugestão na busca da aprendizagem significativa.

Um primeiro exame dos diversos livros selecionados nos mostra diferenças muito grandes na abordagem realizada. Ainda que, nos diferentes textos, o assunto, basicamente, seja sempre o mesmo, em cada caso, o autor definiu objetivos principais, realizou escolhas metodológicas para viabilizar a consecução dos seus objetivos. Por exemplo, privilegiou determinada seqüência na abordagem realizada, estabeleceu uma preponderância da lógica ou da retórica no desenvolvimento do texto, imprimiu um caráter mais algébrico ou geométrico, propôs questões mais ou menos criativas, além daquelas meramente "burocráticas", que objetivam a aprendizagem técnica. Existe uma grande diferença entre os textos que pretendem negociar os significados, para a construção do conhecimento, através de uma apresentação puramente lógica, uma revelação seqüencial de um edifício pronto chamado Cálculo Diferencial e Integral, e aqueles que procuram negociar significados através de problemas interessantes e motivadores, buscando, inicialmente, muito mais trabalhar as idéias gerais, do que estabelecer relações puramente lógicas e formais. 
As diferenças existentes nos textos são tão grandes e numerosas que tornam significativa a escolha efetuada pelo professor, pois essa escolha revela sua concordância, em linhas gerais, com a maneira pela qual o Cálculo deverá ser trabalhado, a fim de obter os resultados esperados.

O presente trabalho consiste em buscar, por meio da análise de livros didáticos, respostas para questões que são objeto de nossas mais profundas preocupações no que concerne ao ensino/aprendizagem do Cálculo Diferencial e Integral, entendendo que, nos textos selecionados, encontram-se indícios significativos de como são desenvolvidos os cursos de Cálculo, especialmente na Universidade de São Paulo. Essas preocupações podem ser definidas através das seguintes questões:

$\diamond$ Como se inicia o curso de Cálculo, ou seja como é feita a "ponte" entre o conhecimento anterior dos alunos e aquilo com que se pretende trabalhar?

$\diamond$ A seqüência apresentada leva em conta o que é mais "natural" para os alunos iniciantes, no sentido da gênese das idéias fundamentais, presente na história?

$\diamond$ Ao introduzir um novo conceito, há problematização, exploração das idéias envolvidas?

$\diamond \mathrm{Em}$ que medida o conhecimento é apresentado como algo pronto, terminado, ou algo que está sendo buscado, construído? Como é feita a negociação dos significados dos conceitos envolvidos?

$\diamond$ Há referência aos matemáticos que elaboraram o Cálculo? Essas referências são episódicas, curiosidades apenas, ou caracterizam o contexto, apresentando os problemas e desafios por eles enfrentados? 
$\diamond$ Quanto o curso proposto mostra que o Cálculo se constitui numa ferramenta fundamental para resolver problemas atuais, assumindo um papel interdisciplinar extremamente relevante?

A fim de encontrar respostas a algumas dessas perguntas, que, evidentemente, não são as únicas que podem ser formuladas, passamos a definir critérios de análise dos livros didáticos selecionados.

\subsection{A análise}

Examinando, mesmo que superficialmente, os livros selecionados, observamos a existência de distintas abordagens realizadas pelos diferentes autores, muito embora o assunto tratado seja basicamente o mesmo.

Existem dois modelos principais, muito diferentes, que norteiam as várias propostas didáticas, no sentido da maior ou menor proximidade de cada texto em relação a esses paradigmas.

O primeiro modelo se constitui na apresentação do Cálculo sistematizado, formal e logicamente organizado, como resultado do trabalho de pensadores, filósofos e matemáticos, durante mais de vinte séculos. Esta é uma abordagem realizada por alguns autores em suas propostas para um primeiro curso de Cálculo Diferencial e Integral. Nesse caso, a seqüência temática, basicamente, é: Números Reais, Funções, Limites, Derivadas e Integrais, e o tratamento metodológico obedece, em muitos casos, à idéia de fornecer uma revelação do Cálculo. A proposta parece basear-se no fato questionável de que a lógica interna consistente deva garantir a aprendizagem significativa por parte dos estudantes. 
O segundo modelo apresenta o Cálculo em construção. Este modelo diverge do anterior por apresentar uma seqüência temática que não obedece necessariamente à estruturação lógica, mas muito mais ao desenvolvimento do Cálculo, ou à sua contemporaneidade. Isto se deve ao fato de basear-se numa metodologia problematizadora, segundo a qual aquilo que deflagra o processo de construção do conhecimento, por parte dos alunos, é a existência de problemas importantes e motivadores. Neste caso, à luz das idéias de Brousseau, numa primeira aproximação, temos três importantes etapas:

- A recontextualização e repersonalização que consiste em explicitar como o conhecimento desejado é contextualizado é tornado pessoalmente necessário para cada estudante. Isto pode ser verificado na ênfase das idéias subjacentes, importantes historicamente ou mesmo por sua atualidade, através da colocação de problemas significativos.

- A negociação que se traduz na maneira pela qual os significados são construídos. Esta questão pode ser examinada através dos seguintes aspectos fundamentais: a linguagem utilizada, a visualização proporcionada, a argumentação estabelecida.

- A redescontextualização e redespersonalização que consiste na formalização e generalização necessárias para transformar o conhecimento contextualizado e personificado num conhecimento que possa ser utilizado em outras situações, precisando, portanto, estar desvinculado do contexto e da pessoa que o construiu.

Assim, a partir das idéias de Brousseau, dentro dos pressupostos teóricos da rede de conhecimentos e significados, que fundamentam o trabalho, selecionamos os seguintes critérios: 


\section{Critério 1: As idéias}

$\diamond$ As idéias fundamentais, que historicamente propiciaram o desenvolvimento do Cálculo, ou que são importantes por sua atualidade, estão explícitas no texto.

$\diamond$ As idéias fundamentais do Cálculo não estão explícitas, pensando na história ou na atualidade, mas há uma grande quantidade de aplicações do Cálculo, após o desenvolvimento dos conceitos.

$\diamond$ Não há dados históricos; o Cálculo é apresentado sistematizado e, nesse sentido, é revelado. A ênfase está situada nos conceitos já formalizados, não nas idéias.

\section{Critério 2: A problematização}

$\diamond \mathrm{O}$ texto parte de importantes problemas motivadores para chegar à construção do conceito.

$\diamond \quad$ O texto parte de alguns exemplos simples para depois introduzir o conceito.

$\diamond \mathrm{O}$ texto inicia diretamente com o conceito para depois colocar exemplos, exercícios ou problemas.

\section{Critério 3: A linguagem}

$\diamond$ Além do texto usual em linguagem matemática, observamos a presença de texto em linguagem corrente, com o qual o autor busca o convencimento do leitor, discute dificuldades, mostra possíveis caminhos. 
$\diamond$ Além do texto usual em linguagem matemática, há texto informativo em linguagem corrente, sem busca de convencimento.

$\diamond \mathrm{O}$ uso da linguagem corrente é mínimo; utiliza primordialmente a linguagem matemática.

\section{Critério 4: A visualização}

$\diamond \mathrm{O}$ texto é rico em figuras, gráficos, utilizando, às vezes, argumentos geométricos ou gráficos para fazer cálculos algébricos.

$\diamond \mathrm{O}$ texto apresenta figuras e gráficos, mas os argumentos são algébricos para serem visualizados na figura.

$\diamond \mathrm{O}$ texto quase não tem figuras ou não tem figura alguma.

\section{Critério 5: A argumentação}

$\diamond$ O autor busca a construção do conhecimento através de aproximações, retornando várias vezes, sem caráter definitivo, logo da primeira vez. Aproveita a intuição.

$\diamond$ Embora a argumentação não seja apenas internalista, podendo mesmo utilizar a intuição, o autor estabelece um caráter definitivo para o conhecimento construído.

$\diamond$ Os argumentos utilizados são provenientes apenas da lógica interna e o caráter do conhecimento construído é definitivo. 


\section{Critério 6: A formalização/generalização}

$\diamond$ A organização do texto mostra o Cálculo em construção, não se constituindo numa apresentação logicamente estruturada; as generalizações e formalizações necessárias são naturalmente obtidas.

$\diamond$ A organização do texto apresenta, inicialmente, o Cálculo em construção, e, após a introdução do novo conceito, parte para um esquema revelador do Cálculo, logicamente estruturado.

$\diamond$ A organização do texto mostra uma revelação do Cálculo; tudo é demonstrado e sempre inserido num contexto logicamente estruturado. 


\begin{tabular}{|c|c|c|c|}
\hline I & $\begin{array}{l}\text { As idéias fundamentais, que } \\
\text { historicamente propiciaram o } \\
\text { desenvolvimento do Cálculo, ou que } \\
\text { são importantes por sua atualidade, } \\
\text { estão explícitas no texto. }\end{array}$ & $\begin{array}{l}\text { As idéias fundamentais do Cálculo } \\
\text { não estão explícitas, pensando na } \\
\text { história ou na atualidade, mas há } \\
\text { uma grande quantidade de } \\
\text { aplicações do Cálculo, após o } \\
\text { desenvolvimento dos conceitos. }\end{array}$ & $\begin{array}{l}\text { Não há dados históricos; o Cálculo é } \\
\text { apresentado sistematizado e, nesse } \\
\text { sentido, é revelado A ênfase está } \\
\text { situada nos conceitos já } \\
\text { formalizados, não nas idéias. }\end{array}$ \\
\hline$P$ & $\begin{array}{l}\text { O texto parte de importantes } \\
\text { problemas motivadores para chegar } \\
\text { à construção do conceito }\end{array}$ & $\begin{array}{l}\text { O texto parte de alguns exemplos } \\
\text { simples para depois introduzir o } \\
\text { conceito }\end{array}$ & $\begin{array}{l}\text { O texto inicia diretamente com o } \\
\text { conceito para depois colocar } \\
\text { exemplos, exercícios ou problemas }\end{array}$ \\
\hline $\mathrm{L}$ & $\begin{array}{l}\text { Além do texto usual em linguagem } \\
\text { matemática, observamos a } \\
\text { presença de texto em linguagem } \\
\text { corrente, com o qual o autor busca o } \\
\text { convencimento do leitor, discute } \\
\text { dificuldades, mostra possíveis } \\
\text { caminhos. }\end{array}$ & $\begin{array}{l}\text { Além do texto usual em linguagem } \\
\text { matemática, há texto informativo em } \\
\text { linguagem corrente, sem busca de } \\
\text { convencimento. }\end{array}$ & $\begin{array}{l}\text { O uso da linguagem corrente é } \\
\text { mínimo; utiliza primordialmente a } \\
\text { linguagem matemática }\end{array}$ \\
\hline $\mathrm{V}$ & $\begin{array}{l}\text { O texto é rico em figuras, gráficos, } \\
\text { utilizando, às vezes, argumentos } \\
\text { geométricos ou gráficos para fazer } \\
\text { cálculos algébricos }\end{array}$ & $\begin{array}{l}\text { O texto apresenta figuras e gráficos, } \\
\text { mas os argumentos são algébricos } \\
\text { ou analíticos para serem } \\
\text { visualizados na figura }\end{array}$ & $\begin{array}{l}\text { O texto quase não tem figuras ou } \\
\text { não tem figura alguma }\end{array}$ \\
\hline$A$ & $\begin{array}{l}\text { O autor busca a construção do } \\
\text { conhecimento através de } \\
\text { aproximações, retornando várias } \\
\text { vezes, sem caráter definitivo, logo } \\
\text { da primeira vez. Aproveita, às } \\
\text { vezes, a intuição. }\end{array}$ & $\begin{array}{l}\text { Embora a argumentação não seja } \\
\text { apenas internalista, podendo } \\
\text { mesmo utilizar a intuição, o autor } \\
\text { estabelece um caráter definitivo } \\
\text { para o conhecimento construído. }\end{array}$ & $\begin{array}{l}\text { Os argumentos utilizados são } \\
\text { provenientes apenas da lógica } \\
\text { interna e o caráter do conhecimento } \\
\text { construído é definitivo }\end{array}$ \\
\hline$F$ & $\begin{array}{l}\text { A organização do texto mostra o } \\
\text { Cálculo em construção, não se } \\
\text { constituindo numa apresentação } \\
\text { logicamente estruturada; as } \\
\text { generalizações e formalizações } \\
\text { necessárias são naturalmente } \\
\text { obtidas. }\end{array}$ & $\begin{array}{l}\text { A organização do texto apresenta, } \\
\text { inicialmente, o Cálculo em } \\
\text { construção, e, após a introdução do } \\
\text { novo conceito, parte para um } \\
\text { esquema revelador do Cálculo, } \\
\text { logicamente estruturado. }\end{array}$ & $\begin{array}{l}\text { A organização do texto mostra uma } \\
\text { revelação do Cálculo; tudo é } \\
\text { demonstrado e sempre inserido num } \\
\text { contexto logicamente estruturado. }\end{array}$ \\
\hline
\end{tabular}

Figura 4: Os critérios para a análise dos livros selecionados. 


\subsection{Os livros didáticos selecionados}

Nossa atuação no Instituto de Matemática e Estatística da Universidade de São Paulo, ministrando diferentes disciplinas, em particular os cursos iniciais de Cálculo Diferencial e Integral, nos propiciou inúmeras reflexões a respeito do assunto, que frutificaram em sucessivos questionamentos e reformulações, na busca incessante da construção do conhecimento significativo.

Neste trabalho, para viabilizar a pesquisa, fizemos uma seleção dos textos disponíveis com base, em primeiro lugar, no nível de aceitação e adoção por parte dos docentes do IME. Muitos dos livros escolhidos têm sido normalmente adotados, alguns na década de sessenta, outros mais recentemente.

Em segundo lugar, selecionamos alguns livros por apresentarem uma proposta original e alternativa, fundamentada em objetivos claros do autor, que demonstram uma preocupação com a aprendizagem significativa por parte dos estudantes, no contexto das idéias teóricas nas quais o presente trabalho se baseia.

Alguns livros de Análise Real e de Cálculo Avançado, também foram selecionados, a fim de poder observar como, em alguns casos, o curso inicial de Cálculo se aproxima, na verdade, muito mais de um curso mais avançado.

De modo geral, diante do grande espectro de livros didáticos que versam sobre Cálculo, um feeling global, fruto de nossa experiência, norteou a escolha realizada. A partir disso, foi composta a seguinte relação de livros, cuja referência completa se encontra na Bibliografia. 
A relação dos livros:

1) W. ALEXANDER et alii: A Programed Course In Calculus - Vol. I, II, III, IV e V - The Committee on Educational Media of the Mathematical Association of America

2) T. M. APOSTOL: Mathematical Analysis

3) T. M. APOSTOL: Calculus - Vol. I

4) G. S. S. ÁVILA: Cálculo Diferencial E Integral - Vol. I

5) P. BOULOS: Introdução Ao Cálculo - Vol I e II

6) K. G. BARTKOVICH et alii: Contemporary Calculus Through Applications

7) M. BRUCKHEIMER et alii: Introducción Al Cálculo Y Al Álgebra - Vol. I e II (Texto de la Open University de Londres)

8) R. C. BUCK: Advanced Calculus

9) R. COURANT: Differential And Integral Calculus - Vol. I

10) R. COURANT and F. JOHN: Introduction To Calculus And Analysis - Vol. I

11) H. P. GREENSPAN and D. J. BENNEY: Calculus - An Introduction To Applied Mathematics

12) H. L. GUIDORIZZI: Um Curso De Cálculo - Vol. I

13) W. KAPLAN: Advanced Calculus

14) W. KAPLAN e D. J. LEWIS: Cálculo E Álgebra Linear - Vol. I

15) S. LANG: Cálculo - Vol. I 
16) L. LEITHOLD: O Cálculo Com Geometria Analítica - Vol. I

17) E. E. MOISE: Cálculo - Um Curso Universitário - Vol. I

18) N. PISKOUNOV: Calcul Différentiel Et Integral

19) W. RUDIN: Principles Of Mathematical Analysis

20) G. F. SIMmONS: Cálculo Com Geometria Analítica - Vol. I

21) M. SPIVAK: Cálculo Infinitesimal - Vol. I e II

22) E. W. SWOKOWSKI: Cálculo Com Geometria Analítica - Vol. I

23) J. WHITE: Análise Real: Uma Introdução

24) A. B. WILLCOX et alii: Introduction To Calculus - Vol. I 
W. ALEXANDER et alii: A Programed Course In Calculus - Vol I, II, III, IV e V The Committee on Educational Media of the Mathematical Association of America (Instrução Programada)

Esta obra difere fortemente das outras, justamente por ser um texto de instrução programada, sendo pois, em certo sentido, completamente insólita. No prefácio encontramos que:

The use of the programmed form in these volumes means that an immediate response is required after presentation of information, and a correct answer is immediately given for comparison. The essence of the programmed form is the activity demanded of the student and the control over the sequence of this activity. The programmed approach is likely to be particularly advantageous in cases where the student is expected to be independent in his work or in cases where the time allowed for class meetings is relatively small. (Alexander et alii, 1968, p. v) ${ }^{13}$

Evidentemente, os autores sugerem ao estudante manter coberta a resposta correta, enquanto está buscando resolver a questão proposta. Observamos que as questões são propostas step by step, procurando inclusive garantir revisões necessárias, para que a questão seguinte possa ser respondida. Os autores procuram fornecer o menor número de informações, mas, assim mesmo, levar o aluno a formular suas conclusões e assim se apropriar dos conceitos. Esta parece ser a característica mais importante da obra.

Para chegar ao conceito de derivada, são colocados três exemplos velocidade de um corpo em movimento, reta tangente ao gráfico de uma função num ponto e densidade de uma barra metálica - e, a partir deles, uma série de perguntas explorando a situação, para, ao final da exploração, fazer o aluno

\footnotetext{
13 O uso da forma programada, nestes volumes, significa que uma resposta imediata é necessária após a apresentação da informação, e que uma resposta correta é fornecida para ser possível a verificação. A essência da instrução programada é a atividade exigida do estudante e o controle sobre a seqüência dessa atividade. A instrução programada
} 
chegar a uma expressão formal, que é a mesma nos três casos. Somente depois é colocada a definição de derivada de uma função num ponto, através de uma expressão que é a mesma que foi obtida nos três exemplos.

É interessante observar, por exemplo, como a demonstração do Teorema do Valor Médio para derivadas acaba sendo feita pelo leitor, mas induzida pelo texto, através de colocações ou perguntas às quais ele deve responder.

Induzir o aluno a fazer exatamente o que os autores desejam que ele faça, é uma constante que caracteriza fortemente este texto.

A linguagem corrente é bastante utilizada. Como o texto é voltado para o trabalho independente do estudante, procura tornar natural a seqüência das demonstrações que pretende sejam feitas.

Os gráficos e figuras são apresentadas, muitas vezes, para que o estudante busque nelas argumentos para suas respostas.

A questão dos limites é desenvolvida de maneira bastante intuitiva, induzindo, como em toda a obra, as respostas do estudante. Nesse tópico não há uma formalização pesada, embora, em geral, os autores procurem garantir, mesmo que de forma mais ou menos intuitiva, a demonstração dos teoremas apresentados.

A proposta dos autores é a de apresentar uma revelação do Cálculo, e, nesse sentido, a seqüência temática é a seguinte: 


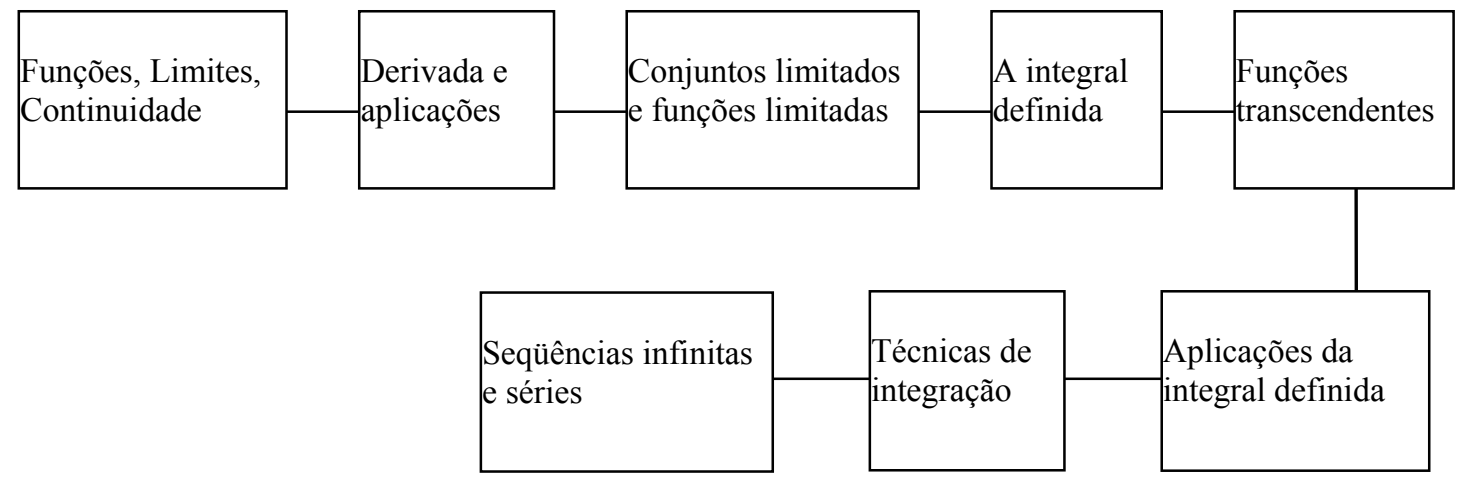

Figura 5: A seqüência temática de W. ALEXANDER et alii 


\section{T. M. APOSTOL: Mathematical Analysis}

No prefácio, o autor afirma que

A clear understanding of the basic concepts of calculus is indispensable for anyone who wishes to learn more advanced concepts in analysis. (Apostol, 1957, p.vi) ${ }^{14}$

A afirmação é pertinente, uma vez que o livro não se destina a um curso inicial de Cálculo. Entretanto, é razoável observar este texto por dois motivos. $\mathrm{O}$ primeiro é o interesse em verificar o quanto alguns outros textos, propostos para o primeiro curso de Cálculo, se aproximam deste, que, garantidamente, não tem tal objetivo. O segundo motivo consiste no fato do mesmo autor ter proposto um outro livro, este sim dedicado ao curso de Cálculo para alunos iniciantes, e será interessante verificar o distanciamento das duas propostas.

A seqüência, correspondente aos tópicos apresentados no Cálculo, é a seguinte:

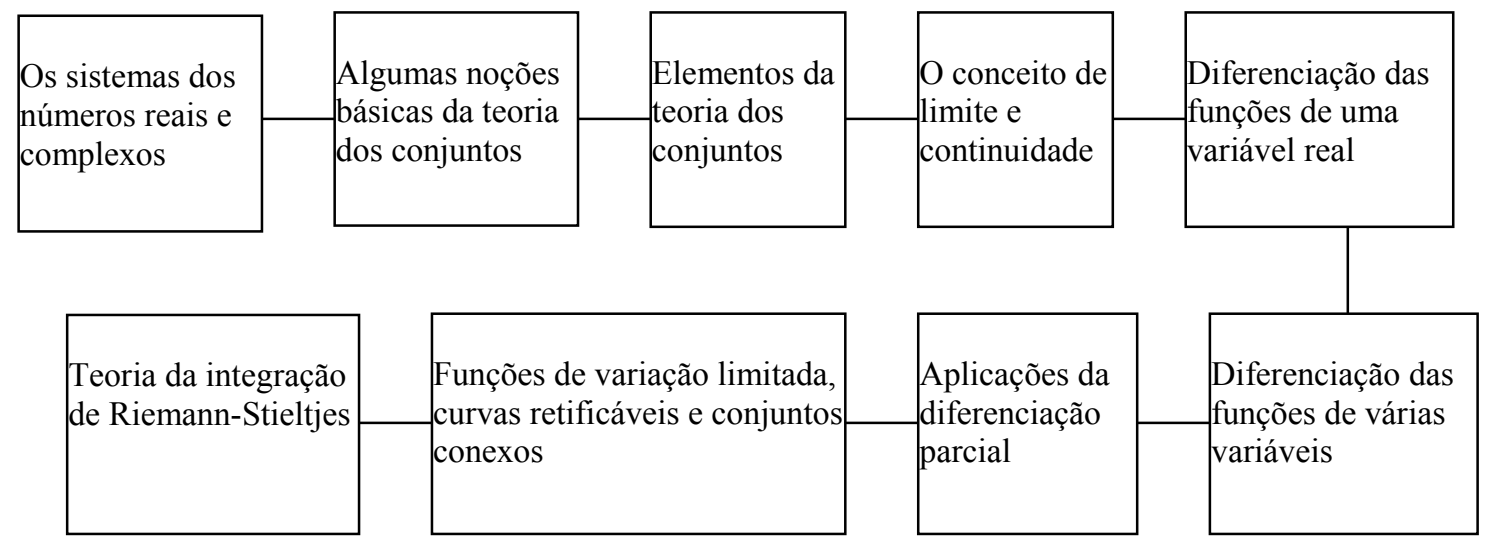

Figura 6: A seqüência temática de T. M. APOSTOL (MATHEMATICAL ANALYSIS)

\footnotetext{
${ }^{14}$ Uma compreensão clara dos conceitos do cálculo é indispensável para todos os que desejam aprender conceitos mais avançados em análise.
} 
Inicialmente, observamos que, conforme esperado, o autor se propõe a fazer uma revelação, não sendo pois objetivo do texto fazer qualquer tipo de problematização, nem explicitação detalhada das idéias fundamentais do Cálculo. O autor utiliza linguagem corrente de maneira reduzida, mas, assim mesmo, estabelece elos com o curso inicial de Cálculo. As figuras existem em pequena quantidade e a argumentação utiliza a lógica interna. O texto apresenta todas as demonstrações conforme se espera de um curso de Análise Real. 
T. M. APOSTOL: Calculus - Vol. I

\section{No Prefácio, o autor afirma que}

There seems to be no general agreement as what should constitute a first course in calculus and analytic geometry. Some people insist that the only way really to understand calculus is to start off with a thorough treatment of the real-number system and develop the subject step by step in a logical and rigorous fashion. Others argue that calculus is primarily a tool for engineers and physicists; they believe the course should stress applications of the calculus by appeal to intuition and by extensive drill on problems which develop manipulative skills. There is much that is sound in both these points of view. Calculus is a deductive science and a branch of pure mathematics. At the same time it is very important to remember that calculus has strong roots in physical problems and that it derives much of its power and beauty from the variety of its applications. (Apostol, 1962., p. vii) ${ }^{15}$

A observação do autor, há mais de trinta anos, continua extremamente válida nos dias atuais, pois observamos que essas divergências nos cursos iniciais de Cálculo, continuam existindo. Entretanto, it is possible to combine a strong theoretical development with sound training and technique.(id., p. vii) ${ }^{16}$

A seqüência dos temas abordados pelo autor difere da maioria dos outros textos. Grosso modo, ele começa com o Cálculo Integral e depois expõe o Cálculo Diferencial, inserindo os assuntos que considera necessários como suplementos. Além disso, a fim de evitar interrupções no fluxo principal das idéias desenvolvidas, algumas seções, assinaladas com $\star$, podem ser deixadas para um estudo posterior, conforme sugestão do próprio autor.

\footnotetext{
15 Parece não existir concordância geral sobre o que deveria consistir um primeiro curso em cálculo e geometria analítica. Alguns insistem em que a única forma de realmente entender cálculo é começar com um verdadeiro tratamento do sistema dos números reais e desenvolver o assunto, passo a passo, de maneira lógica e rigorosa. Outros argumentam que o cálculo é primeiramente uma ferramenta para engenheiros e físicos; eles acreditam que o curso deveria enfatizar aplicações do cálculo, apelando para a intuição e o enfrentamento de problemas que desenvolvem habilidades técnicas. Em ambos os pontos de vista há aspectos que fazem sentido. O cálculo é uma ciência dedutiva e é um ramo da matemática pura. Ao mesmo tempo, é preciso lembrar que o cálculo possui fortes raízes em problemas físicos e que muito de sua potência e beleza derivam da variedade de aplicações.

16 ...é possível combinar um desenvolvimento fortemente teórico com preparo seguro e técnico.
} 
Logo de início, encontramos uma introdução histórica na qual o autor coloca a sua visão sobre a utilidade do Cálculo, como ferramenta poderosa na resolução de um sem número de problemas, nas mais diferentes áreas do conhecimento humano. As idéias gerais do Cálculo são explicitadas, idéias essas que dizem respeito à velocidade, área, volume, taxa de variação, continuidade, reta tangente. A sua opção inicial é pela exposição do método da exaustão, utilizado com sucesso por Arquimedes (287-212 A.C.), sendo transformado no que passou a ser conhecido como o Cálculo Integral e que recebeu o maior impulso no séc. XVII, principalmente devido aos esforços de Isaac Newton (1642-1727) e de Gottfried Leibniz (1646-1716). Até o séc. XIX, o assunto continuou a ser estudado, e, com Augustin-Louis Cauchy (1789-1857) e Bernhard Riemann (1826-1866), adquiriu uma base matemática firme. Segundo o autor, Arquimedes percebia a necessidade de demonstração dos fatos que conseguia estabelecer através de seu método, mas deixava claro que isso deveria ocorrer após uma visão antecipada do teor das questões.

A escolha de Apostol parece ser adequada para estabelecer uma ponte com o conhecimento dos alunos iniciantes, para os quais o problema de calcular áreas e volumes de figuras mais gerais parece estar muito próximo dos problemas de calcular áreas e volumes de figuras simples que foi resolvido na escola média. Ao final do exemplo de aplicação do método de exaustão para a área sob o gráfico de uma parábola e acima do eixo das abcissas, encontramos uma análise crítica ao método da Arquimedes, que termina afirmando que

$$
\begin{aligned}
& \text { (...) the kind of thinking is very suggestive and often very helpful. } \\
& \text { Logically, however it suffers from the defect that no one has been able } \\
& \text { to assign an exact meaning to the idea of an "infinitesimally small } \\
& \text { quantity." Today we know how to introduce the integral in terms of the } \\
& \text { notion of real number without using mysterious and unexplained ideas } \\
& \text { like "infinitesimals". (ib., p. 11) }
\end{aligned}
$$

\footnotetext{
17 ...o tipo de pensamento é muito sugestivo e muitas vezes benéfico. Logicamente, entretanto, possui o defeito de que ninguém foi capaz de atribuir um significado exato à idéia de uma "quantidade infinitamente pequena". Atualmente,
} 
Com essa incursão na história, várias idéias de como se trabalha conceitualmente no Cálculo já foram, nesta altura, semeadas pelo autor.

A comunicação com o leitor é estabelecida através de muitos textos em linguagem corrente, buscando sempre a garantia do entendimento de seus objetivos. Há uma grande quantidade de figuras sugestivas e criativas. No tópico sobre derivadas, por exemplo, é interessante observar a quantidade de ilustrações relacionando uma função com sua derivada.

Devido a seus propósitos, o autor constrói os conceitos através de processos aproximativos; procurando fazer com que o leitor, ao alcançar a formalização definitiva dos conceitos, tenha passado por várias etapas sucessivas.

Nas seções assinaladas com $\star$, procede à formalização de maneira definitiva, satisfazendo o leitor que busca perceber o Cálculo sistematizado, segundo a lógica interna dedutiva.

A seqüência temática é a seguinte:

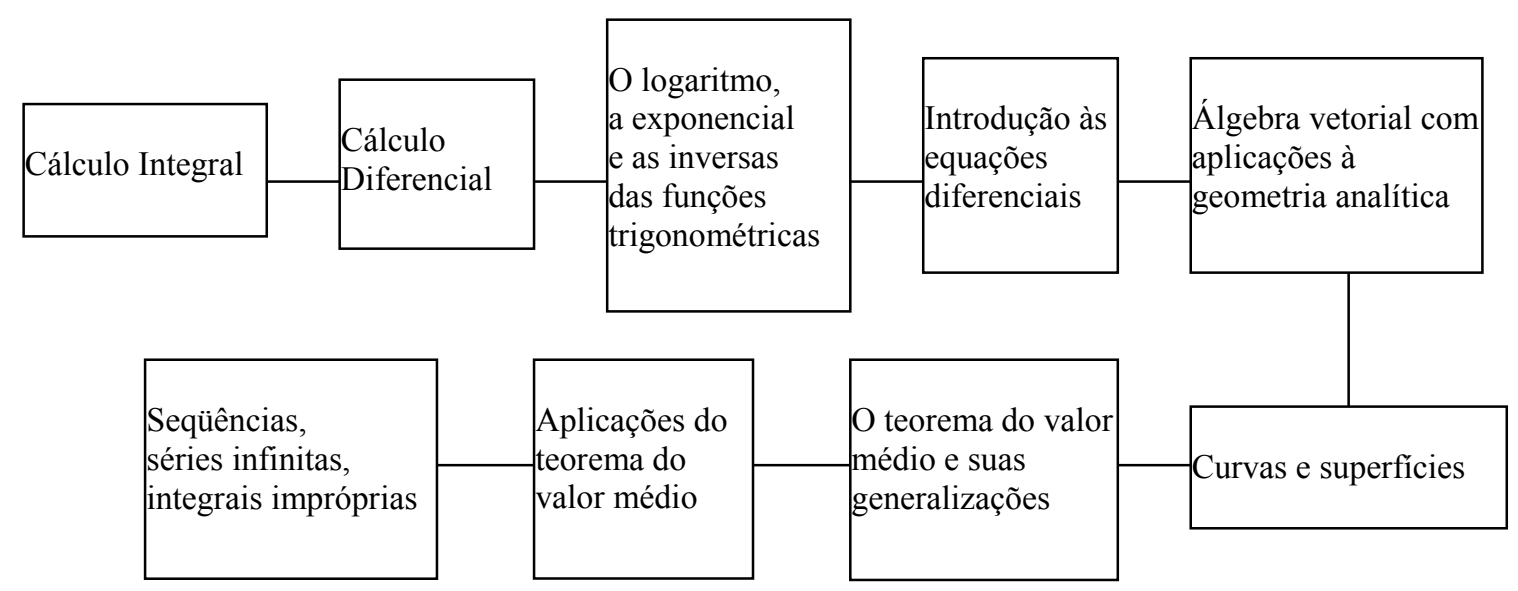

Figura 7: A seqüência temática de T. M. APOSTOL (CALCULUS)

sabemos como introduzir a integral em termos da noção de número real sem utilizar idéias misteriosas e inexplicadas como "infinitesimais". 


\section{G. S. S. ÁVILA: Cálculo Diferencial E Integral - Vol. 1}

No prefácio, o autor coloca que

O Cálculo Diferencial e Integral desenvolveu-se em íntima interação com os vários ramos da Ciência - sobretudo a Física - desde os tempos de Galileu. (...) Mas seus conceitos fundamentais são profundos e sutis, e desafiaram os melhores matemáticos por cerca de século e meio. A devida apreciação desses conceitos só pode ser adquirida gradualmente e por via intuitiva. É por isto mesmo - e porque a melhor pedagogia é antes de tudo uma questão de bom senso - que o Cálculo deve ser apresentado com um mínimo de formalismo, com apelo à intuição e aos problemas de Física e Geometria que Ihe deram origem. É importante atentar para esses fatos quando, em nossos dias, o ensino da Matemática ainda padece de formalismo e rigor excessivos e extemporâneos e de pouca, ou quase nenhuma, preocupação em relacionar a Matemática com outras áreas do conhecimento. Isto constitui-se, freqüentemente um entrave à tarefa mais importante, que é a apresentação livre e desembaraçada dos conceitos. (Ávila,1981 p.ix)

O autor, dessa forma, focaliza talvez uma das causas dos grandes problemas enfrentados nos cursos de Cálculo. De fato, quando a importância primordial reside no fato de revelar todo um conjunto de conhecimentos, articulados coerentemente, segundo uma lógica interna, com pouca, ou, às vezes, nenhuma articulação com outras áreas do conhecimento humano, essa revelação se torna inútil e desprovida de significado e os conceitos envolvidos não são encarados com a devida importância.

Continuando, Ávila afirma que

(...) a idéia de que ao aluno de Matemática se deva ministrar, desde o início, um ensino rigoroso e isolado das outras ciências encerra um grave erro, sob dois aspectos: de um lado, priva-se o estudante da correta apreciação da Matemática, cujo valor mais autêntico reside nas idéias, na criatividade e não apenas no rigor e no encadeamento lógico 
das demonstrações. (...) De outro lado, esse ensino isolado não corresponde à realidade histórica; de fato, as exigências de desenvolvimento de teorias e métodos matemáticos em Física, Astronomia e nas demais ciências têm se constituído nas fontes mais estimuladoras da criação matemática. (id., p.x)

A preocupação inicial de Ávila parece ser a de retomar os assuntos mais importantes que os alunos normalmente deveriam ter trabalhado na escola média. As questões são trabalhadas com detalhe e com bastante visualização gráfica.

O autor explora bastante as idéias do Cálculo. Alguns problemas são colocados antes dos conceitos que deseja estabelecer. O que é digno de nota é o fato de ir-se aproximando, através de colocações provisórias para, finalmente, chegar no conceito em sua forma definitiva. Há muitas figuras e gráficos possibilitando verificar os argumentos algébricos utilizados.

O texto é rico em linguagem corrente, procurando todo o tempo convencer o leitor. Além disso, ao final de cada Capítulo, o autor desenvolve um texto sobre os matemáticos que trabalharam com o tema tratado, o que parece estimular a curiosidade do leitor e a percepção de que o conhecimento não foi descoberto, mas construído.

A seqüência temática proposta é bastante tradicional, mas a exposição não é tão formal. Muitos conceitos são colocados conforme vão sendo necessários, no desenvolvimento dos exemplos.

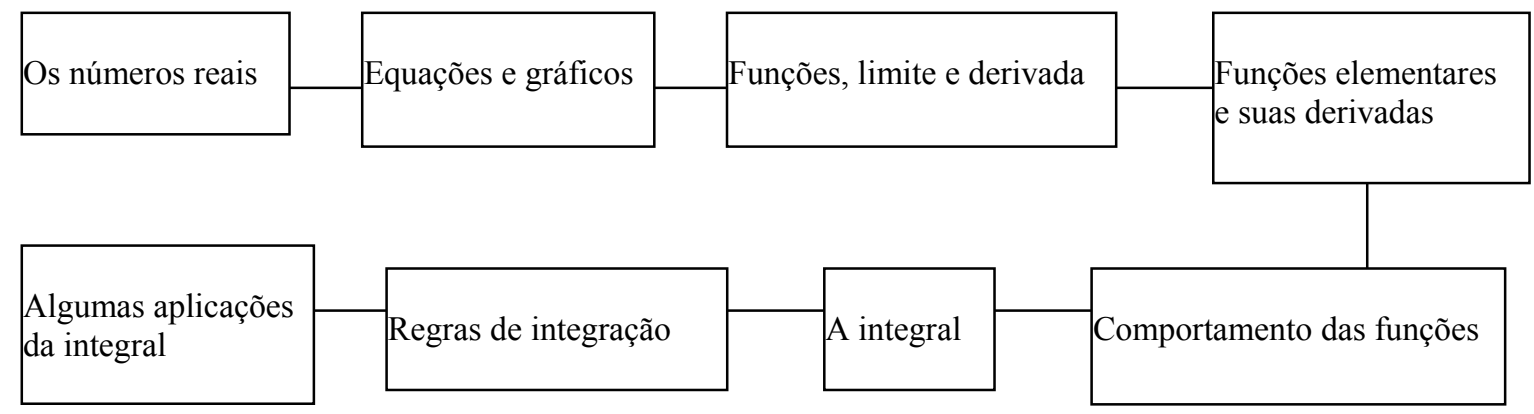

Figura 8: A seqüência temática de G. S. S. ÁVILA 
K. G. BARTKOVICH, J. A. GOEBEL, J. L. GRAVES, and D. J. TEAGUE: Contemporary Calculus Through Applications

No prefácio, os autores esclarecem que

(...) the text responds to the following three frequently cited concerns:

1. Students should be able to apply mathematics to problems that are stated in new and different contexts. In other words, students should understand mathematics, in contrast with merely substituting numbers into formulas.

2. Mathematics, and calculus in particular, is applied to virtually every field of human endeavor. Students should appreciate and understand a broad range of these applications, and they should be able to use mathematics as a tool for modeling a variety of real-world phenomena.

3. The numeric, symbolic, and graphic capabilities of computers and calculators have given technology a crucial role in the mathematics classroom. (Bartkovich, K. G. et alii, 1996, p. x) ${ }^{18}$

Os autores têm o objetivo de propor um curso voltado para as aplicações, que desenvolva o Cálculo através da investigação por parte dos alunos e que proporcione ferramentas com as quais o aluno possa compreender o mundo no qual ele vive. Nesse sentido, todo o texto enfatiza a problematização, visando propiciar ao aluno o prazer da descoberta. Os problemas propostos são criativos, originais, e visam levar à construção dos conceitos através de aproximações, por etapas, e não de forma definitiva inicialmente, logo na primeira vez. As idéias fundamentais do Cálculo são assim construídas de

18 (...) o texto responde às seguintes preocupações específicas, freqüentemente citadas:

1. Os estudantes deveriam ser capazes de aplicar a matemática aos problemas que são apresentados em novos e diversos contextos. Ou seja, os estudantes deveriam entender matemática, ao invés de apenas substituir números em fórmulas.

2. A matemática, e o cálculo em particular, é aplicada em praticamente todos os campos da busca científica humana. Os estudantes deveriam admirar e compreender a ampla gama de aplicações, e deveriam ser capazes de usar a matemática como uma ferramenta para modelar uma grande variedade de fenômenos do mundo real.

3. Os atributos numéricos, simbólicos, e gráficos dos computadores e calculadoras têm dado à tecnologia um papel crucial na sala de aula de matemática. 
maneira significativa, uma vez que elas realmente resolvem problemas importantes para os alunos. Este texto apresenta o Cálculo sendo construído, como resposta aos problemas colocados.

O fato dos autores proporem e estimularem a utilização de programas gráficos no computador como também o uso de calculadoras gráficas, mostra a preocupação em propor um curso inserido no contexto atual, que assume a existência das modernas tecnologias e as torna realidade em sala de aula.

A seqüência temática apresentada é a seguinte:

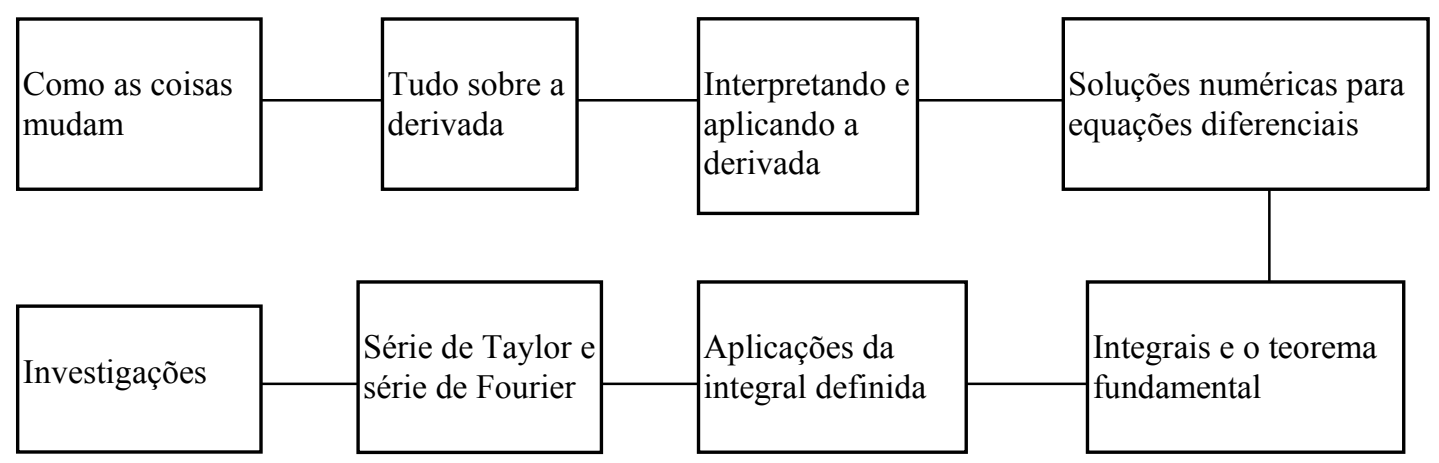

Figura 9: A seqüência temática de K. G. BARTKOVICH e t alii

Quanto ao aspecto da formalização, observamos que alguns assuntos são formalizados e generalizados com todos os detalhes, mas o que chama a atenção na proposta dos autores é a construção dos conceitos de maneira sólida, convencendo de sua necessidade.

A fim de tornar mais claros e visíveis os objetivos dos autores, e a riqueza dos detalhes, passamos a transcrever um longo trecho do Prefácio.

The fabric of the course is woven with seven themes that are an indispensable part of virtually every segment of the course. These themes address important student needs and are described here. 
1. Developing Understanding: Calculus offers students a repertoire of new techniques for describing the world around them and should be accessible to as wide an audience as possible. For that reason, this text encourages intuitive understanding of many topics. Although mathematical rigor may be appropriate, it should not be an obstacle to the success of students. Every student may not be able to prove the theorems of calculus, however each should obtain a solid understanding of the concepts of calculus.

To help students develop their conceptual understanding, graphical, numerical, and algebraic interpretations are used together whenever possible in each section of the text. Students are led to discover concepts for themselves as often as is feasible, primarily through mathematics laboratory experiences.

2. Data, Applications, and Mathematical Models: Much of our information about the world comes to us in the form of data. Problems presented in this textbook describe realistic situations that can be modeled using calculus. As much as possible, major concepts are introduced through data, applications, and mathematical modeling. These applications come from a wide variety of areas in which calculus is used as a tool to solve problems. While the physical sciences provide a wealth of applications of calculus, examples are drawn from many other areas of study. As students see a wide variety of applications they will begin to appreciate the power of calculus.

3. Computer and Calculator as Tools: Much of traditional calculus involves extensive paper-and-pencil manipulation. While students must be able to do some manipulations, technology makes obsolete the skills required for solving difficult problems with paper and pencil. Computer technology empowers us to solve problems with "messy" data and large numbers of computations, which is exactly how problems appear in the real world.

Technology also is used to experiment with different values for parameters in problems, to by different strategies for solution, to test out various conjectures, and to ask "What if...?" questions that otherwise would not be feasible to investigate. Students must, however, 
know how to interpret results, when a result is reasonable, and when technology is not going to provide the best solution to a particular problem. Each of these requirements further emphasizes the need for students to develop a conceptual understanding of calculus.

4. Numerical Algorithms: Approximations for the derivative, the definite integral, and solutions to differential equations can be found using numerical algorithms. Since the techniques used in these algorithms reinforce the broad concepts of calculus, the algorithms provide more than just the solution to a problem. Numerical algorithms do have limitations, and the text will help students develop an understanding of the accuracy and the appropriateness of various numerical methods.

5. Discrete Phenomena: Calculus involves the study of phenomena that are represented by continuous functions. Because computations can be carried out very rapidly, it is possible to study these phenomena using discrete techniques. Recursive techniques, difference quotients, and other discrete concepts help students move from the discrete to the continuous domain. Links between discrete and continuous phenomena ate emphasized frequently in the textbook.

6. Computer and Calculator Laboratory Experiences: Computer and calculator lab work is the centerpiece of the entire course. Students use technology as a tool for investigation and discovery. Labs activities allow students to discover concepts, to develop their intuition related to calculus, and to investigate extended problems in groups and individually. These labs are designed to culminate in written reports that summarize and analyze a particular investigation.

7. Writing about Mathematics: This textbook requires that students write about mathematics, including both concepts and the interpretations of these concepts. The students will use the language of mathematics and communicate their ideas to other individuals familiar with the subject. Writing about mathematics completes a process that begins with the translation of a problem statement into mathematical notation, then uses mathematics to investigate the problem, and ends 


\section{with translating the results back into a verbal explanation and summary}

$$
\text { (id., p. xi) })^{19}
$$

${ }^{19}$ O curso foi desenvolvido através de sete temas indispensáveis, referentes às necessidades dos estudantes e aqui descritos:

1) Desenvolvendo o entendimento: Cálculo oferece aos estudantes um repertório de novas técnicas para descrição do mundo, e deveria ser acessivel a uma audiência o mais ampla possivel. Por essa razão, este texto estimula o entendimento intuitivo de muitos tópicos. Embora o rigor matemático possa ser apropriado, este não deveria ser um obstáculo ao sucesso dos estudantes. Todo estudante pode não ser capaz de provar os teoremas do cálculo, porém cada um deveria obter compreensão sólida dos conceitos do cálculo.

Para auxiliar os estudantes a desenvolver essa compreensão conceitual, interpretações gráficas, numéricas, e algébricas são utilizadas simultaneamente, quando possível, em cada seção do texto. Os estudantes são levados a descobrir conceitos por si mesmos, sempre que possivel, principalmente através de experiências matemáticas empíricas.

2) Dados, aplicações, e modelos matemáticos: uma grande parte da informação chega até nós na forma de dados. Os problemas apresentados neste livro-texto descrevem situações realistas que podem ser modeladas usando cálculo. Tanto quanto possivel, os conceitos fundamentais são introduzidos através de dados, aplicações, e modelos matemáticos. Estas aplicações derivam de uma grande variedade de áreas nas quais o cálculo é usado como uma ferramenta para a solução de problemas. Embora a física ofereça uma série de aplicações do cálculo, os exemplos são obtidos também de muitas outras áreas de estudo. Como os estudantes vêem aplicações variadas, poderão começar a admirar a força do cálculo.

3) Computador e calculadora como ferramentas: uma grande parte do cálculo tradicional envolve o contínuo manuseio de lápis e papel. Embora os estudantes devam estar familiarizados com esses instrumentos, a tecnologia torna obsoletas as habilidades necessárias para solucionar problemas complexos utilizando lápis e papel. A informática nos permite resolver problemas com dados "confusos" e em grande quantidade, exatamente como os problemas aparecem no mundo real.

A tecnologia também é usada em experimentos com diferentes valores para os parâmetros dos problemas, através dos quais podem ser utilizadas diversas estratégias de solução, testadas várias conjecturas, feitas perguntas do tipo "O que acontece se...", que seriam inviáveis sem ela. Os estudantes devem, porém, saber como interpretar os resultados, quando o resultado é razoável, e quando a tecnologia não irá oferecer a melhor solução para um problema particular. Cada um desses requisitos enfatizam mais a necessidade dos estudantes desenvolverem um entendimento conceitual do cálculo.

4) Algoritmos numéricos: Aproximações para a derivada, a integral definida, e soluções para equações diferenciais podem ser encontradas usando algoritmos numéricos. Considerando que as técnicas utilizadas nesses algoritmos reforçam os conceitos amplos do cálculo, os algoritmos oferecem mais do que apenas a solução para o problema. Algoritmos numéricos têm limitações, de fato, e o texto auxiliará os estudantes a desenvolver o entendimento da precisão e propriedade dos vários métodos numéricos.

5) Fenômenos discretos: Cálculo envolve o estudo de fenômenos que são representados por funções contínuas. Devido ao fato de que compilações podem ser realizadas rapidamente, é possível estudar esses fenômenos utilizando técnicas discretas. Técnicas recursivas, quocientes diferenciais, e outros conceitos discretos auxiliam os estudantes a passar do domínio discreto para o domínio contínuo. Ligações entre fenômenos discretos e contínuos são enfatizadas com freqüência no livro-texto.

6) Experiências laboratoriais com computador e calculadora: $O$ trabalho de laboratório utilizando computador e calculadora é a peça central de todo o curso. Os estudantes usam a tecnologia como ferramenta de investigação e descoberta. As atividades de laboratório permitem aos estudantes descobrir conceitos, desenvolver sua intuição relacionada ao cálculo, e investigar problemas mais complicados tanto em grupo quanto individualmente. Essas atividades culminam na elaboração de relatórios escritos que sumarizam e analisam uma investigação específica.

7) Escrevendo sobre Matemática: Este livro-texto exige que os estudantes escrevam sobre matemática, incluindo tanto os conceitos quanto as interpretações dos mesmos. Os estudantes utilizarão a linguagem matemática e comunicarão suas idéias aos outros indivíduos familiarizados com o assunto. Escrever sobre matemática complementa um processo que começa com a tradução de um problema escrito em notação matemática, e depois usa a matemática para investigar o problema, terminando com a tradução dos resultados novamente em linguagem corrente, através de uma explanação verbal resumida. 
P. BOULOS: Introdução Ao Cálculo - Vol. I e II

No prefácio, o autor esclarece que:

O objetivo foi dar as idéias principais do Cálculo, bem como uma certa habilidade na parte técnica. A maneira com que tal objetivo foi procurado constitui uma característica importante deste livro. Através de uma linguagem clara e simples, muitas vezes coloquial (para não enfadar o aluno), são apresentados os conceitos com grande número de exemplos; os teoremas com ilustrações que revelam seus conteúdos geométricos (sempre que isso foi possível) sendo freqüentemente usados raciocínios de caráter intuitivo a fim de tornar os resultados "naturais"; e os exemplos relativos à parte técnica, em número suficiente, de modo a evitar ao aluno o desânimo por excesso de dúvidas.

(...) Procurou-se, neste livro, dizer a verdade honestamente, sem sofisticações nem uso de simbologia excessiva, que constituem, a nosso ver, um dos entraves para aceitação do Cálculo por parte do aluno. (Boulos, 1974, p. xi)

O autor apresenta uma abordagem que não inclui a história do desenvolvimento das idéias. O texto inicia com uma rápida revisão do conteúdo tratado na escola média, para, no Capítulo 2, iniciar o assunto Limite e Derivada. O parágrafo sobre limites aparece com uma observação de que poderá ser postergado ou omitido, a critério do professor. Assim, a questão é tratada de maneira intuitiva, para introduzir o conceito de derivada. Há pouca problematização para a introdução desse conceito, ficando apenas no exemplo da reta tangente. Também na introdução de integral, a problematização é pouca, com poucos exemplos sobre área, para logo chegar ao conceito de primitiva de uma dada função.

A linguagem coloquial do autor torna o texto leve, agradável à leitura. Às vezes, coloca perguntas no desenvolvimento do texto. Parece que o autor procura o tempo todo discutir o assunto com o leitor, e não apenas expor as 
suas verdades. Assim, procura convencer de que seus argumentos são razoáveis, antes da colocação das definições ou proposições.

Há muitos gráficos que são bem explorados, utilizando as figuras para tirar conclusões. Embora o autor utilize recursos intuitivos, estabelece um caráter definitivo ao conhecimento construído.

O autor formaliza os resultados, deixando alguns tópicos para os numerosos apêndices, procurando assim obter um curso de Cálculo completo, no sentido do Cálculo sistematizado, logicamente estruturado e revelado. $A$ seqüência temática apresentada é a seguinte:

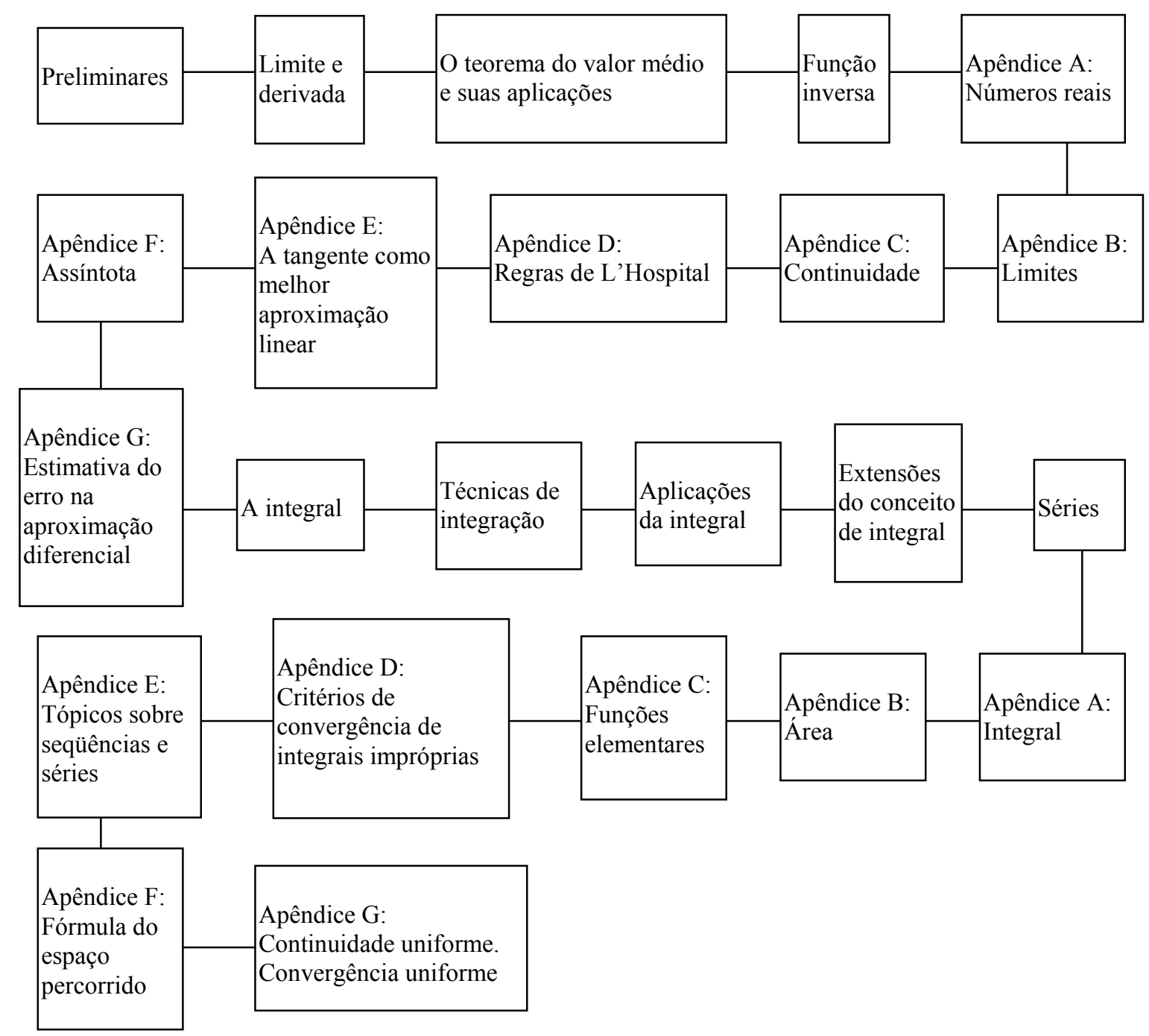

Figura 10: A seqüência temática de $P$. BOULOS 
M. BRUCKHEIMER et alii: Introducción Al Cálculo Y Al Álgebra - Vol. I e II (Texto de la Open University de Londres)

No Prólogo del editor, encontramos que

La mayor parte del material aquí utilizado há sido tomado de los textos de correspondencia de la Open University Foundation Course in Mathematics. Los cursos de la Open university proporcionam un método a nivel universitario, para el estudio independiente, mediante un sistema integrado que incluye libros de texto, programas de radio $y$ de televisión, un sistema de tutorías en cada localidad y unos cursos breves com asistencia personal en común. (Bruckheimer, M. et alii, 1976, p. ix) $)^{20}$

Assim, por basear-se em material preparado para cursos, de nível universitário, por correspondência, que pressupõem bastante trabalho independente dos alunos, encontramos uma abordagem diferente da usual. A seqüência temática não é totalmente "tradicional"; observamos, por exemplo, que o conceito de integral definida para resolver o problema do cálculo de áreas, está colocado antes da questão das derivadas.

Tanto no tratamento dado à integral, como no caso das derivadas, há colocação de problemas, antes da introdução dos conceitos.

$\mathrm{Na}$ questão dos limites, observamos que a definição formal de limite de uma função num ponto aparece após a noção ter sido tratada intuitivamente, de modo mais informal, diversas vezes.

Em todo o texto, chama a atenção a linguagem utilizada pelos autores, com grande uso da linguagem corrente, buscando o convencimento do leitor. Há muitos gráficos e figuras, algumas extremamente sugestivas, com argumentos muitas vezes geométricos, a partir das ilustrações. Outro fato muito interessante

\footnotetext{
${ }^{20}$ A maior parte do material aqui utilizado foi extraído dos textos por correspondência da Open University Foundation Course in Mathematics. Os cursos da Open University proporcionam um método, em nível universitário, para estudo
} 
é a presença de algumas questões para o leitor tentar interagir com o desenvolvimento da argumentação, bem como exercícios propostos para verificar se determinadas afirmações são verdadeiras ou falsas.

A formalização dos argumentos não está sempre presente; alguns fatos são formalmente demonstrados, mas há inúmeras evidências de que os autores buscam garantir, primordialmente, a compreensão dos conceitos e proporcionar una base sólida para la iniciación y desarollo de deseable destreza operativa. (id., p.) $)^{21}$

A seqüência temática apresentada é a seguinte:

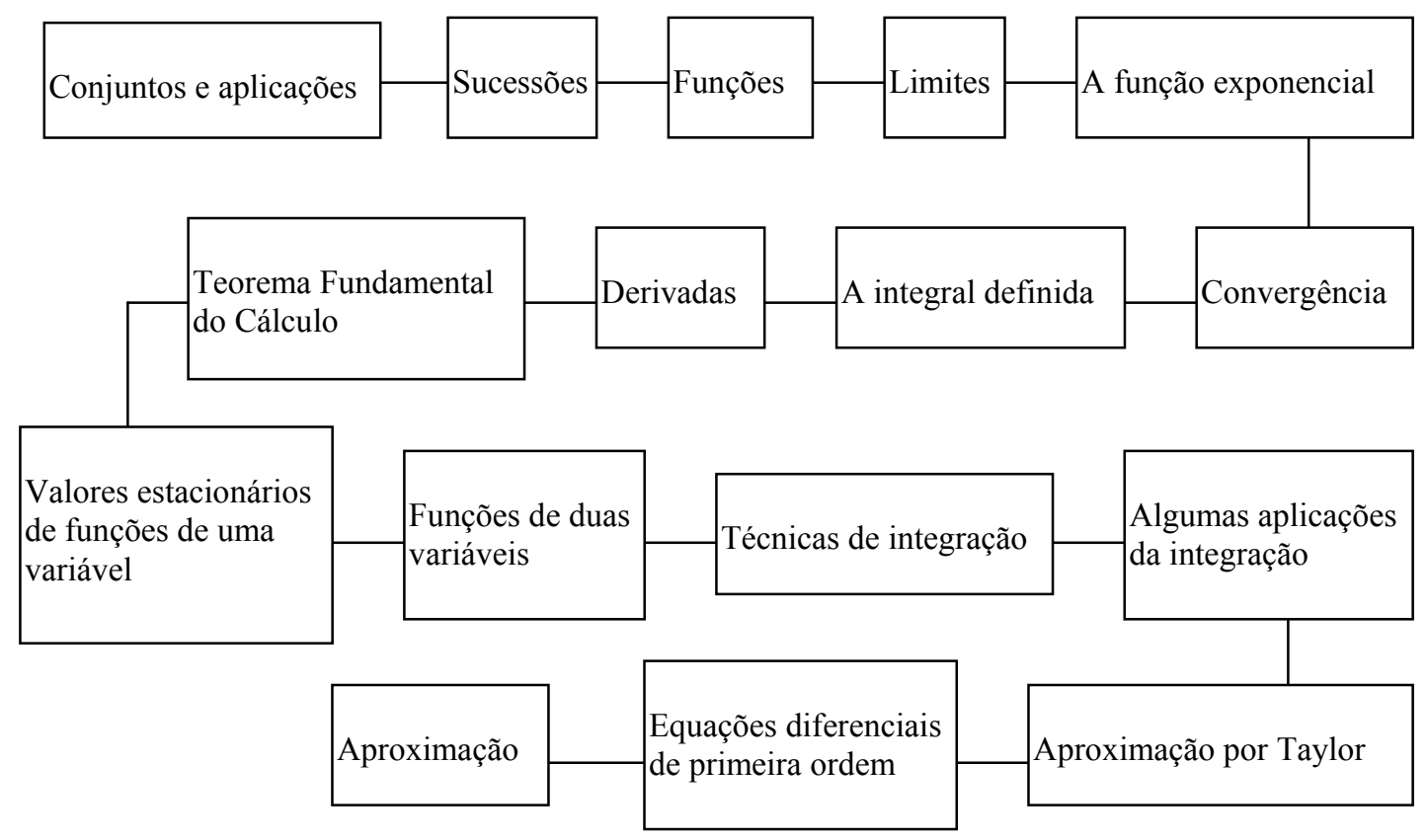

Figura 11: A seqüência temática de M. BRUCKHEIMER et alii

independente, através de um sistema integrado que inclui livros, programas de rádio e televisão, um sistema tutorial em cada localidade e breves cursos com assistência coletiva.

${ }^{21}$ proporcionar uma base sólida para a iniciação e o desenvolvimento de uma destreza operatória desejável. 


\section{R. C. BUCK: Advanced Calculus}

No prefácio, o autor diz esperar que o aluno encare o livro com um certo grau de curiosidade e sem preconceitos. Além disso,

The general purpose of the book is to present a modern treatment of the fundamentals of analysis in a form which emphasizes both structure and technique, and which will help students in mathematics and the sciences to achieve what is often called mathematical maturity. Specifically, the basic objectives are the following:

1) To review portions of the elementary calculus with rigor, but without losing the student's interest by retracing too familiar ground

2) To give a systematic modern approach to the differential and integral calculus of functions and transformations in several variables

3) To develop analytical and numerical techniques for attacking some of the problems that arise in applications of mathematics

4) To introduce students to the language, fundamental concepts, and standard theorems of analysis so that they may be prepared to read appropriate mathematical literature on their own, with understanding and enjoyment

5) To display the structure of analysis, not solely as a tool but as a subject in its own right, for the benefit of those students whose interests lean toward research in mathematics, without sacrificing intelligibility to abstractness.

(...) We have adopted a geometrical viewpoint which makes it possible to treat many topics in such a fashion that they apply simultaneously to functions of one, two, or more variables. The resulting economy of ideas bears fruit in an increased flexibility and maturity on the part of 
the student, with less reliance upon memorization and more upon fundamental understanding. (Buck, 1965, p.vi) ${ }^{22}$

Este não é um texto para um curso inicial de Cálculo. As preocupações do autor são no sentido de apresentar um conteúdo que aprofunda o Cálculo ministrado no primeiro curso, e procura generalizações conceituais. O autor afirma buscar uma real compreensão e querer evitar a memorização, o que é extremamente importante.

Não há muita problematização. Entretanto, vale a pena observar no Apêndice II, o assunto Aplicações da Matemática, é tratado com um texto repleto de questionamentos, onde o autor coloca sua visão de Modelagem Matemática. Em seguida, desenvolve o exemplo específico do pêndulo, com detalhe.

No livro todo, o autor utiliza a linguagem corrente, buscando convencer e, às vezes, propõe questões que irá responder no decorrer do desenvolvimento. As figuras aparecem com bastante freqüência, mas os argumentos são algébricos para serem verificados na figura. A argumentação do autor, baseia-se na lógica interna.

O autor cuida da generalização e formalização, apresentando um todo logicamente estruturado, como é habitual num texto desse nível.

\footnotetext{
22 O propósito geral do livro é o de apresentar um tratamento moderno dos fundamentos da análise segundo uma forma que enfatiza tanto a estrutura como a técnica, e que ajudará os estudantes de matemática e das ciências a adquirir aquilo que, muitas vezes, é denominado maturidade matemática. Especificamente, os objetivos básicos são os seguintes:

1) Revisar partes do cálculo elementar, com rigor, mas sem perder o interesse do estudante em refazer caminhos familiares

2) Dar um tratamento moderno sistemático ao cálculo diferencial e integral de funções e transformações de várias variáveis

3) Desenvolver técnicas numéricas e analíticas para enfrentar alguns dos problemas que surgem nas aplicações da matemática

4) Introduzir os estudantes na linguagem, nos conceitos fundamentais e teoremas standard de análise, de maneira que eles venham a ser preparar para a leitura de literatura matemática adequada, com entendimento e prazer

5) Expor a estrutura da análise, não apenas como uma ferramenta, mas como um assunto por si só, para benefício daqueles estudantes cujos interesses estão voltados para a pesquisa em matemática, sem sacrificar a inteligibilidade com a abstração.

(...) Adotamos um ponto de vista geométrico o que torna possível tratar vários tópicos de tal maneira que eles se aplicam simultaneamente a funções de uma, duas, ou mais variáveis. A economia de idéias resultante frutifica numa flexibilidade crescente e maturidade por parte do estudante, com menos confiança na memorização e mais na compreensão.
} 
A seqüência temática apresentada é a seguinte:

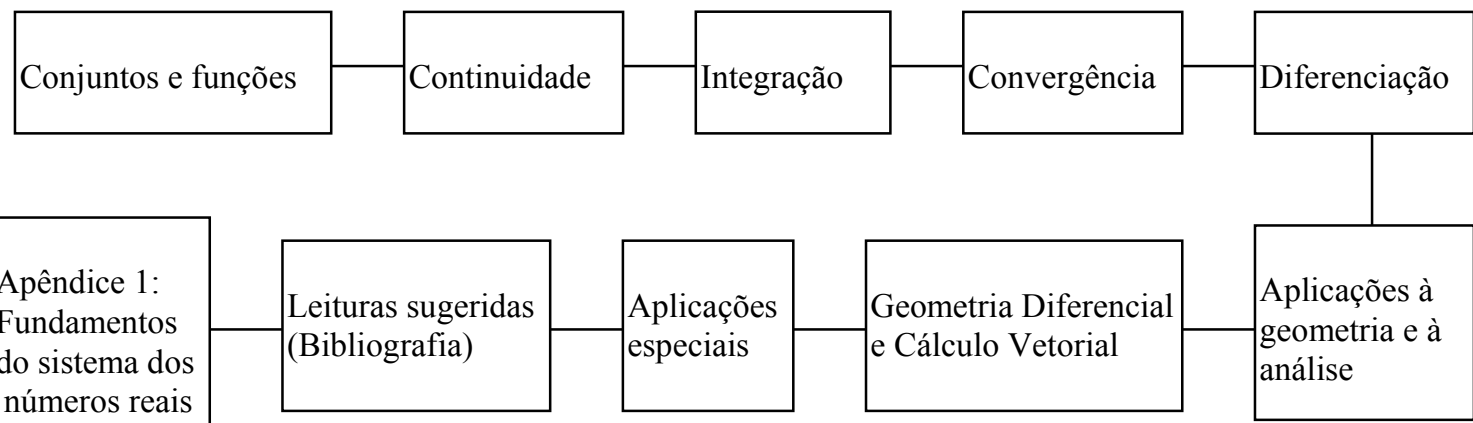

números reais

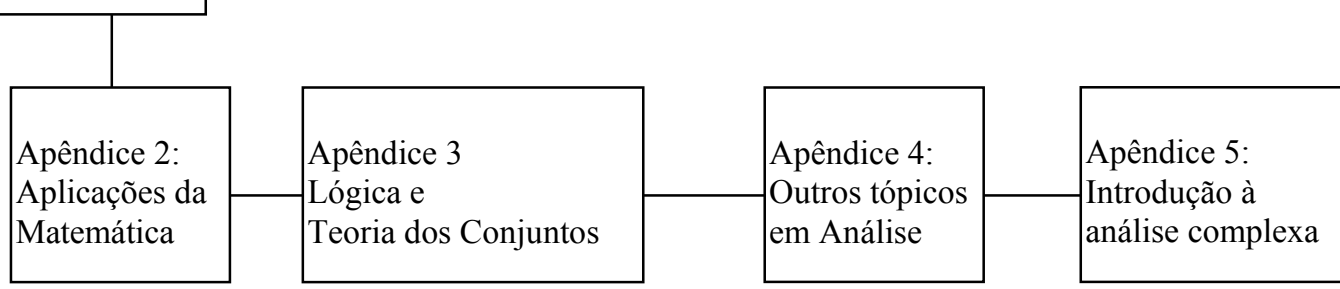

Figura 12: A seqüência temática de R. C. BUCK 


\section{R. COURANT: Differential And Integral Calculus - Vol. I}

No prefácio, encontramos que

The reader will notice especially the complete break away from the outof-date tradition of treating the differential calculus and the integral calculus separately. This separation, a mere result of historical accident, with no good foundation either in theory or in particle convenience in teaching, hinders the student from grasping the central point of the calculus, namely, the connection between definite integral, indefinite integral, and derivative. (Courant, 1945, p.v) ${ }^{23}$

A observação do autor data de 1934, quando da primeira edição alemã, e denota sua crença de que a apresentação sistematizada do Cálculo não seria eficiente para a consecução dos objetivos daqueles que trabalham com 0 ensino/aprendizagem do Cálculo. Ainda, o autor alerta para o seguinte fato:

I do not promise to save the reader the trouble of thinking, but I do seek to lead the way straight to useful knowledge, and aim at making the subject easier to grasp, not only by giving proofs step by step, but also by throwing light on the interconnections and purposes of the whole. (id., p.vi) ${ }^{24}$

Antes de iniciar o desenvolvimento do texto propriamente dito, o autor coloca Observações Introdutórias sobre o Cálculo Diferencial e Integral. A relevância nos faz transcrevê-las na íntegra.

$$
\text { Introductory Remarks }
$$

When the beginner comes in contact with the so-called higher mathematics for the first time, he is apt to be obsessed by the feeling

\footnotetext{
23 O leitor notará especialmente a completa ruptura com a tradição desatualizada de tratar separadamente o cálculo diferencial e o cálculo integral. Essa separação, um mero resultado de acidente histórico, não possui uma boa fundamentação, nem teórica, nem prática, da conveniência de assim ensinar. Ela impede ao estudante de compreender o ponto central do cálculo, qual seja a conexão entre integral definida, integral indefinida e derivada.

${ }^{24}$ Eu não prometo poupar o leitor da tarefa de pensar, mas procuro conduzi-lo diretamente ao conhecimento útil, e desejo facilitar a compreensão do assunto, não apenas fornecendo provas passo a passo, mas também lançando uma luz nas interconexões e propósitos do todo.
} 
that there is a certain discontinuity between school mathematics and university mathematics. This feeling ultimately rests on more than the historical circumstances which have caused university teaching to take a form differing so widely from that of the school. For the very nature of the higher mathematics, or rather, of the modern mathematics, developed during the last three centuries, distinguishes it from the elementary mathematics which wholly dominated the school curriculum until recently and whose subject-matter was often taken over almost directly from the mathematics of the ancient Greeks.

A leading characteristic of elementary mathematics is its intimate association with geometry. Even where the subject passes beyond the realm of geometry into that of arithmetic, the fundamental ideas still remain geometrical. Another feature of ancient mathematics is perhaps its tendency to concentrate on particular cases. Things which today we should regard as special cases of a general phenomenon are set down higgledy-piggledy without any visible relationship between them. Its intimate association with geometrical ideas and its stress on individual niceties give the older mathematics a charm of its own. Yet it was a definite advance when at the beginning of the modern age in mathematics quite different tendencies developed, acting as the stimulus for a great expansion of the subject, which in spite of many improvements in detail had in a sense stood still for centuries.

The fundamental tendency of all modern mathematics is towards the replacement of separate discussions of individual cases by more and more general systematic methods, which perhaps do not always do full justice to the individual features of a particular case, but which, owing to their generality and power, give promise of a wealth of new results. Again, the concept of number and the methods of analysis have come to occupy more and more independent positions and now dominate geometry entirely. These new tendencies towards the development of mathematics along a variety of lines are most clearly exhibited in the rise of analytical geometry, whose development is chiefly due to Fermat and Descartes, and of the differential and integral calculus, which is generally regarded as having originated with Newton and Leibnitz. 
The three hundred years during which modern mathematics has existed have seen such important advances not only in pure mathematics, but in an immense variety of applications to science and engineering, that its fundamental ideas and above all the concept of a function have by degrees become very widely known and have eventually penetrated even into the school curriculum.

In this book my aim has been to develop the most important facts in the differential and integral calculus so far that at the close the reader, although he may have had no previous knowledge of highs mathematics, may be well equipped on the one hand for the study of the more advanced branches and of the foundations of the subject, or on the other hand, for the manipulation of the calculus in the varies realms in which it is applied.

I should like to warn the reader specially against a danger which arises from the discontinuity mentioned in the opening paragraph. The point of view of school mathematics tempts one to linger over details and to lose one's grasp of general relationships and systematic methods. On the other hand, in the "higher" point of view there lurks the opposite danger of getting out of touch with concrete details, so that one is left helpless when faced with the simplest cases of individual difficulty, because in the world of general ideas one has forgotten how to come to grips with the concrete. The reader must find his own way of meeting this dilemma. In this he can only succeed by repeatedly thinking out particular cases for himself and acquiring a firm grasp of the application of general principles in particular cases; herein lies the chief task of anyone who wishes to pursue the study of Science. (Courant, 1945, p.1 $)^{25}$

\footnotetext{
25 Observações Introdutórias

Quando o iniciante entra em contato, pela primeira vez, com a assim chamada matemática superior, ele pode ficar obcecado pelo sentimento de que há uma certa descontinuidade entre a matemática da escola média e a matemática da universidade. No fundo, este sentimento não está apenas apoiado nas circunstâncias históricas que tornaram o ensino universitário tão diferente daquele ministrado na escola média. Devido à verdadeira natureza da matemática superior, ou melhor, da matemática moderna, desenvolvida durante os três últimos séculos, ela se distingue da matemática elementar que dominou inteiramente o currículo da escola até recentemente e cujo conteúdo foi quase que diretamente elaborado a partir da matemática dos antigos Gregos.

Uma característica principal da matemática elementar é sua associação íntima com a geometria. Mesmo quando o assunto está longe do domínio da geometria, e está mais ligado à aritmética, as idéias fundamentais ainda são geométricas. Outra característica da matemática antiga é talvez a sua tendência em se concentrar em casos particulares. Coisas, que hoje em dia podemos encarar como casos particulares de fenômenos gerais, são estabelecidas sem nenhuma relação de proximidade evidente entre si. A associação intima com idéias geométricas e a ênfase nas descobertas individuais dão, à
} 
As importantes observações do autor demonstram sua preocupação, dentre outras, com a ponte entre o que é feito na escola média e no nível universitário, isto há mais de sessenta anos. A idéia, bastante difundida hoje em dia, de que o primeiro curso de Cálculo com o qual o aluno se defronta ao entrar na Universidade, seja um curso onde o conhecimento é revelado, como um todo logicamente estruturado, onde as idéias principais se perderam pois o principal objetivo parece ter-se tornado mostrar aquilo que a linguagem matemática consegue fazer, já era questionada pelo autor há muito tempo. Conseqüência imediata é o fato de tantos alunos que diziam gostar de matemática na escola média, de repente se encontrarem diante de coisas que não têm significado, e com as quais não conseguem interagir satisfatoriamente.

Após uma parte introdutória na qual são recuperados alguns conceitos desenvolvidos na escola média, o autor explora o conceito de limite de uma seqüência através de vários exemplos, nos quais examina a convergência, ou não, de maneira intuitiva. Só então coloca a definição formal de limite de uma seqüência de números reais. Finalmente, depois, coloca o conceito de limite

matemática antiga, um charme intrínseco. Entretanto, foi um avanço definitivo, quando, no início da era moderna,, foram desenvolvidas tendências totalmente diferentes na matemática, atuando como estímulo para uma grande expansão do conteúdo, que, apesar de muitos aperfeiçoamentos nos detalhes, tem, em certo sentido, permanecido o mesmo durante séculos.

A tendência fundamental de toda a matemática moderna está voltada para a substituição de discussões isoladas de casos individuais por métodos sistemáticos mais e mais gerais, que talvez não façam sempre total justiça às características individuais de um caso particular, mas que, devido à sua generalidade e potência, fazem antever a abundância de novos resultados. Novamente, o conceito de número e os métodos de análise vieram ocupar posições cada vez mais independentes e passaram a dominar inteiramente a geometria. Estas novas tendências com relação ao desenvolvimento da matemática na direção de uma variedade de ramos estão mais evidentes no nascimento da geometria analítica, cujo desenvolvimento é devido principalmente a Fermat e Descartes, e do cálculo diferencial e integral, que, normalmente, é olhado como tendo sido originado com Newton e Libnitz.

Os trezentos anos, durante os quais a matemática moderna tem existido, testemunharam avanços de tal importância, não apenas na matemática pura, mas também numa imensa variedade de aplicações da ciência e da engenharia. Desse modo, suas idéias fundamentais e, principalmente, o conceito de função, têm sido, gradual e profundamente conhecidas por todos e, finalmente influenciou também o currículo da escola média.

Meu objetivo, neste livro, foi o de desenvolver os fatos mais importantes no cálculo diferencial e integral, o mais próximo possível do leitor, pois, mesmo que ele não tenha conhecimento prévio algum de matemática superior, pode estar apto para o estudo dos ramos mais avançados e os fundamentos do assunto ou para a manipulação do cálculo nos diversos domínios em que se aplica.

Gostaria, especialmente, de prevenir o leitor a respeito de um perigo que resulta da descontinuidade mencionada no parágrafo inicial. O ponto de vista da escola média induz à demora nos detalhes e à perda da compreensão das relações gerais e dos métodos sistemáticos. Por outro lado, do ponto de vista "superior", esconde-se o perigo oposto de escapar dos detalhes concretos, de modo que alguém pode se sentir incapaz diante dos casos mais simples de dificuldades individuais, uma vez que no mundo das idéias gerais, esqueceu como lidar com o concreto. O leitor deve encontrar sua maneira própria de enfrentar esse dilema. Nisto, apenas pode ter êxito, refletindo por si só sobre casos particulares e adquirindo uma firme compreensão da aplicação dos princípios gerais nos casos particulares; aí se encontra a tarefa principal para quem deseja empreender o estudo da Ciência. 
quando a variável é contínua. A questão da continuidade foi colocada, inicialmente, de maneira intuitiva, sendo que o conceito formal só aparece muito depois. Conforme o próprio autor alerta no Apêndice I ao Capítulo I, in spite of all its defects intuition still remains the most important driving force for mathematical discovery, and intuition alone can bridge the gap between theory and application. (id., p. 57$)^{26}$

O Capítulo II, As idéias Fundamentais do Cálculo Diferencial e Integral, é dedicado à colocação das idéias mesmo, partindo primeiro daquilo que é mais próximo dos alunos, ou seja o cálculo de áreas, que respeita inclusive a gênese das idéias. Há referências aos matemáticos, não com muito detalhe.

Mais à frente, observamos o parágrafo The Derivative and the Difference Quotient, onde o autor discute, com cuidado, a questão da passagem ao limite do quociente de diferenças $\Delta y / \Delta x$, onde primeiro é efetuado o quociente, para só depois efetuar o limite quando o denominador tende a zero.

Na questão de integração, há um tópico sobre integração gráfica, onde encontramos duas ilustrações muito sugestivas de como é feita a integração e a relação com o coeficiente angular da reta tangente. A argumentação do autor se baseia nas figuras. Hoje em dia seria muito mais simples, evidentemente mostrar esses fatos através de um programa computacional gráfico.

Ao longo de todo o texto observamos a utilização da linguagem corrente, para esclarecer aquilo que foi feito formalmente. Dessa forma, o autor consegue propor um curso com um bom nível de profundidade e no qual as idéias não ficaram escondidas atrás de uma máscara lógico-formal. A obra atinge um alto nível de generalização, constituindo um texto de Cálculo extremamente completo.

\footnotetext{
${ }^{26}$ Apesar de todos os seus defeitos, a intuição ainda permanece como a principal força motora para a descoberta matemática, e somente a intuição pode fazer a ponte entre a teoria e a aplicação.
} 
A seqüência temática, proposta pelo autor, é a seguinte:

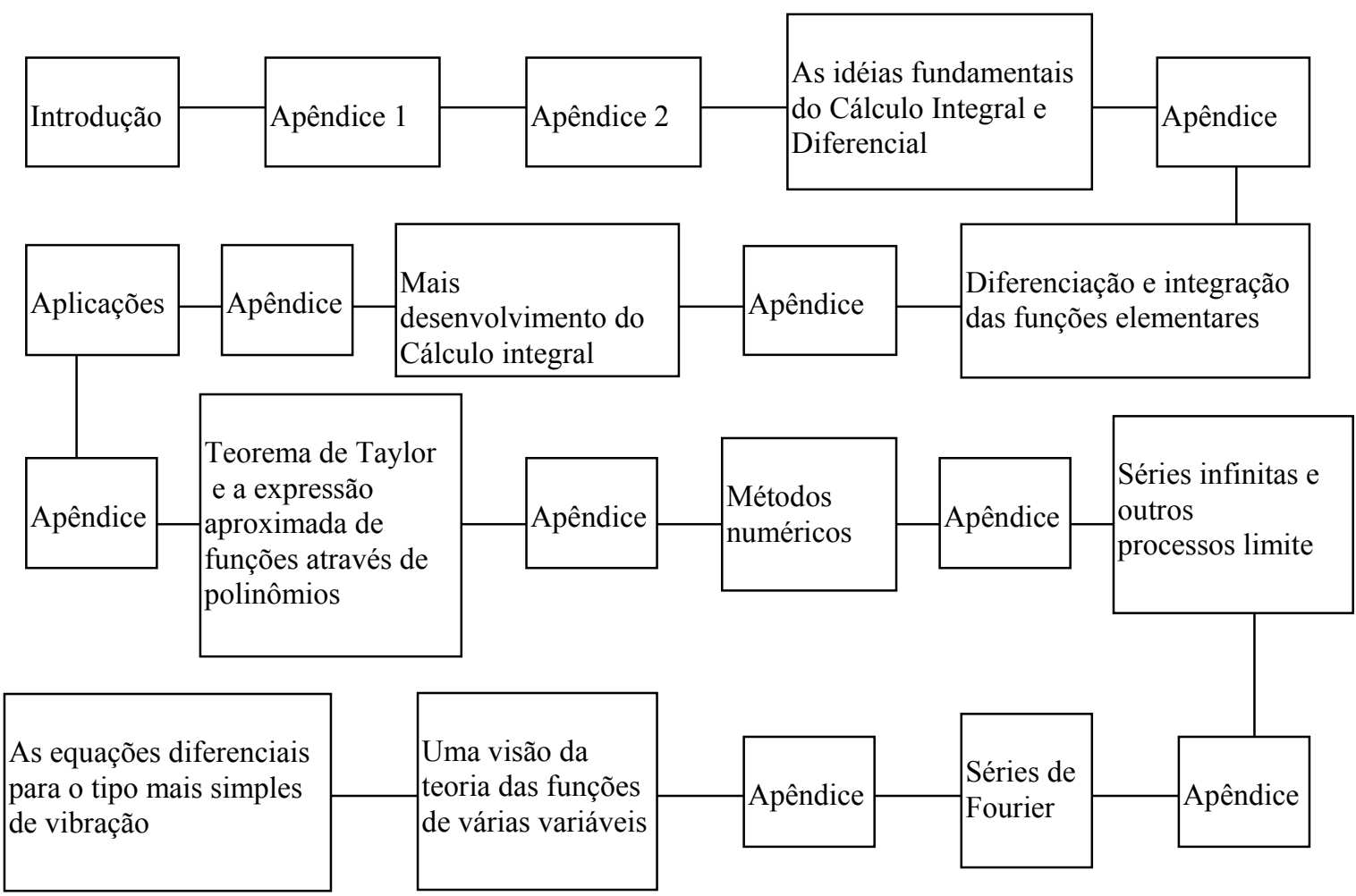

Figura 13: A seqüência temática de R. COURANT 
R. COURANT and F. JOHN: Introduction To Calculus And Analysis - Vol. I

\author{
Os autores, no Prefácio, afirmam que a intenção do livro é
}

To lead the student directly to the heart of the subject and to prepare him for active application of the knowledge. It avoids the dogmatic style which conceals the motivation and the roots of the calculus in intuitive reality. To exhibit the interaction between mathematical analysis and its various applications and to emphasize the role of intuition remains an important aim of this new book. Somewhat strengthened precision does not, we hope, interfere with this aim.

Mathematics presented as a closed, linearly ordered, system of truths without reference to origin and purpose has its charm and satisfies a philosophical need. But the attitude of introverted science is unsuitable for students who seek intellectual independence rather than indoctrination; disregard for applications and intuition leads to isolation and atrophy of mathematics. It seems extremely important that students and instructors from smug purism.

The book is addressed to students on various levels, to mathematicians, scientists, engineers. It does not pretend to make the subject easy by glossing over difficulties, but rather tries to help the genuinely interested reader by throwing light on the interconnections and purposes of the whole.

Instead of obstructing the access to the wealth of facts by lengthy discussions of a fundamental nature we have sometimes postponed such discussions to appendices in the various chapters. (Courant and John, 1965, p.vi) ${ }^{27}$

\footnotetext{
27 Conduzir o estudante diretamente ao âmago do assunto e prepará-lo para a aplicação prática de seu conhecimento. Evita-se o estilo dogmático que oculta tanto a motivação, como as raízes do cálculo, na realidade, intuitivas. Exibir a interação entre a análise matemática e suas várias aplicações e enfatizar o papel da intuição, permanece sendo um importante objetivo deste novo livro. Um pouco mais de rigor, esperamos, não irá interferir nesse objetivo.

A matemática apresentada como um sistema de verdades, fechado, linearmente ordenado, sem referência às origens e propósitos, tem seu charme e satisfaz uma necessidade filosófica. Mas a atitude da ciência introvertida é inadequada para os estudantes que procuram independência intelectual em lugar de doutrinação; desconsiderar as aplicações e a intuição acarreta o isolamento e a atrofia da matemática. Parece ser extremamente importante que os estudantes e os instrutores estejam protegidos de tal purismo convencido.

O livro é dirigido a estudantes de vários níveis, a matemáticos, cientistas, engenheiros. Não procura facilitar o assunto, encobrindo as dificuldades, mas, antes, procura auxiliar o leitor verdadeiramente interessado lançando uma luz nas interconexões e propósitos do todo.
} 
No primeiro Capítulo, os autores apresentam os pressupostos que consideram necessários para o desenvolvimento do curso. O que realmente impressiona é o uso da linguagem corrente, procurando tornar mais explícitos os fatos que estão descritos em linguagem matemática. Encontramos, no meio da exposição, questões, como How can we describe an irrational real number? ${ }^{28}$ buscando uma certa interação com o leitor.

No Capítulo seguinte, na exposição sobre as Idéias Fundamentais do Cálculo, encontramos alguns dados históricos e a colocação inicial do problema do cálculo de áreas de figuras planas. Em quase 30 páginas, os autores tratam de questões de áreas e o cálculo de algumas integrais, para depois, introduzir a questão da derivada de uma função em um ponto, através do problema da tangente ao gráfico de uma função em um ponto e da velocidade instantânea de um corpo em movimento.

Neste texto, encontramos um exemplo do tratamento dado pelos autores a questões delicadas que estão envolvidas nos conceitos fundamentais do Cálculo.

If we wish to obtain a clear grasp of the meaning of the differential calculus, we must beware of the old fallacy of imagining the derivative as the quotient of two "quantities" $d y$ and $d x$ which are actually "infinitely small". The difference quotient $\Delta y / \Delta x$ has a meaning only for differences $\Delta x$ which are not equal to zero. After forming this genuine difference quotient we must perform the passage to the limit by means of a transformation or some other device which also in the limit avoids division by zero. It does not make sense to suppose that first $\Delta x$ and $\Delta y$ go through something like a limiting process and reach values which are infinitesimally small but still not zero, so that $\Delta x$ and $\Delta y$ are replaced by "infinitely small quantities" or "infinitesimals" $d x$ and $d y$, and that the quotient of these quantities is then formed. Such a conception of the

Em lugar de obstruir o acesso à abundância dos fatos, com discussões prolixas de natureza fundamental, muitas vezes postergamos tais discussões aos apêndices dos vários capítulos.

${ }^{28}$ Como podemos descrever um número real irracional? 
derivative is incompatible with mathematical clarity; in fact is entirely meaningless. For many people it undoubtedly has a certain charm of mystery, always associated with the word "infinite"; in the early days of the differential calculus even Leibnitz himself was capable of combining these vague mystical ideas with a thoroughly clear handling of the limiting process. But today the mysticism of infinitely small quantities has no place in the calculus. (id., p. 171) 29 $^{29}$

Esta obra é extremamente cuidadosa com a "implantação" dos conceitos, buscando não ficar apenas no formalismo e na "clareza" que lhe é inerente, clareza esta que só existe para os leitores não iniciantes, que já estão habituados às questões do Cálculo.

Os autores colocam várias ilustrações e muitas vezes tecem seus argumentos a partir das figuras. Há busca de convencimento. O fato de não haver a separação entre o Cálculo Diferencial e o Cálculo Integral, usual nas propostas mais "reveladoras" do Cálculo, torna o texto uma busca constante das relações que podem ser estabelecidas entre os dois processos, de diferenciação e de integração.

A generalização e a formalização são aspectos fundamentais do livro, tornando-o absolutamente completo.

Ao final, encontramos duas páginas de dados biográficos, com nomes e datas, dos matemáticos que contribuíram para o desenvolvimento do Cálculo.

\footnotetext{
29 Se pretendemos obter uma clara compreensão do significado do cálculo diferencial, precisamos tomar cuidado com a antiga falácia de imaginar a derivada como o quociente de duas "quantidades" dy e dx que são realmente "infinitamente pequenas". O quociente de diferenças $\Delta y / \Delta x$ possui significado apenas para diferenças $\Delta x$ que são não nulas. Após formar este verdadeiro quociente de diferenças, precisamos executar a passagem ao limite através de uma transformação ou de algum outro mecanismo que também no limite evite a divisão por zero. Não faz sentido supor que primeiro $\Delta x$ e $\Delta y$, através de um processo de limite, atingem valores que são infinitamente pequenos, mas ainda não nulos, de modo que $\Delta x$ e $\Delta y$ são substituídos por "quantidades infinitamente pequenas" ou "infinitésimos" $d x$ e dy, e que só então o quociente dessas quantidades é considerado. Tal concepção da derivada é incompatível com a clareza matemática; com efeito, ela não tem sentido. Para muitos, sem dúvida, ela possui um certo charme misterioso, sempre associado à palavra "infinito"; nos primórdios do cálculo diferencial, mesmo Leibnitz era capaz de combinar essas vagas idéias místicas com um tratamento minuciosamente claro do processo de limite. Entretanto, hoje em dia, o misticismo das quantidades infinitamente pequenas não tem espaço no cálculo.
} 
A seqüência temática proposta é a seguinte:

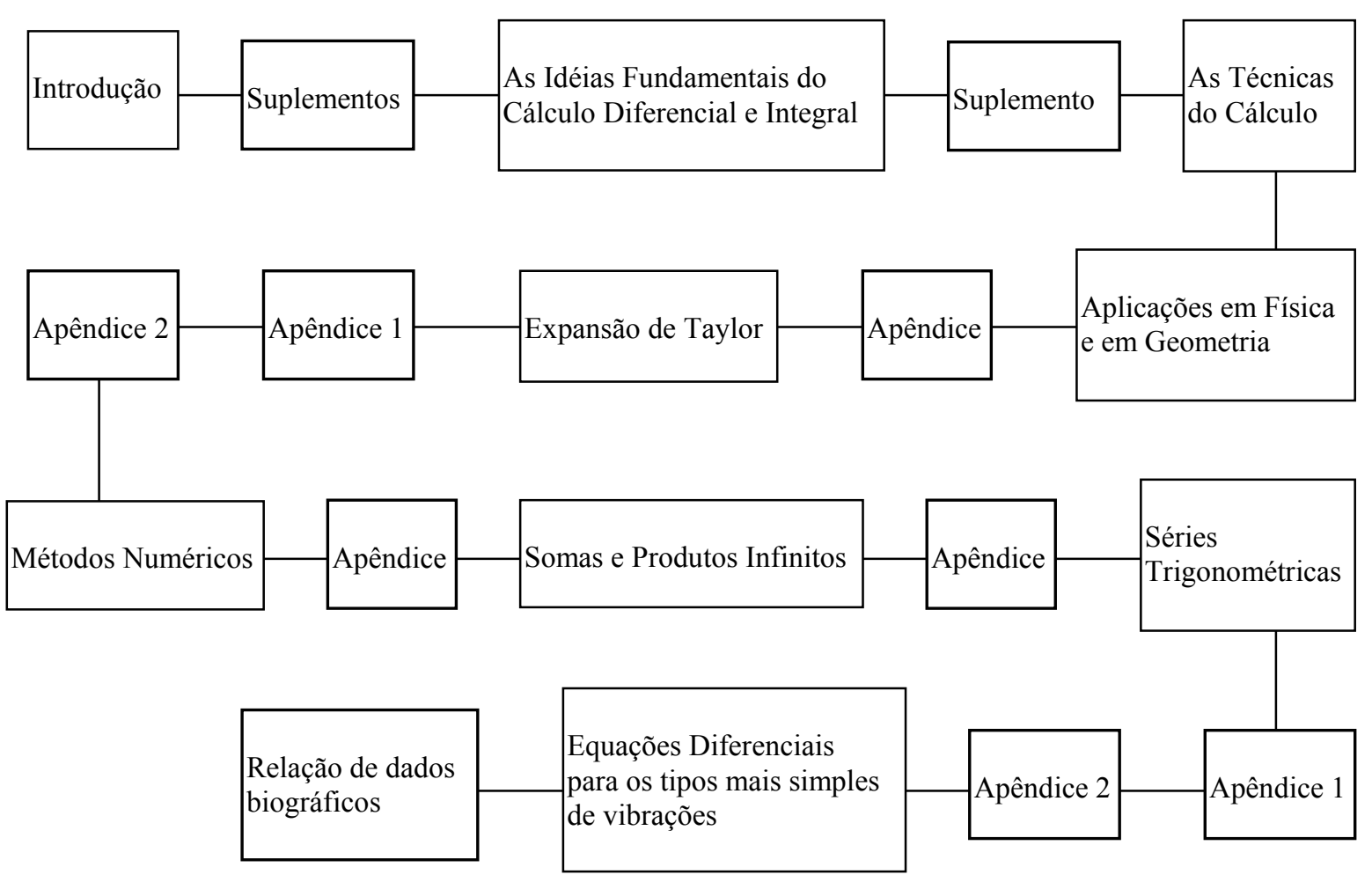

Figura 14: A seqüência temática de R. COURANT and F. JOHN 


\title{
H. P. GREENSPAN and D. J. BENNEY: Calculus: An Introduction To Applied Mathematics
}

No prefácio, encontramos que:

In presenting calculus as an introduction to applied mathematics, we begin an educational curriculum whose basic objective is the twofold capability of formulating a problem mathematically and extracting, by any means, useful and desirable information. The selection of subject matter, the emphasis placed and the priorities assigned are all predicated to this end, and, in a more personal sense, they reflect our experience and judgment as scientists. Accordingly, our values are quite different from those most commonly expressed in mathematics texts. (Greenspan et alii, 1973, p.ix)

Neste texto observamos pois, mais uma vez, uma proposta que privilegia a Modelagem Matemática, como instrumento para estabelecer uma relação significativa entre o mundo real e o instrumental oferecido, em particular, pelo Cálculo. Na Introdução ao primeiro Capítulo sobre Limites, os autores colocam afirmações importantes, que transcrevemos:

\begin{abstract}
Science seeks to understand the world we live in, and mathematics is a primary means to this end. By an often beautiful and intrinsically mysterious process, the laws of nature can be expressed as mathematical equations and manipulated to yield new and even unsuspected knowledge. Mathematics becomes the "automatic machine" that frees the mind from the burden of overwhelming detail and allows thereby the perception of what is really fundamental. Calculus in this respect, or by any other standard, a major intellectual triumph of civilization, which has been a mainstay of scientific and technological progress since its creation in the seventeenth century by Isaac Newton and Gottfried Leibniz.
\end{abstract}

\footnotetext{
${ }^{30}$ Ao apresentar o Cálculo como uma introdução à matemática aplicada, iniciamos um curriculum educacional cujo objetivo básico é a dupla capacidade de formular matematicamente um problema e extrair de algum modo informações úteis e desejáveis. A seleção do conteúdo, a ênfase colocada e as prioridades fixadas buscam essa finalidade, e, num sentido mais pessoal, refletem nossa experiência e juízo como cientistas. De acordo com isso, nossos valores são bastante diferentes daqueles normalmente expressos em textos matemáticos.
} 
This study of the subject will focus on the areas of greatest application, which deal with the mathematical formulation of a problem and its solution by approximate and exact methods. The objective is the twofold ability to translate a problem into a correct mathematical statement and to effect a useful solution by approximate methods, mainly those which can by systematic improvement provide the exact answer in some limiting sense. (id., p.1) 31 $^{31}$

Conforme vemos, a proposta dos autores é bastante ambiciosa, no sentido de tornar o curso de Cálculo contextualizado, com o intuito de desenvolver um assunto útil para a resolução de problemas importantes.

Logo de início, encontramos, como primeiro exemplo, o problema de calcular a área da região determinada possivelmente por uma cardióide. (This could be the floor plan of some exotic room which is to be resurfaced). ${ }^{32}$ A partir das figuras são feitos os cálculos algébricos, com muito cuidado, procurando convencer da razoabilidade, para chegar a uma primeira idéia de limite. Outros problemas do mesmo estilo estão propostos, inclusive um deles que motiva uma falsa "demonstração" para a afirmação incorreta: num triângulo retângulo, o comprimento da hipotenusa é igual à soma dos comprimentos dos catetos (que contradiz o Teorema de Pitágoras). A questão é colocada para que o leitor reflita e descubra o erro na argumentação.

Ainda no mesmo Capítulo, ao introduzir a idéia intuitiva de função, através de vários exemplos detalhados, chamam-nos a atenção, nos Exercícios da seção 1.2, a colocação de questões do tipo:

\footnotetext{
31 A ciência procura entender o mundo em que vivemos, e a matemática é um meio importante para essa finalidade. Através de um processo bonito e, muitas vezes, intrinsecamente misterioso, as leis da natureza podem ser expressas através de equações matemáticas e manipuladas para produzir conhecimento novo e mesmo inesperado. A matemática se torna a "máquina automática" que liberta a mente do fardo dos detalhes esmagadores e possibilita assim a percepção daquilo que é realmente fundamental. Nesse sentido, ou segundo qualquer outro critério, o Cálculo é o maior triunfo da civilização e tem sido o suporte do progresso científico e tecnológico desde sua criação, no século XVII, por Isaac Newton e Gottfried Leibniz.

O estudo do assunto está focalizado nas áreas de maior aplicação que tratam da formulação matemática de um problema e sua solução por métodos aproximados ou exatos. O objetivo é a dupla habilidade de traduzir um problema segundo uma formulação matemática correta e produzir uma solução útil através de métodos aproximados, principalmente aqueles que através de aperfeiçoamento sistemático produzem a resposta exata num sentido de limite.

${ }^{32}$ Este poderia ser o piso de algum quarto exótico que precisa ser trocado.
} 
- Discuss the difficulties involved in determining functions which quantitatively describe the following situations:

i) A sensation such as pain or love.

ii) The exact coast line of the United States at any time.

iii) The exact outline of a man's head (compare with that for someone who is bald).

iv) A curve representing the data of an experiment which may involve a small random error. (id., p.15) ) $^{33}$

Normalmente, os textos trabalham funções através de suas expressões algébricas, sem nenhum questionamento a respeito de quais grandezas podem estar envolvidas.

O primeiro Capítulo faz a apresentação, através de problemas, dos conceitos importantes do Cálculo, apoiados na idéia de limite, de forma bastante intuitiva. À página 36, aparece a definição formal de limite de uma função num ponto, mas antes disso a idéia intuitiva de limite foi trabalhada diversas vezes, numa variedade de contextos. Esse Capítulo, por si só, fornece um levantamento de quais conceitos são trabalhados no Cálculo.

Ao longo de toda a obra, há muito texto em linguagem corrente. Há boas figuras e, muitas vezes, a partir delas, são realizados os cálculos. Os autores procuram convencer da razoabilidade dos argumentos, não apenas através de recursos provenientes da lógica interna, mas também por raciocínios, por exemplo intuitivos.

\footnotetext{
33 Discuta as dificuldades envolvidas na determinação de funções que descrevam quantitativamente as seguintes situações:

i) Uma sensação como sofrimento ou amor.

ii) O litoral exato dos Estados Unidos em qualquer instante.

iii) O contorno exato da cabeça de um homem (compare com a de alguém que é calvo).

iv) Uma curva que representa os dados de uma experiência que pode envolver um pequeno erro ao acaso.
} 
Desde o primeiro exemplo, os autores mostram estar preocupados com métodos aproximados, tentando evidenciar que nos problemas, muitas vezes, a solução aproximada é aquela que pode ser encontrada e que portanto deve ser perseguida, o que, sem dúvida, é uma perspectiva muito mais realista. Interessante observar que o primeiro exemplo apresentado é retomado adiante, com um tratamento mais formal.

A formalização e as generalizações são bem cuidadas e a seqüência temática apresentada é a seguinte:

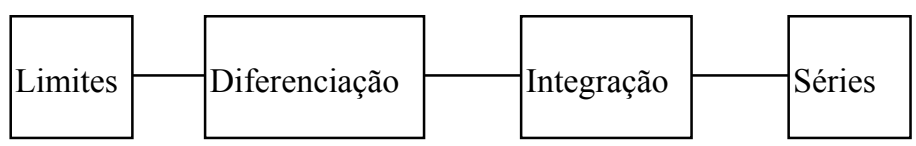

Figura 15: A seqüência temática de H. P. GREENSPAN and D. J. BENNEY

Cada tópico está subdividido em vários itens, mas os autores apresentam esses poucos como norteadores da seqüência proposta. 


\section{H. L. GUIDORIZZI: Um Curso De Cálculo - Vol. I}

No Prefácio, o autor afirma que seu livro se baseia nos cursos de Cálculo que tem ministrado aos alunos da Escola Politécnica da USP, do Instituto de Matemática e Estatística da USP e do Instituto de Ensino de Engenharia Paulista. Além disso, alerta para o fato de que procurou fazer com que os conceitos e teoremas apresentados venham, sempre que possível, acompanhados de uma motivação ou interpretação geométrica ou física.

O autor parece fazer uma revelação do Cálculo sistematizado e, dessa forma, busca explicitar as idéias de um ponto de vista internalista, sem recorrer aos problemas que motivaram o seu desenvolvimento. Os problemas servem, basicamente, para ilustrar a revelação dos resultados, não se caracterizando como um ponto de partida para o desenvolvimento das idéias sobre o tema; exemplos tentam constituir a motivação para a colocação dos novos conceitos, a partir dos quais irá, subseqüentemente, desenvolver todo um conjunto lógico de resultados, perfeitamente articulados.

A linguagem utilizada pelo autor não tem como objetivo convencer da razoabilidade dos argumentos na perspectiva do estudante, pois utiliza recursos provenientes da lógica interna do conhecimento sistematizado. Há uma quantidade razoável de figuras, que desempenham um papel coadjuvante, pois, essencialmente, os argumentos são algébricos para serem verificados nas figuras.

A preocupação com a formalização e a generalização está continuamente presente; somente algumas poucas demonstrações são deixadas para o final da seção ou colocadas em apêndice.

O autor não faz referência à gênese do Cálculo e a seqüência temática apresenta o Cálculo sistematizado e logicamente estruturado. Assim, temos: 


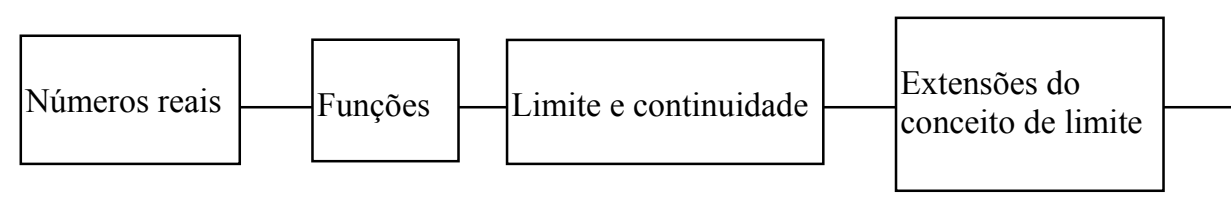

Teoremas

do anulamento, do valor intermediário e de Weierstrass

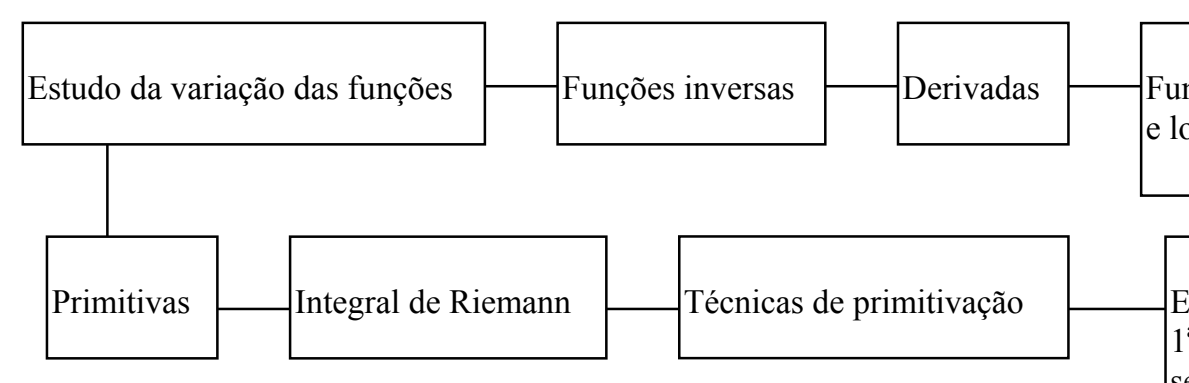

Equações diferenciais de $1^{\mathrm{a}}$ ordem, de variáveis separáveis e lineares

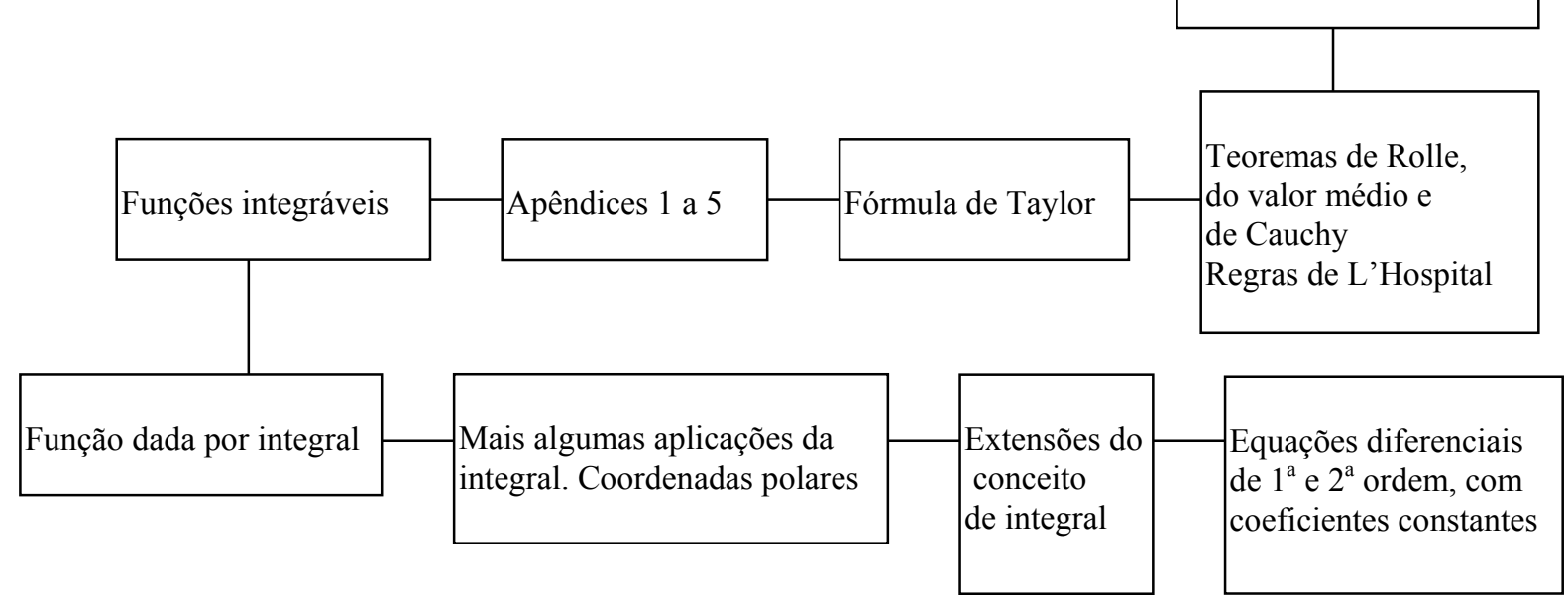

Figura 16: A seqüência temática de H. L. Guidorizzi 


\section{W. KAPLAN: Advanced Calculus}

No Prefácio, o autor diz que o livro tem por objetivo garantir material suficiente para um curso de Cálculo Avançado. Assim sendo, não é um livro proposto para um curso inicial de Cálculo. A seqüência temática obedece ao seguinte esquema:

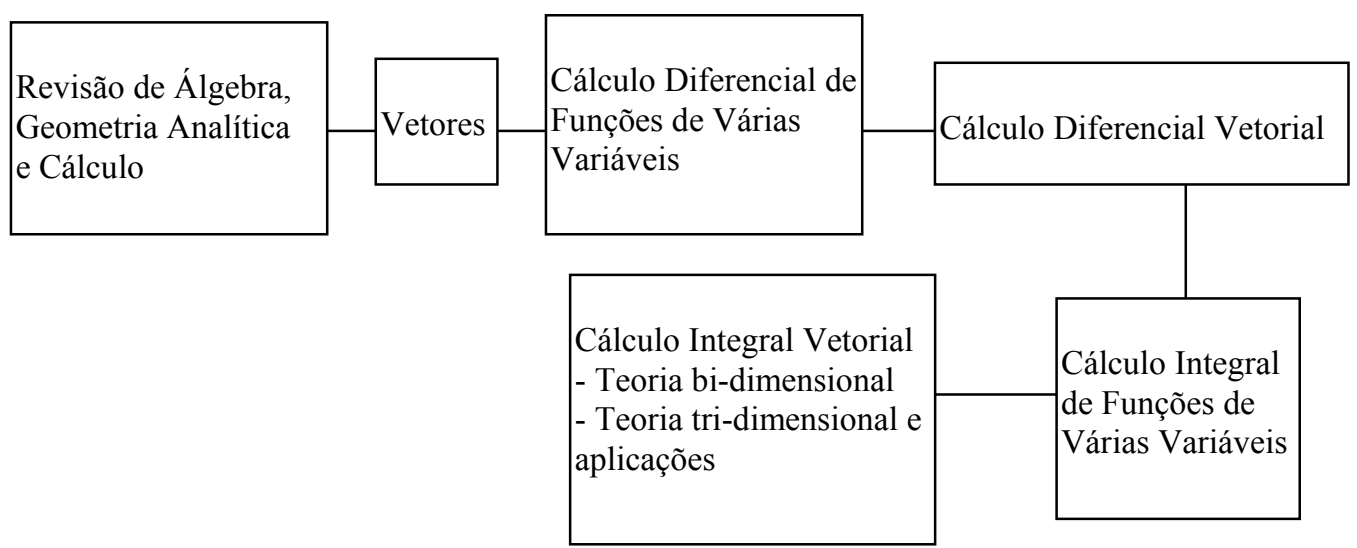

Figura 17: A seqüência temática de W. KAPLAN

$\mathrm{Na}$ parte inicial, onde o autor faz uma revisão daquilo que considera necessário para desenvolver o seu curso, não encontramos uma explicitação clara das idéias fundamentais do Cálculo, nem problematizações correspondentes. Trata-se apenas de uma recuperação rápida e reveladora dos conceitos e propriedades que já apareceram em cursos anteriores. A partir daí, já no Capítulo referente a Vetores, encontramos um texto leve, com exemplos, significações.

Embora o autor não tenha por objetivo colocar problemas para viabilizar a construção dos conceitos, todo o texto é caracterizado por um discurso agradável com o qual procura convencer da necessidade e da pertinência dos seus passos. O texto tem muitas figuras e a partir delas induz muitas vezes o que irá desenvolver formalmente. O próprio autor já afirmou no Prefácio que nem todos os teoremas serão formalmente demonstrados, colocando, entretanto, ao final de cada Capítulo, referências onde poderão ser encontrados 
os detalhes ou as demonstrações que não foram desenvolvidas no texto. Entretanto, o livro todo é muito cuidadoso, nos aspectos de formalização e generalização e, com as referências bibliográficas, parece querer proporcionar um texto absolutamente completo. 
W. KAPLAN e D. J. LEWIS: Cálculo E Álgebra Linear - Vol. I

No Prefácio, os autores salientam que o objetivo principal é a integração da Álgebra Linear com o Cálculo. Apesar de que estas duas disciplinas possam ser tratadas independentemente, elas ganham muito em profundidade e significado quando relacionadas entre si. Evidentemente, esclarecem também que essa integração aparecerá fortemente em tópicos posteriores do Cálculo, pois nas questões iniciais não há como integrar a Álgebra Linear.

$\mathrm{Na}$ Introdução, a proposta é a de apresentar um resumo dos tópicos de álgebra, geometria e trigonometria que serão utilizados no decorrer do livro. No Capítulo 1, há uma apresentação de Geometria Vetorial no plano. Assim, estabelecidos todos os pontos considerados pré-requisitos, no Capítulo 2, iniciase propriamente o assunto que diz respeito ao Cálculo.

A seqüência temática apresentada é a seguinte:

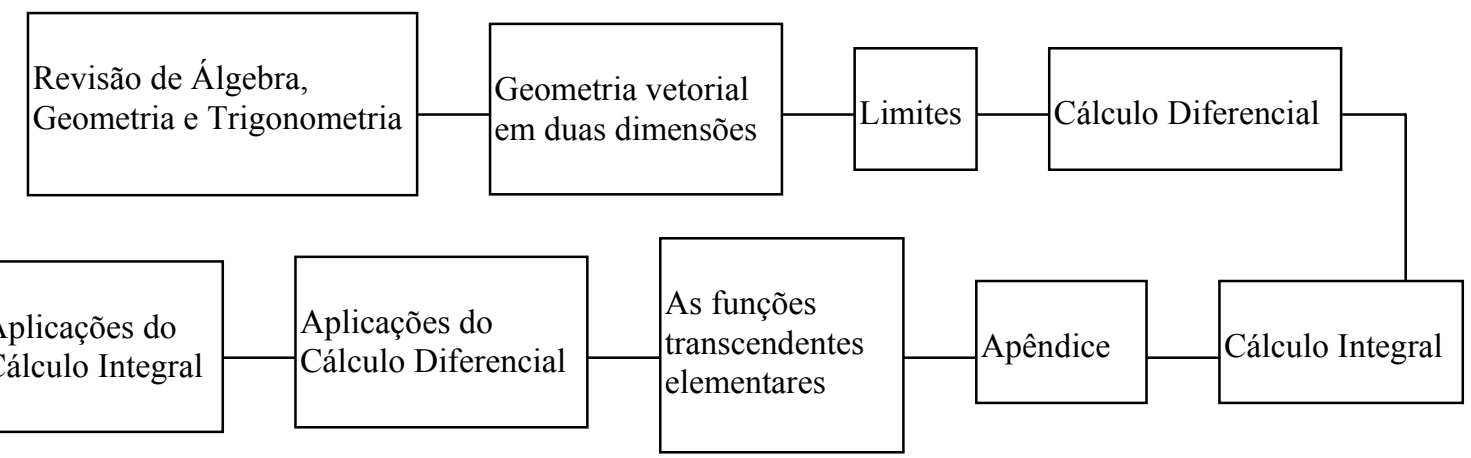

Figura 18: A seqüência temática de W. KAPLAN and D. J. LEWIS

No Capítulo 2, o autor estabelece o conceito de função e uma certa terminologia com a qual irá trabalhar. Quando faz a Análise Qualitativa de Funções de Uma Variável, pela primeira vez, utiliza a palavra limite, referindo-se ao que acontece em determinada figura. O exemplo é bem detalhado, sem nenhuma formalização. Algumas páginas depois, no tópico referente a Limites, após um exemplo, coloca a definição formal de limite de uma função num ponto, 
que, em seguida, explora em diversos exemplos, sempre referindo-se às figuras presentes na exposição. A questão é bastante trabalhada, e as demonstrações formais das propriedades são feitas muito depois, numa seção separada.

Ao iniciar o Capítulo 3, Cálculo Diferencial, há oito exemplos de situações envolvendo a razão de variação de duas grandezas, para depois ser colocada a definição de derivada de uma função num ponto.

No Capítulo 4, Cálculo Integral, encontramos logo de início, o conceito de integral indefinida, sem outros preâmbulos.

Neste livro, temos portanto uma apresentação do Cálculo que respeita a sistematização lógica, sem considerar a gênese das idéias. Entretanto, a maneira pela qual os autores tratam o assunto mostra uma grande preocupação em garantir a compreensão através de argumentos inicialmente intuitivos ou baseados nas ilustrações, para depois haver a formalização. A linguagem corrente está sempre presente, tornando o texto mais leve. Não há preocupação explícita com a problematização dos conceitos que vão sendo introduzidos, mas muito mais com a verificação de que eles funcionam e resolvem os problemas que aparecem depois. 
S. LANG: Cálculo - Vol. 1

\section{No prefácio, escrito em 1963, encontramos que}

O propósito de um primeiro curso de Cálculo é ensinar ao estudante as noções básicas de derivada e integral, bem como as técnicas fundamentais e as aplicações que as acompanham.

(...) Este livro é escrito para o estudante, para dar-lhe um acesso agradável e imediato ao assunto. Espero ter encontrado um meiotermo entre a insistência em detalhes especiais e a ausência de bastante exercícios técnicos, necessários para adquirir a desejada familiaridade com o assunto. Em todo caso, certos hábitos de rotina de matemático sofisticado são inconvenientes para um primeiro curso.

Isto não significa que o chamado rigor tenha que ser abandonado. 0 desenvolvimento lógico da matemática deste curso, à parte dos axiomas mais básicos, procede segundo as etapas abaixo:

Teoria dos Conjuntos

Inteiros (números relativos)

Números racionais (frações)

Números (isto é, números reais)

Limites

Derivadas

e assim por diante.

Somente um louco sugeriria começar um tal curso com Teoria dos Conjuntos. Acontece que o ponto mais satisfatório para iniciar o assunto é entre limites e derivadas. Em outras palavras, qualquer estudante está pronto para aceitar como intuitivamente óbvias as noções de número e limites, bem como suas propriedades básicas. Por algum motivo, tornou-se moda afirmar que o melhor lugar para entrar no assunto é entre números e limites. A experiência, porém, tem 
mostrado que os alunos não estão psicologicamente preparados para aceitar isso e resistem tremendamente.

Acontece que podemos atender a ambos os pontos de vista. Os argumentos que mostram como as propriedades de limite podem ser deduzidas das dos números formam um todo isolado. Logicamente tais argumentos devem preceder o assunto deste curso. Eles estão expostos aqui num apêndice. Se o estudante sentir necessidade de tal fundamentação, tudo o que tem a fazer é ler o apêndice e considerá-lo como o Cap. 0. De qualquer maneira, todo o conteúdo do livro é tão rigoroso quanto qualquer matemático desejaria que fosse (no que tange a objetos que foram definidos analiticamente). Nenhuma palavra precisa ser mudada em demonstração alguma. Espero que esta explicação elimine de uma vez por todas as possiveis controvérsias sobre o chamado rigor. (Lang, 1971, p.vii)

O que percebemos imediatamente é a preocupação do autor em escrever um texto especialmente voltado ao aluno, mas que satisfaça também ao professor, entendido como um matemático, que possui exigências quanto ao rigor da exposição.

A seqüência temática apresentada não respeita a gênese das idéias, conforme podemos observar:

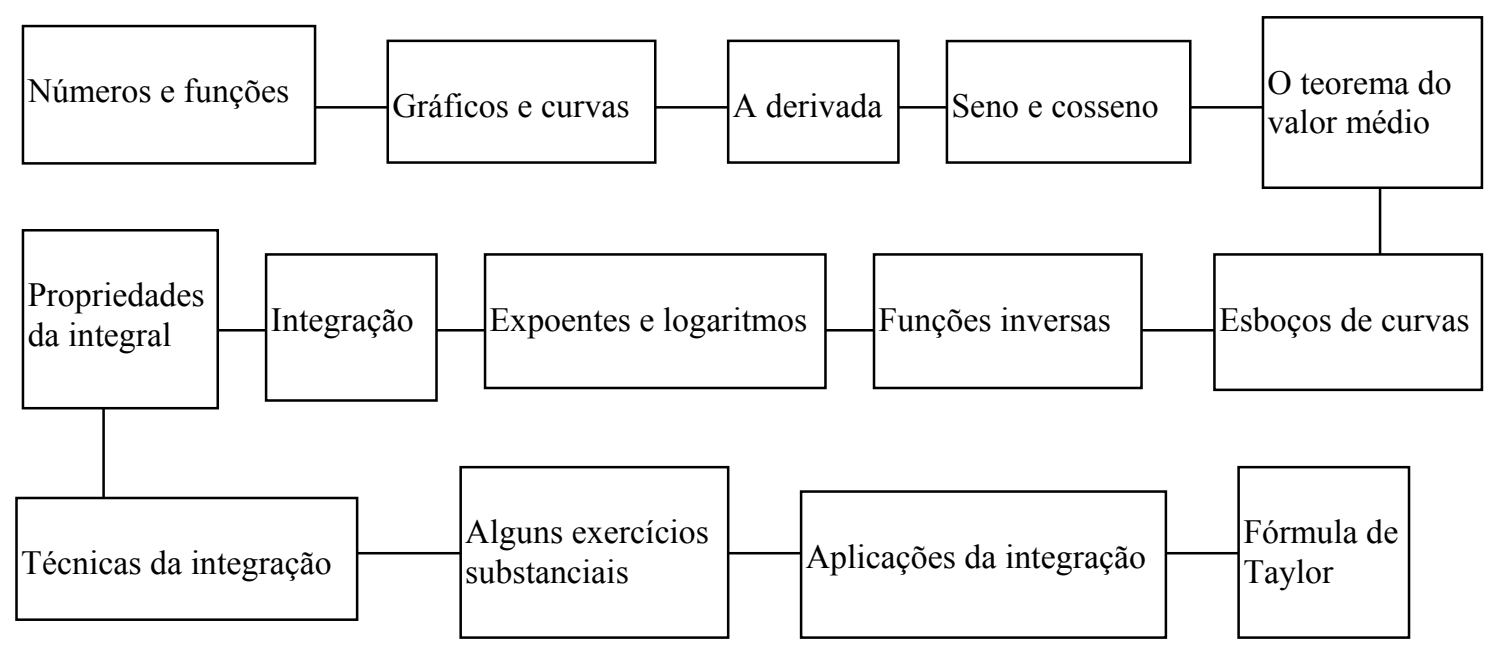

Figura 19: A seqüência temática de S. LANG 
As idéias fundamentais do Cálculo, não são apresentadas a partir de problemas reais e importantes. Após a introdução de cada conceito, há exploração de muitos problemas interessantes, principalmente no caso da derivada como taxa de variação.

Quanto à questão da linguagem, o próprio autor afirma que: geralmente não se reconhece que algumas das maiores dificuldades em ensinar Matemática são análogas às de ensinar uma língua estrangeira. (As escolas secundárias são responsáveis por isso. Um treinamento adequado no curso secundário resolveria o problema.) Conseqüentemente, fiz grandes esforços para conduzir o estudante verbalmente, por assim dizer, ao uso adequado da linguagem matemática (id., p. viii). De fato, o texto busca levar o leitor à aceitação dos argumentos utilizados, procurando convencer de sua razoabilidade.

No aspecto da visualização, às vezes, utiliza argumentos geométricos no desenvolvimento algébrico efetuado nos cálculos (ver na introdução à derivada, por exemplo). Não utiliza explicitamente argumentos de caráter intuitivo, e as preocupações com o rigor são resolvidas, estabelecendo um caráter definitivo para os argumentos utilizados. Apresenta generalizações e formalizações, como esperado.

Finalmente, nas palavras do próprio autor, não escrevi este curso no estilo que usaria para uma monografia avançada sobre tópicos sofisticados. Uma monografia avançada escrevemos para nós mesmos, porque queremos dar forma permanente à nossa visão de alguma bela parte de Matemática da qual não é fácil obter exposições acessíveis, mais ou menos da maneira pela qual um compositor põe em notação musical sua sinfonia (id., p. viii). 


\section{LEITHOLD: O Cálculo Com Geometria Analítica - Vol. I}

Num livro escrito para o estudante, o autor coloca, no Prefácio, que procurou fazer uma abordagem voltada para a experiência e maturidade de um principiante, sem omitir passagens ou explicações. Nesse sentido, procurou fazer um texto detalhado, com uma linguagem acessível. A seqüência temática é aquela do Cálculo sistematizado, logicamente estruturado, não respeitando, nesse sentido, a gênese das idéias fundamentais.

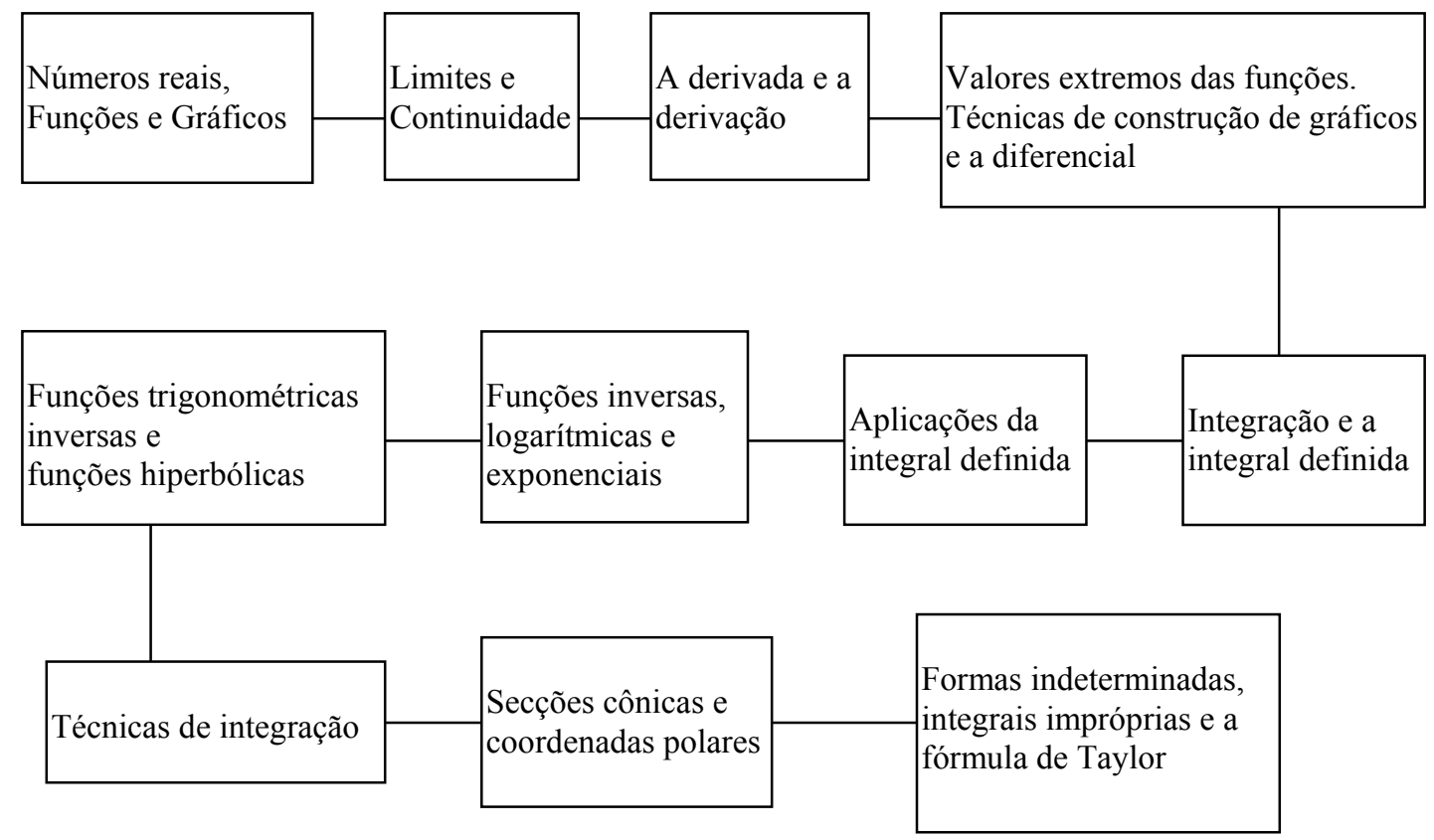

Figura 20: A seqüência temática de L. LEITHOLD

Em todo o texto, há bastante riqueza de detalhes, com muitos exemplos minuciosamente resolvidos. As idéias do Cálculo, entretanto não são exploradas em profundidade, através de problemas importantes. $O$ texto procura convencer o leitor sobre a razoabilidade dos cálculos realizados, através de comentários que estabelecem as conexões. Há um grande número de figuras para visualização daquilo que foi obtido através de cálculos algébricos. A argumentação obedece à lógica interna, com argumentos de caráter definitivo. 
A formalização e generalização são cuidadosas e, no próprio Prefácio, o autor afirma que

Espero que o leitor tome consciência de que as demonstrações dos teoremas são necessárias; procurei torná-las bastante motivadoras e explicá-las cuidadosamente, de forma que sejam compreensiveis para o estudante que adquiriu um nível razoável de conhecimento das seções que as precedem. Se um teorema está enunciado sem demonstração, a sua discussão foi ampliada com figuras e exemplos e, em tais casos, sempre ressaltei que se trata de uma ilustração do conteúdo do teorema, e não de sua demonstração. (Leithold, 1994, p. ix) 


\section{E. E. MOISE: Cálculo - Um Curso Universitário - Vol. I}

Este autor explicita, no Prefácio, a sua disposição em propor um curso de Cálculo onde o conhecimento é buscado por um processo de aproximações, pois a profundidade dos conceitos envolvidos não pode ser alcançada imediatamente, logo na primeira vez em que eles são colocados. Assim:

1. O processo em espiral. Os conceitos centrais do cálculo são profundos. Não se espera que possam ser aprendidos todos de uma vez, nas formas pelas quais um matemático moderno pensa a respeito deles. Portanto, neste livro, as idéias mais difíceis são apresentadas em uma série de formas diferentes, em ordem crescente de dificuldade, generalidade e exatidão. (...) O tratamento em espiral, no qual os conceitos aparecem em várias formas conforme a teoria se desenvolve, pretende tornar os conceitos mais simples de se aprender. Mas este não é o único propósito. Os processos pelos quais idéias especiais são generalizadas e idéias heurísticas se tornam concretas e exatas são parte do substrato do que devemos ensinar. (...)

2. Motivação. O desejo de resolver enigmas interessantes é muito forte; não há nenhum nível de maturidade no qual ele desapareça; e devemos apelar para ele continuamente. A maioria das vezes, entretanto, quando novas idéias são introduzidas, elas devem ser motivadas por um sentimento de força e pela luz que possam lançar sobre idéias já consideradas significativas. Por exemplo, se apresentamos as somas de Riemann, com toda generalidade, muito antes de lidarmos com problemas nos quais elas são necessárias, não é razoável esperar que o estudante domine suas dificuldades. Da mesma forma, a completividade do sistema numérico real, no sentido de Dedekind, não é necessária, absolutamente, na teoria dos limites; esta teoria tem exatamente a mesma forma no domínio racional e no domínio dos limites. Se deixarmos para apresentar a idéia de completividade no momento em que é necessária, no estudo de funções contínuas em um intervalo, é mais provável que seja compreendida, em parte porque talvez consiga a atenção do aluno.(...) 
3. Caixas Negras. É geralmente aceito que, num laboratório de física, a estudante deve construir, tanto quanto possivel, seu próprio equipamento. Ninguém aprende muita coisa observando a execução da proverbial "caixa negra". Em Matemática, a situação é semelhante: não aprendemos os princípios matemáticos, ouvindo mencioná-los uma vez, não importa quão elegantemente; precisamos conviver com eles e usá-los. (...) Deve ser entendido que o fato de se evitar as caixas negras não tem nenhuma conexão particular com a procura do rigor lógico. Certamente, se tivermos que escolher, é melhor dominar uma idéia por uma forma heurística, usando-a repetidamente, que ouvir uma vez uma rigorosa exposição e então esquecê-la. (Moise, 1970, p. ix)

As preocupações do autor são extremamente significativas e diferenciam o texto de outros a respeito do mesmo conteúdo. Entretanto, a questão do rigor também constitui um aspecto característico deste livro e, muitas vezes, parece ocasionar a mudança de foco: da compreensão das idéias e problemas para a formalização.

Nesse sentido, logo no primeiro Capítulo, Desigualdades e Completividade, encontramos uma exposição de leis, regras, teoremas, a respeito de um assunto sobre o qual os alunos ingressantes na Universidade possuem dificuldades importantes e a formalização apresentada não resolve essas dificuldades, mas talvez constitua um obstáculo à compreensão e manipulação, pois não estão sequer acostumados a esse tipo de tratamento.

Essa característica do livro faz com que as idéias e problemas importantes para motivá-las se percam e o curso de Cálculo se torne extremamente rigoroso e formal. Mesmo assim, chama a atenção a busca da construção do conhecimento, por aproximações, sem estabelecer um caráter definitivo, logo na primeira vez.

Há um número razoável de ilustrações, mas os argumentos não partem delas. A linguagem utilizada não busca explicitamente convencer. 
A seqüência temática apresentada é a seguinte:

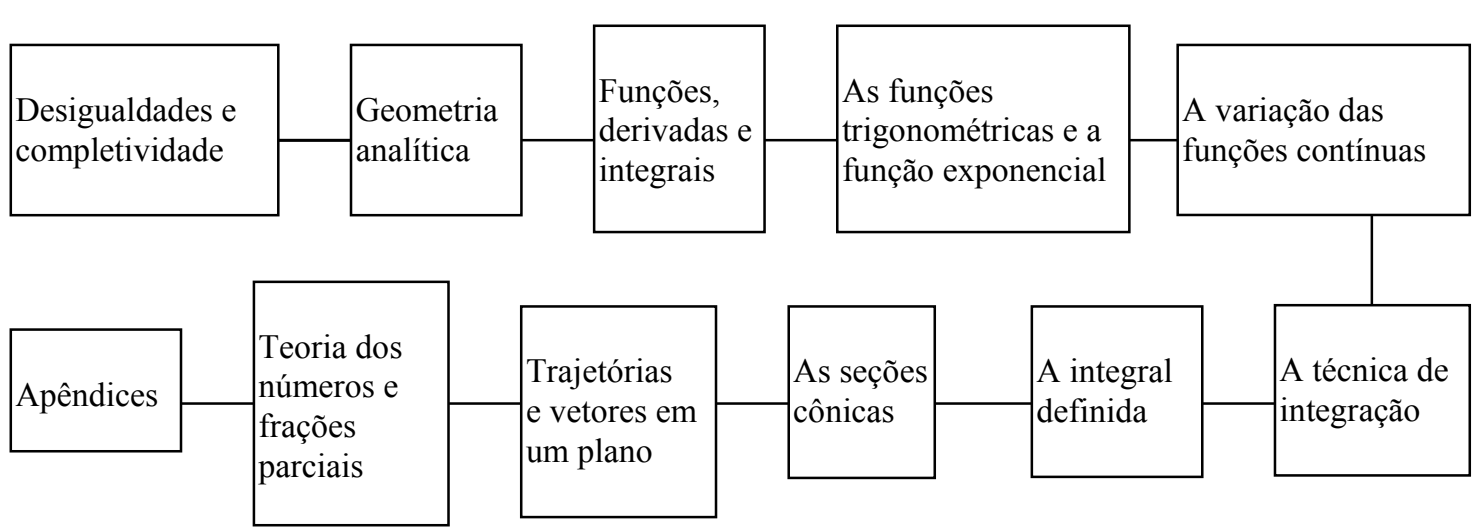

Figura 21: A seqüência temática de E. E. MOISE 


\section{N. PISKOUNOV: Calcul Différentiel Et Integral}

No reduzido avant-propos, o autor coloca que o livro

est destiné a tous ceux qui entreprennent l'étude systématique du cours de mathématiques supérieurs dans les écoles supérieures techniques. (Piskounov, p.15) ${ }^{34}$

A seqüência temática apresentada evidencia o objetivo do autor em mostrar o Cálculo sistematizado, não apresentando uma seqüência baseada no desenvolvimento do Cálculo como historicamente ocorreu.
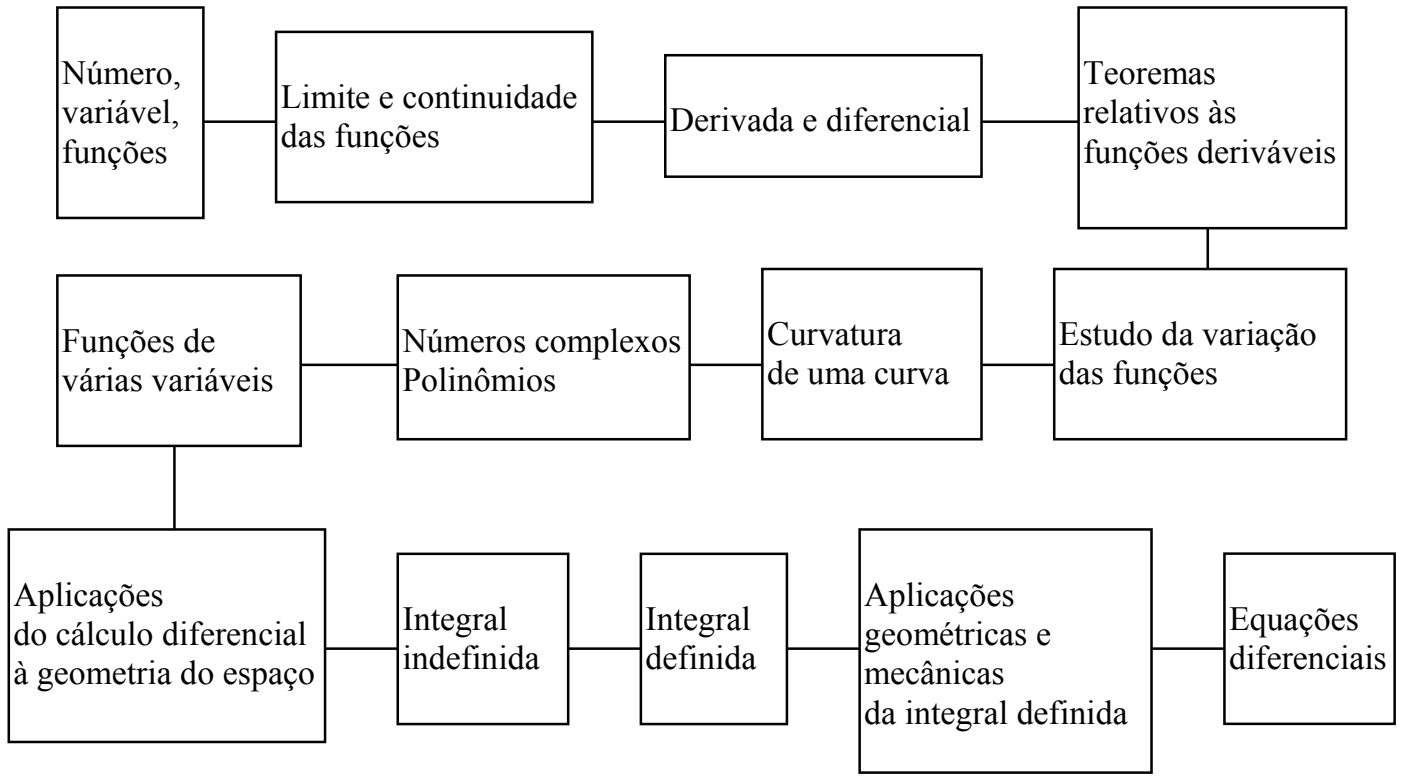

Figura 22: A seqüência temática de N. PISKOUNOV

As idéias fundamentais não são apresentadas como solucionadoras de problemas importantes. Não há colocação de problemas para motivar a introdução dos conceitos, embora coloque diversas aplicações posteriores (ver Cap. III, sobre Derivadas). Na parte de integrais, observamos o desenvolvimento da operação de primitivação, como inversa da derivação,

\footnotetext{
34 destina-se a todos aqueles que empreendem o estudo sistemático do curso de matemática superior nas escolas técnicas superiores.
} 
antes de falar em área sob o gráfico de uma curva. O autor não utiliza a linguagem corrente para convencer. Como se trata de uma revelação do Cálculo, a justificação se dá através de argumentos que obedecem à lógica interna; os exemplos são resolvidos com detalhe, em geral sempre após o conceito ter sido colocado. Há bastante ilustrações, mas os argumentos são algébricos para serem verificados na figura. O autor cuida da generalização e da formalização, demonstrando, normalmente, todas as proposições ou teoremas. 


\section{W. RUDIN: Principles Of Mathematical Analysis}

Este é um texto de Análise Real que funciona como paradigma de um curso logicamente estruturado, onde os conceitos são revelados, de maneira seqüencial, sem qualquer indício de problematização. Não há, evidentemente, explicitação clara das idéias do Cálculo.

Entretanto, normalmente, o curso de Análise Real não é ministrado para os alunos ingressantes, não sendo, portanto, um curso inicial. Pressupõe-se que o estudante já cursou alguns semestres de Cálculo, e que, portanto, ao chegar no nível deste curso, várias questões que serão abordadas com rigor, já estão articuladas.

O livro não apresenta figura alguma. Caracteriza-se por considerar que a justificação através da prova, além de ser necessária, é também suficiente. Nesse sentido, não há necessidade de qualquer tipo de convencimento, a não ser aquele que é garantido pela lógica interna. Evidentemente, a seqüência dos temas abordados é aquela esperada, do Cálculo revelado.

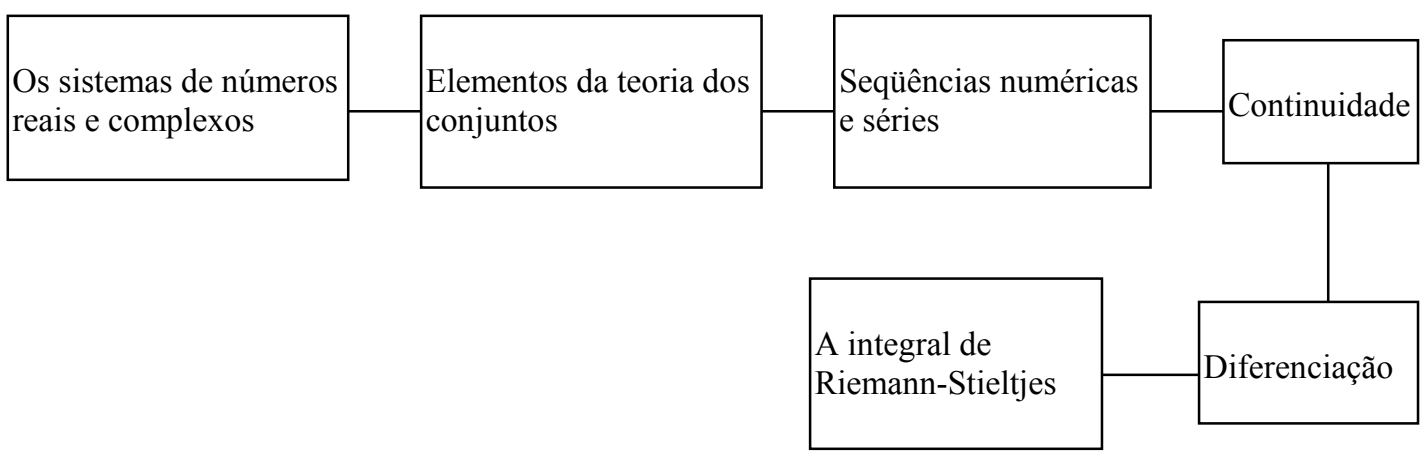




\section{G. F. SIMMONS: Cálculo Com Geometria Analítica - Vol. I}

No Prefácio, o autor diz que:

O texto em si é tradicional na matéria e na organização. Dei grande ênfase à motivação e à compreensão intuitiva, e os refinamentos da teoria foram negligenciados. A maioria dos estudantes revela impaciência com a parte teórica do assunto, e com razão, pois a essência do Cálculo não está em teoremas e em como prová-los, mas nos instrumentos que fornece e na forma de utilizá-los. Meu propósito maior foi o de apresentar o Cálculo como arte poderosa de resolver problemas, arte que é indispensável em todas as ciências quantitativas. Naturalmente, desejo convencer o estudante que os instrumentos-padrão do Cálculo são razoáveis e legítimos, mas não à custa de transformar o assunto numa disciplina lógica enfadonha, dominada por definições supercuidadosas, apresentações formais de teoremas e provas meticulosas. É minha esperança que toda explicação matemática nestes capítulos pareça ao estudante atento ser tão natural e inevitável quanto a água que flui no leito do rio. O objetivo principal do texto é explorar assuntos para os quais o Cálculo é útil - o que ele nos possibilita fazer e compreender - e não qual é a sua natureza lógica, quando encarado do ponto de vista especializado (e limitado) do matemático puro moderno. (Simmons, 1987, p. xvi)

A proposta do autor é pois a de apresentar um curso muito próximo ao estudante. A gênese das idéias não é respeitada; as idéias do Cálculo estão bastante explícitas e exploradas através de problemas de aplicação.

A linguagem é, muitas vezes, coloquial, com perguntas para questionar a compreensão. Há numerosas figuras e a partir delas procura induzir os raciocínios necessários. A argumentação utiliza freqüentemente a intuição e nem sempre o caráter dedutivo é explorado. Como ele próprio assumiu no Prefácio, não considera que a justificação através da prova seja suficiente para propiciar o convencimento. 
$\mathrm{Na}$ parte da integração, inicia pela integral indefinida, como operação inversa da derivada. A seqüência apresentada é a do Cálculo sistematizado:

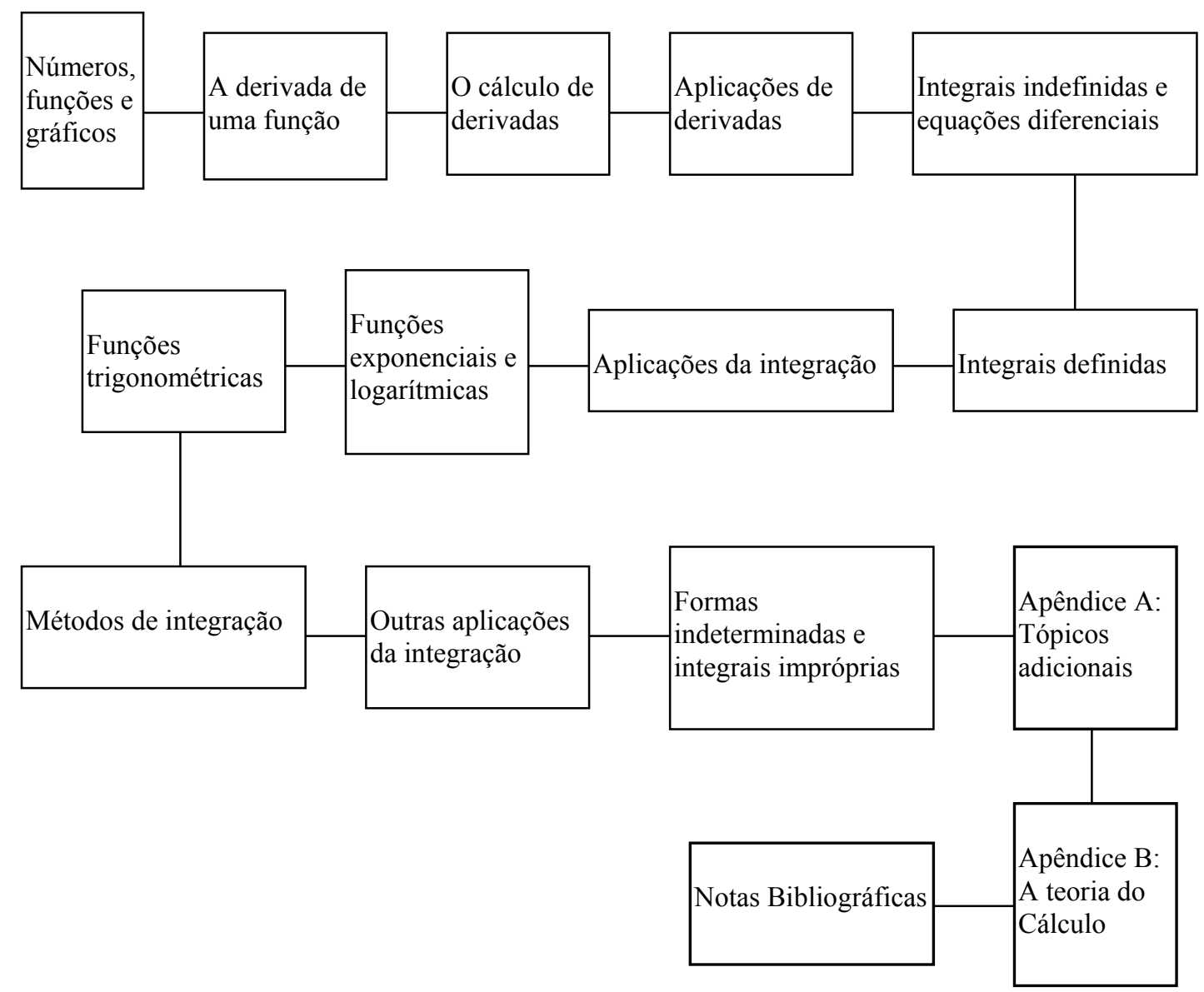

Figura 24: A seqüência temática de G. F. SIMMONS

No final da obra, encontramos 70 páginas dedicadas a Notas Biográficas, onde o autor apresenta alguns tópicos da História do Cálculo, o que pode ser muito motivador para o aluno interessado, mas que está colocado à parte do desenvolvimento do curso. 


\section{SPIVAK: Cálculo Infinitesimal}

La idea central que há estado presente en la confección de cada uno de los detalles de este libro, ha sido la de apresentar el Cálculo, no simplesmente como un preludio de las matemáticas, sino como el primer encuentro real com las mismas. Puesto que fueron los fundamentos del análisis los que suministraron el material que sirvió de base para el desarollo de las formas modernas de discurso matemático, deberia verse en el Cálculo una ocasión de profundizar en los conceptos básicos de lógica, en vez de tratar de eludirlos. Además de fomentar la intuición de los estudiantes acerca de los hermosos conceptos del análisis, es desde luego igualmente importante convencerlos de que la précision y el rigor no constituyen ni obstáculos para la intuición ni tampoco fines en si mismos, sino simplemente el medio natural para formular y tratar las questiones matemáticas. (Spivak, 1975, p.vii) $^{35}$

Para esse primeiro real encontro do estudante com a matemática, o autor propõe uma abordagem que privilegia a lógica, como ele próprio esclarece no Prefácio. Nesse sentido, a proposta é a de um texto que apresenta o Cálculo organizado, logicamente estruturado, onde o rigor e a precisão devem, segundo o autor, constituir os meios naturais para formular as questões matemáticas.

Assim, não há explicitação suficiente das idéias nas quais o Cálculo se baseia, nem dos problemas que motivaram sua elaboração.

A linguagem utilizada não pretende fornecer motivos de convencimento, uma vez que a justificação através da prova deve ser suficiente para garantir a compreensão. Mesmo assim, no Capítulo referente a Limites, encontramos dez

\footnotetext{
35 A idéia central, que esteve presente na elaboração de cada um dos detalhes deste livro, foi a de apresentar o Cálculo, não apenas como um prelúdio da matemática, mas como o primeiro real encontro com ela. Uma vez que foram os fundamentos da análise os que forneceram o material que serviu de base para o desenvolvimento das formas modernas de discurso matemático, dever-se-ia enxergar no Cálculo uma oportunidade de aprofundar os conceitos básicos da lógica, em lugar de procurar escondê-los. Além de fomentar a intuição dos estudantes a respeito dos belos conceitos da análise, é também igualmente importante convencê-los de que a precisão e o rigor não constituem obstáculos para a intuição, nem, tampouco, fins em si mesmos, mas apenas o modo natural para formular e tratar as questões matemáticas.
} 
páginas com exemplos que são visualizados em figuras, às quais o autor recorre para fornecer suas explicações.

A seqüência temática é a seguinte:

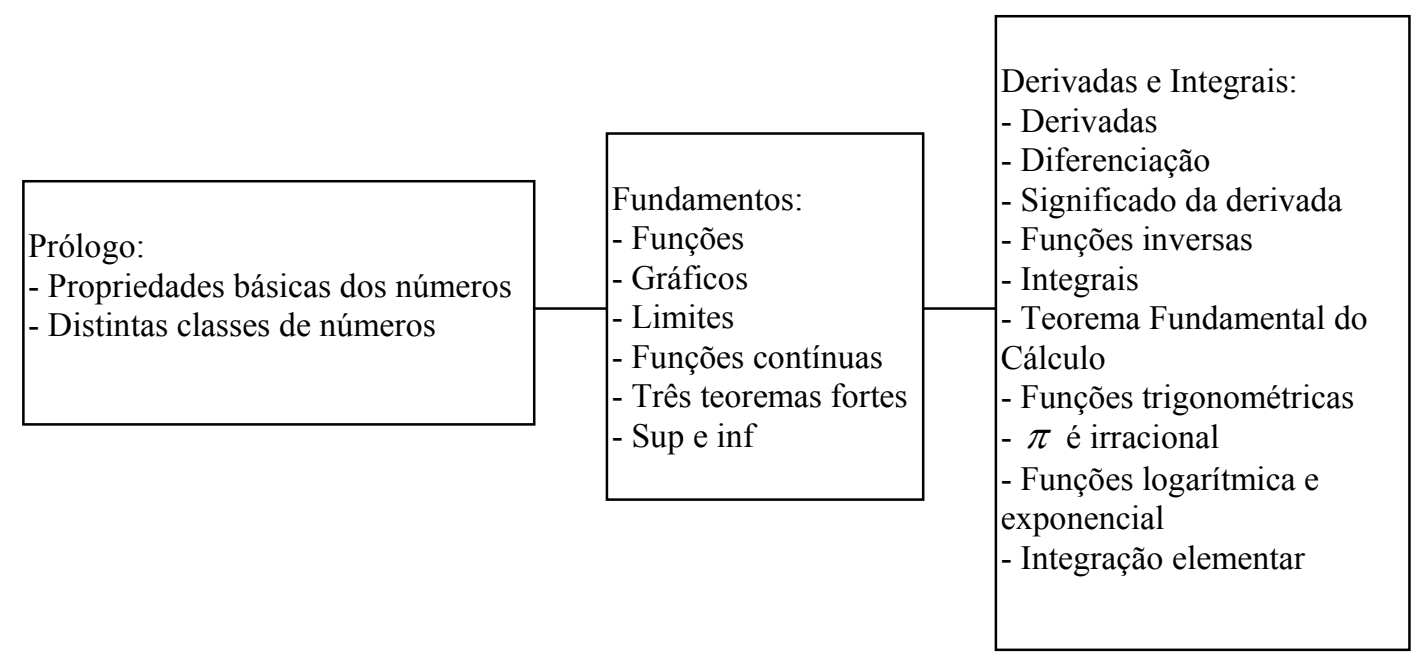

Figura 25: A seqüência temática de M. SPIVAK 
E. W. SWOKOWSKI: Cálculo Com Geometria Analítica - Vol. I

Logo nas primeiras páginas, o autor apresenta um formulário, onde inclui uma grande quantidade de fórmulas referentes às derivadas e às integrais e inclusive a diversos outros assuntos normalmente constantes do conteúdo desenvolvido na escola média. Parece, com isso, querer garantir que, pelo menos, rapidamente, seja possível encontrar aquilo que normalmente os estudantes imaginam ser o fundamental num curso de Cálculo.

No Prefácio, encontramos que a presente edição, revisão da original,

(...) foi empreendida com três objetivos em mente. O primeiro é tornar o livro mais voltado para o estudante, ampliando discussões e proporcionando maior número de exemplos e ilustrações para melhor esclarecer os conceitos. Para auxiliar ainda mais o leitor, foram acrescentadas, em muitas seções do texto, sugestões para a resolução de problemas. O segundo objetivo é enfatizar a utilidade do Cálculo por meio de aplicações atualizadas de derivadas e integrais. O terceiro objetivo - tornar o livro tão livre de erros quanto possível - foi alcançado por meio de um exame cuidadoso do texto ...(Swokowski, 1994, p. xix)

Ainda encontramos uma página dirigida ao estudante, onde o autor coloca que o Cálculo foi descoberto no século XVII, e, em seguida, tece algumas considerações sobre quais tipos de problemas atuais podem ser resolvidos através da utilização do Cálculo. Esses problemas são apenas citados, a título informativo. Nenhum deles é detalhado, nem mesmo proposto nesse instante.

A seqüência temática apresentada é a seguinte: 


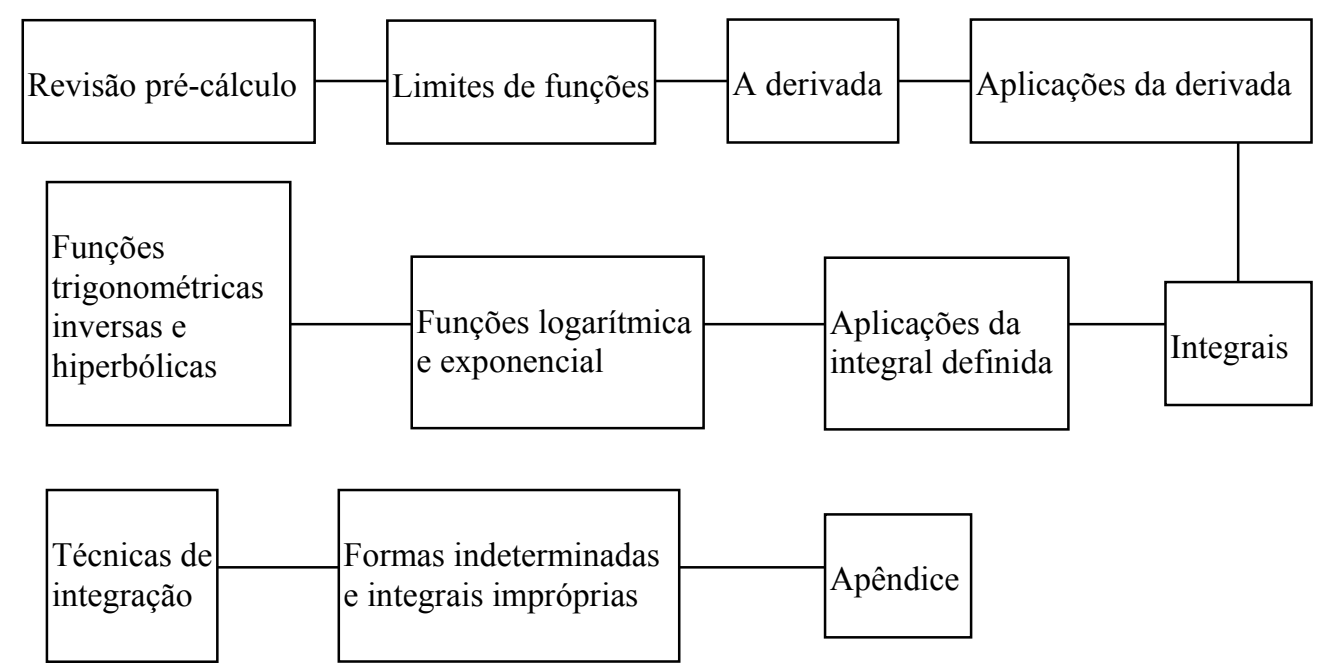

Figura 26: A seqüência temática de E. W. SWOKOWSKI

Esta é a seqüência do Cálculo estruturado, logicamente organizado.

O autor inicia seu texto com uma Revisão Pré-Cálculo, na qual retoma diversos assuntos que considera essenciais para 0 desenvolvimento subseqüente. Em seguida, no Capítulo 2, desenvolve o conceito de limite de uma função que é uma das idéias fundamentais que distinguem o cálculo da álgebra e da trigonometria. Podemos observar que o autor busca convencer tanto através de cálculos, como de figuras ou da linguagem. O uso da intuição é também bastante explorado. Somente após quinze páginas, desse tipo de tratamento, aparece a definição formal de limite.

No Capítulo sobre Derivadas, observamos que há três exemplos, desenvolvidos com detalhe, reta tangente ao gráfico de uma função num ponto, velocidade instantânea e taxa instantânea de variação, nos quais sempre obtém a expressão usual que, em seguida, vai colocar como sendo aquela que define a derivada de uma função em um ponto. Na parte sobre integração, primeiro trabalha a integração indefinida, como operação inversa da derivação, e só depois coloca a questão do cálculo de áreas. 
Todo o texto é trabalhado no sentido de primeiro apresentar exemplos trabalhados com detalhe, antes da introdução do conceito. Os problemas mais interessantes são propostos depois. O texto busca o convencimento do leitor, e para isso utiliza argumentos muitas vezes intuitivos, não apenas decorrentes da lógica interna. A formalização e generalização são bem cuidadas. 


\title{
A. J. WHITE: Análise Real: Uma Introdução
}

Como os outros livros de Análise Real, este também não se destina aos alunos ingressantes na Universidade. Segundo o autor

\begin{abstract}
Os únicos pré-requisitos indispensáveis para a leitura deste livro são: interesse pela matemática e disposição para, ocasionalmente, conter a descrença quando uma idéia familiar aparecer sob uma forma estranha. Entretanto, mesmo um estudante excepcional somente tiraria proveito da leitura do livro se tivesse adquirido previamente um razoável conhecimento dos processos do cálculo elementar. $\mathrm{Na}$ verdade, o livro é resultante de vários cursos destinados a estudantes de segundo ano de matemática na Universidade de Aberdeen, cujo preparo anterior foi um curso de cálculo e geometria analítica de tipo bastante tradicional. Seria portanto mais realístico acrescentar um curso deste tipo à lista de pré-requisitos.
\end{abstract}

Há pelo menos duas omissões notáveis no texto. Primeira: apesar da insistência que se faz o tempo todo em provas rigorosas, não há nenhuma discussão formal sobre o mecanismo da lógica e da teoria dos conjuntos envolvido. (...) Segunda: não há nada sobre cálculo de funções de várias variáveis reais. O único contexto razoável para tal discussão é a teoria dos espaços lineares, e fornecer as ferramentas necessárias tornaria o texto longo demais. (White, 1973, no Prefácio)

Dessa forma, o texto não tem por objetivo explicitar as idéias do Cálculo, nem de colocar problemas para motivar a construção dos conceitos. A idéia é a de apresentar um conjunto logicamente estruturado, formalizado. Mesmo assim, a linguagem corrente é razoavelmente utilizada (ver, por exemplo, a introdução ao Cap.5, sobre a Integral de Riemann). Há pouquíssimas figuras, e a argumentação, normalmente utilizada, obedece à lógica interna.

A seqüência temática é a seguinte: 


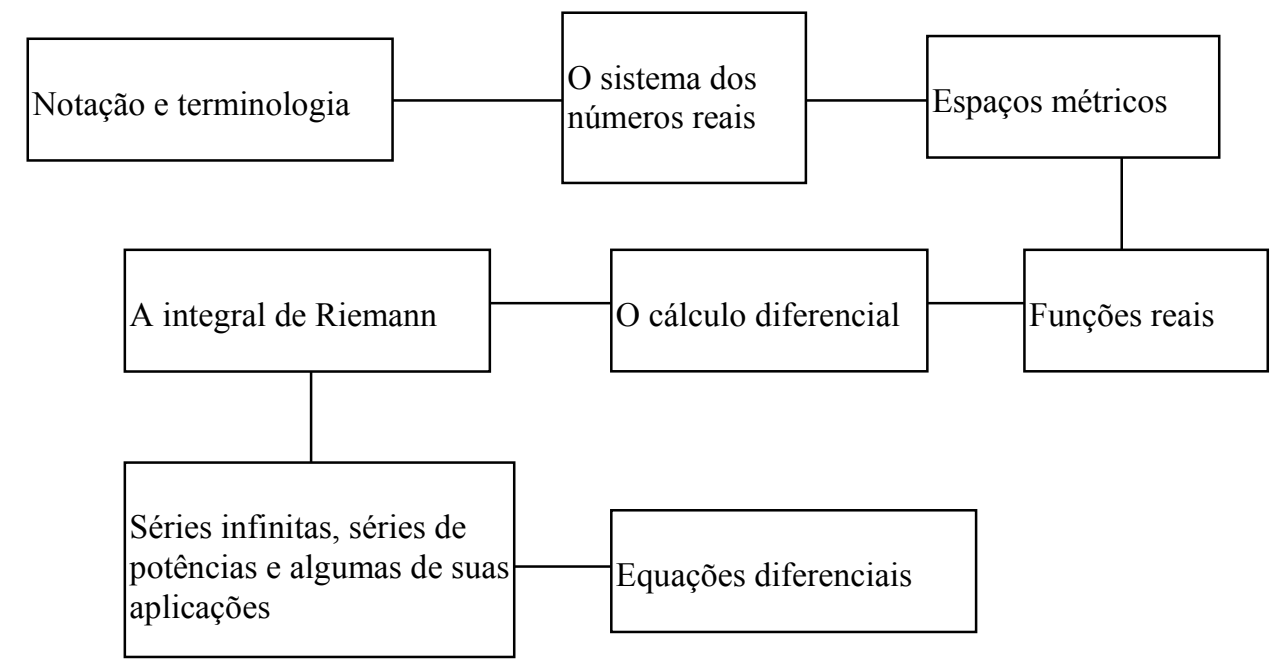

Figura 27: A seqüência temática de A. J. WHITE 


\title{
A. B. WILLCOX; R. C. BUCK; H. G. JACOB and D. W. BAILEY: Introduction To Calculus - Vol. I
}

\author{
No Prefácio, encontramos que
}

Our program for introducing continuity and limits is not the traditional one. Continuity comes first, via a highly geometrical approach. Since this is the first significant idea of the calculus encountered by the student, considerable attention is devoted to its evolution from the most informal and intuitive image suggested by the words "continuous curve". Next, the idea of a function being limiting, os having a limit, at a point is defined as a sort of almost-continuity. This seems to us to be the natural progression from a simple intuitive idea to a more sophisticated variation. The discussion is informal - no $\varepsilon^{\prime}$ 's or $\delta$ 's appear until the first chapter of Introduction to Calculus 2. The ideas of continuity and limits, which could hardly be more basic to the subject, must appeal to the intuition of the student if he is to take them at all seriously. We believe in rigor at this level only when it contributes to clarity, and we believe that an insistence on complete logical detail can often inhibit rather than enhance understanding. If the basic ideas of derivative and integrals can be transmitted by an intuitive approach, so can the ideas of continuity and limits. We have tried to do all these things. (Willcox, 1971, p. ix $)^{36}$

$\mathrm{Na}$ Introdução ao primeiro capítulo, encontramos algumas considerações a respeito do Cálculo, desde os gregos até Newton, o Pai do Cálculo, e que the importance of the calculus derives from the intrinsic power and beauty of its ideas and the many and varied contacts between these ideas and the "real

\footnotetext{
${ }^{36}$ Nosso programa para introduzir continuidade e limites não é o tradicional. A continuidade vem antes, através de um tratamento fortemente geométrico. Uma vez que esta é a primeira idéia significativa do cálculo encontrada pelo estudante, uma atenção considerável é dedicada à sua evolução a partir da imagem mais informal e intuitiva, sugerida pelas palavras "curva contínua". Em seguida, a idéia de uma função limitada ou tendo um limite em um ponto, é definida como uma quase-continuidade. Isto nos parece ser o caminho natural, para se chagar, partindo de uma simples idéia intuitiva, a uma noção mais sofisticada. A discussão é informal - nenhum $\varepsilon$ ou $\delta$ aparecerá antes do primeiro capítulo do Introduction to Calculus 2. As idéias de continuidade e limites, que dificilmente poderiam ser mais básicas para o assunto, devem fazer apelo à intuição do estudante se ele as considerar com seriedade. Neste nível, acreditamos em rigor apenas quando ele contribui na clareza, e acreditamos que uma insistência ou detalhamento lógico completo podem, muitas vezes, inibir, em lugar de aumentar a compreensão. Se as idéias básicas sobre derivada e integral podem ser transmitidas através de uma abordagem intuitiva, o mesmo ocorre com as idéias de continuidade e limites. Nós tentamos fazer isso.
} 
world". (id., p.1) ${ }^{37}$ Em seguida, coloca dois problemas, um deles a respeito do excesso de velocidade de um motorista numa estrada e o outro sobre um aro de latão construído com arame delgado. Esses problemas são colocados de maneira a despertar interesse, na forma de puzzles, com questionamentos ao longo do enunciado. A resolução será feita posteriormente.

Ao iniciar a questão sobre funções, há uma série de exemplos em linguagem corrente, antes de colocar funções dadas por expressões matemáticas. Estes exemplos, muitos não triviais, são trabalhados em detalhe, e, a partir dos gráficos, são feitas observações importantes.

Partindo dos gráficos feitos, o autor inicia a discussão sobre a continuidade de uma função num ponto por meio de vizinhanças. O trabalho com funções contínuas é bastante longo, chegando a resultados importantes e gerais. A definição de limite de uma função em um ponto é conseqüência. Diferentemente dos livros mais tradicionais, este desenvolve limites em apenas duas páginas, sem propor uma grande quantidade de exercícios sobre cálculo de limites.

No Capítulo sobre Derivadas, há a colocação de três problemas, onde chega à expressão da derivada da função envolvida no ponto dado, mas só depois, na seção seguinte, coloca a definição formal de derivada, que depois explora numa série de exemplos. Na parte de Integrais, observamos primeiro a questão da integral definida, a partir do problema de calcular o valor médio de uma função num dado intervalo e depois o de calcular a área sob o gráfico de uma função e acima do eixo das abcissas. Posteriormente, desenvolve a primitivação.

Ao longo de todo o desenvolvimento, o uso da linguagem corrente torna a leitura bastante agradável. Observamos também que das ilustrações são

\footnotetext{
37 a importância do cálculo deriva da potência e beleza intrínsecas de suas idéias e dos muitos e variados contatos entre essas idéias e o "mundo real".
} 
tiradas conclusões importantes para a argumentação realizada no texto. O livro apresenta diversas problematizações para depois colocar os conceitos. No decorrer do texto há questionamentos, buscando uma certa interatividade com o leitor. Ainda é importante observar que in our writing we have had in mind the student.(id., p. x) ${ }^{38}$

No decorrer de toda a obra, além da busca do convencimento, o autor mostra preocupação com a generalização dos resultados, cuidando da formalização.

A seqüência temática apresentada é a seguinte:
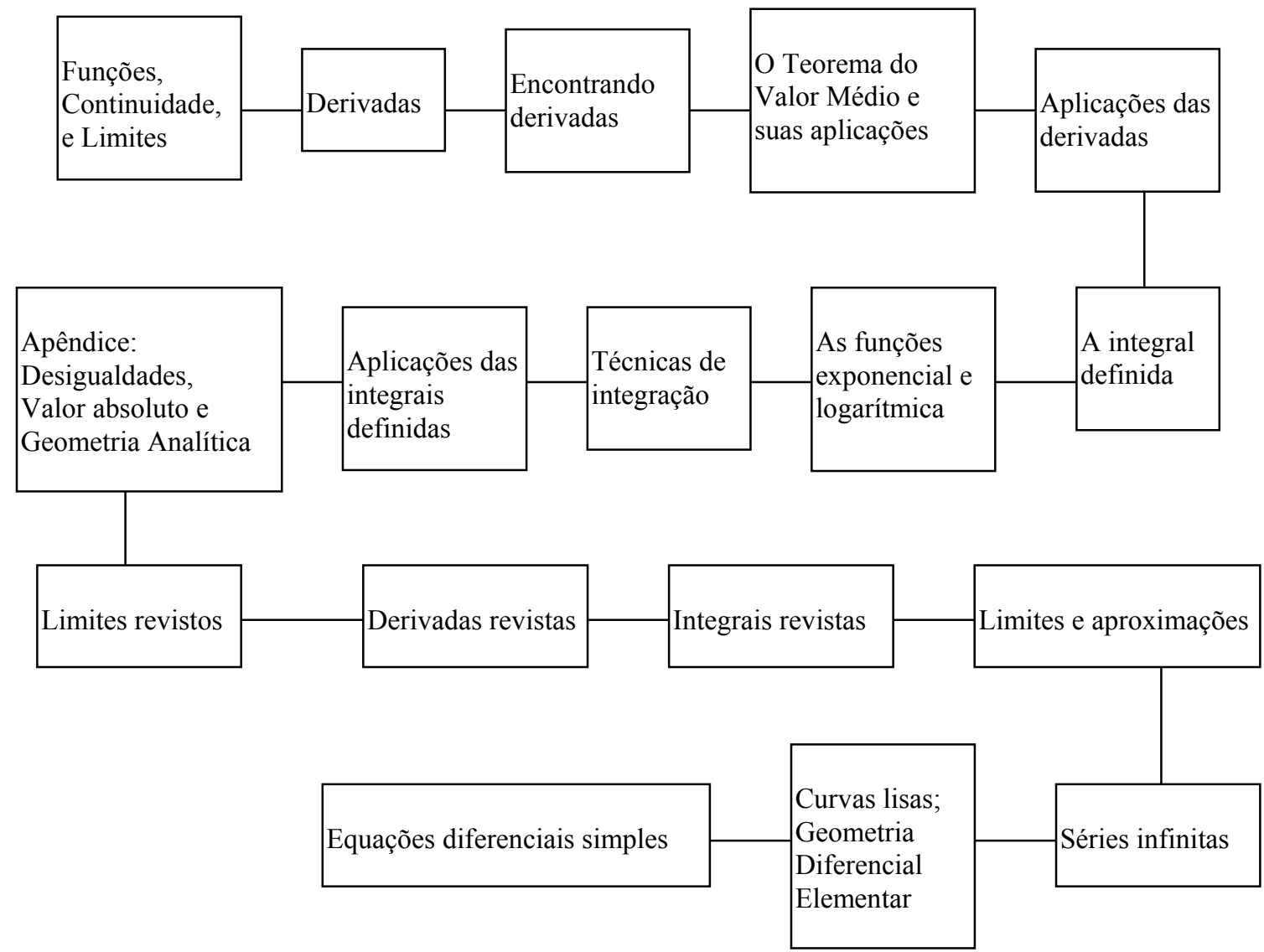

Figura 28: A seqüência temática de A. B. WILLCOX et alii

\footnotetext{
38 ao escrever, tivemos em mente o estudante.
} 


\begin{tabular}{|c|c|c|c|c|c|c|c|c|c|c|c|c|c|c|c|c|c|c|}
\hline & \multicolumn{3}{|c|}{ I } & \multicolumn{3}{|c|}{$\mathbf{P}$} & \multicolumn{3}{|c|}{$\mathbf{L}$} & \multicolumn{3}{|c|}{$\mathbf{V}$} & \multicolumn{3}{|c|}{$\mathbf{A}$} & \multicolumn{3}{|c|}{$\mathbf{F}$} \\
\hline Alexander et alii & & • & & $\cdot$ & & & $\cdot$ & & & $\cdot$ & & & & - & & & & - \\
\hline Apostol (Análise) & & & $\bullet$ & & & $\bullet$ & & & $\cdot$ & & & $\cdot$ & & & $\bullet$ & & & • \\
\hline Apostol (Cálculo) & $\cdot$ & & & $\cdot$ & & & $\cdot$ & & & $\cdot$ & & & $\cdot$ & & & & $\bullet$ & \\
\hline Ávila & & $\bullet$ & & $\bullet$ & & & $\cdot$ & & & & $\bullet$ & & $\cdot$ & & & & $\bullet$ & \\
\hline Bartkovich et alii & $\bullet$ & & & $\bullet$ & & & $\bullet$ & & & $\bullet$ & & & $\cdot$ & & & $\bullet$ & & \\
\hline Boulos & & $\bullet$ & & & $\bullet$ & & $\bullet$ & & & $\bullet$ & & & & $\bullet$ & & & $\bullet$ & \\
\hline Bruckheimer et alii & $\bullet$ & & & $\bullet$ & & & $\bullet$ & & & $\bullet$ & & & $\bullet$ & & & $\bullet$ & & \\
\hline Buck & & $\bullet$ & & & & $\bullet$ & $\bullet$ & & & & $\bullet$ & & & & $\bullet$ & & & $\bullet$ \\
\hline Courant & - & & & - & & & - & & & - & & & & - & & - & & \\
\hline Courant / John & $\bullet$ & & & $\bullet$ & & & $\bullet$ & & & $\bullet$ & & & & $\bullet$ & & $\bullet$ & & \\
\hline Greenspan / Benney & $\bullet$ & & & $\bullet$ & & & $\bullet$ & & & $\bullet$ & & & $\bullet$ & & & $\bullet$ & & \\
\hline Guidorizzi & & $\bullet$ & & & $\bullet$ & & & & $\bullet$ & & $\bullet$ & & & & $\bullet$ & & & $\bullet$ \\
\hline Kaplan & & & $\bullet$ & & $\bullet$ & & $\bullet$ & & & $\bullet$ & & & & & $\bullet$ & & & $\bullet$ \\
\hline Kaplan / Lewis & & - & & & - & & - & & & - & & & - & & & & & - \\
\hline Lang & & $\bullet$ & & & & $\bullet$ & $\bullet$ & & & $\bullet$ & & & & & $\bullet$ & & & $\bullet$ \\
\hline Leithold & & $\bullet$ & & & $\bullet$ & & $\bullet$ & & & & $\bullet$ & & & & $\bullet$ & & & - \\
\hline Moise & & & $\bullet$ & & & $\bullet$ & & $\cdot$ & & & $\bullet$ & & $\cdot$ & & & & & $\bullet$ \\
\hline Piskounov & & - & & & - & & & - & & & - & & & & • & & & - \\
\hline Rudin & & & $\bullet$ & & & $\bullet$ & & & • & & & • & & & - & & & $\bullet$ \\
\hline Simmons & & $\bullet$ & & & $\bullet$ & & $\bullet$ & & & $\bullet$ & & & $\bullet$ & & & & $\bullet$ & \\
\hline Spivak & & & $\bullet$ & & & $\bullet$ & & & • & & $\bullet$ & & & & $\bullet$ & & & $\bullet$ \\
\hline Swokowski & & $\bullet$ & & & $\bullet$ & & $\bullet$ & & & & $\bullet$ & & & $\bullet$ & & & $\bullet$ & \\
\hline White & & & $\bullet$ & & & $\bullet$ & & $\cdot$ & & & & • & & & - & & & $\bullet$ \\
\hline Willcox et alii & $\bullet$ & & & $\bullet$ & & & $\bullet$ & & & $\cdot$ & & & & $\bullet$ & & & $\bullet$ & \\
\hline
\end{tabular}

Figura 29: A análise dos livros segundo os critérios selecionados 


\section{Capítulo 4. Análise dos resultados}

\subsection{Os resultados da pesquisa}

Gostaríamos de observar, inicialmente, que as preocupações destacadas na Introdução deste trabalho eram em maior número do que as que se constituíram no objeto de estudo. Assim, nem tudo está respondido.

Examinando os resultados obtidos na análise dos livros selecionados, podemos perceber o quanto alguns deles apresentam propostas que mais se aproximam daquelas de um curso de Análise Real, que não é, de maneira alguma, um curso inicial, muito menos um curso proposto para todos os alunos que freqüentam os cursos de Cálculo.

Assim, encontramos livros que não focalizam de maneira preponderante a questão das idéias do Cálculo, através de problemas importantes e motivadores, ainda que vários deles, embora não partam de situações problema, consigam mostrar que o Cálculo tem diversas aplicações nas diferentes áreas do conhecimento.

No conjunto de livros selecionados observamos que muitos deles são extremamente significativos, importantes e compatíveis com o modelo constituído a partir das idéias de Brousseau. Em poucas palavras, podemos dizer que livros bons sempre existiram. 


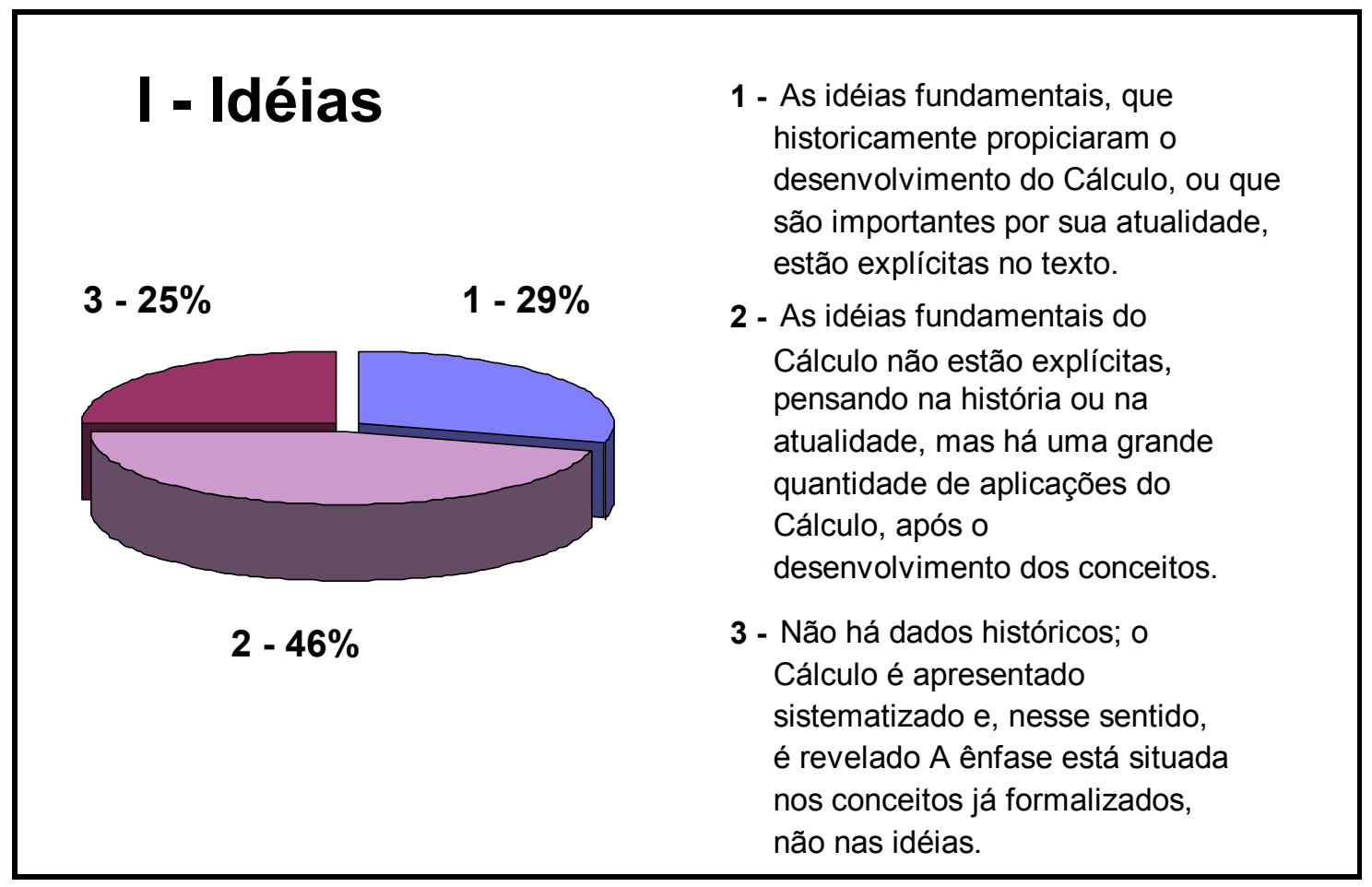

Fig. 30: Distribuição dos livros segundo o critério IDÉIAS

No conjunto dos livros selecionados, observamos que $29 \%$ deles explicitam fortemente as idéias do Cálculo, importantes historicamente ou por sua atualidade (1). Em $46 \%$ dos livros, observamos algumas preocupações com as idéias, mas sem a explicitação clara de que elas existiram antes da formalização (2). Os restantes $25 \%$, não mostram preocupação alguma com as idéias do Cálculo, como existentes antes da estruturação do todo. 


\section{P - Problematização}

\section{$3-29 \%$}

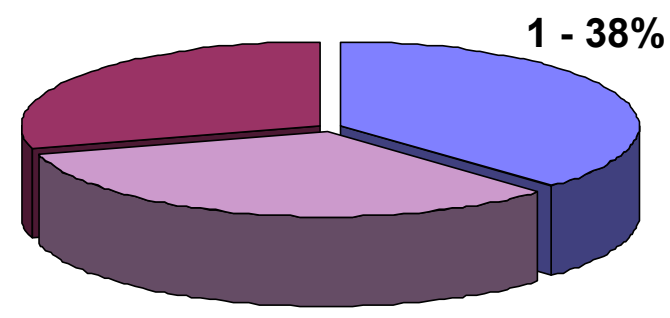

$2-33 \%$
1 - O texto parte de importantes problemas motivadores para chegar à construção do conceito.

2 - O texto parte de alguns exemplos simples para depois introduzir o conceito.

3 - O texto inicia diretamente com o conceito para depois colocar exemplos, exercícios ou problemas.

Figura 31: Distribuição dos livros segundo o critério PROBLEMATIZAÇÃO

Com relação à problematização, em $38 \%$ dos livros observados, encontramos problemas importantes para motivar a introdução dos conceitos (1); em $33 \%$, os problemas aparecem como aplicações do Cálculo, não motivando os conceitos (2), e, nos restantes $29 \%$, não aparecem problemas interessantes em quantidade relevante. 


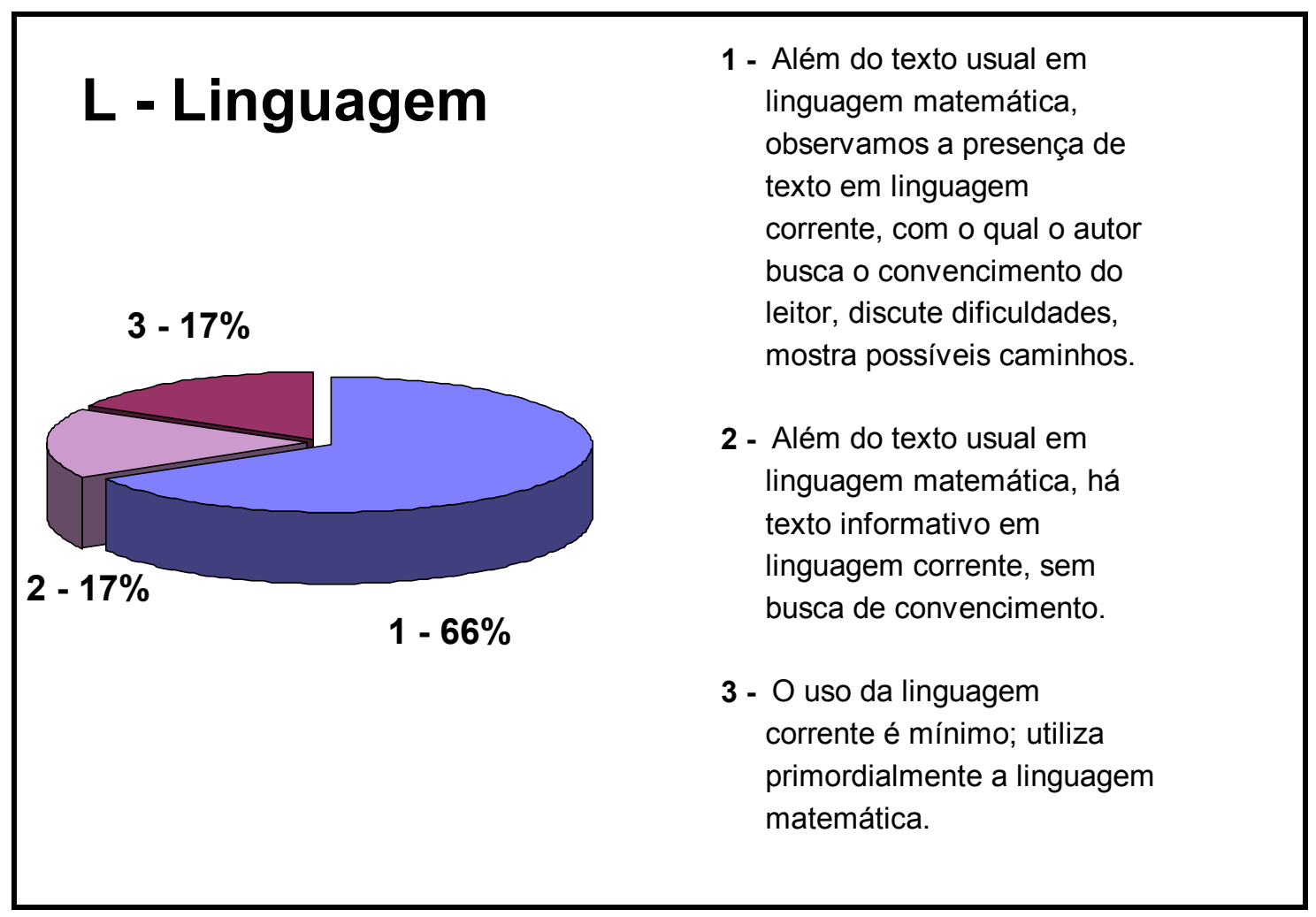

Fig.32: Distribuição dos livros segundo o critério LINGUAGEM

Com relação à negociação dos significados, podemos perceber que a linguagem corrente como ferramenta poderosa na busca do convencimento é utilizada por $66 \%$ dos autores (1). Entretanto, no restante dos livros observados, 17\% mostram preocupação em reduzi-la ao mínimo (3), como é usual em cursos posteriores, para estudantes de Matemática, ou então, mesmo utilizando-a, também $17 \%$ não procuram, através dela, convencer (2). 


\section{V - Visualização}

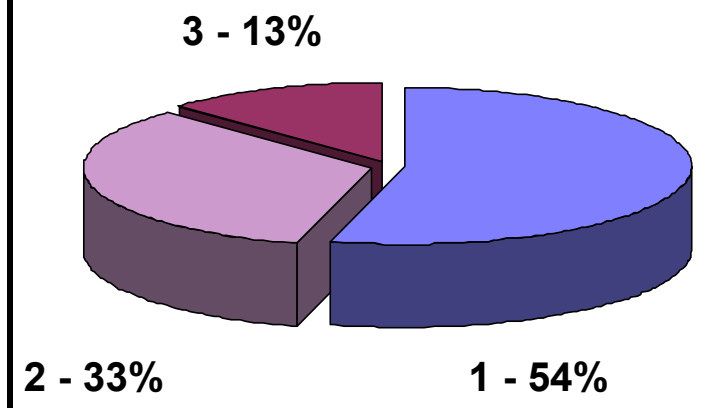

1 - O texto é rico em figuras, gráficos, utilizando, às vezes, argumentos geométricos ou gráficos para fazer cálculos algébricos.

2 - O texto apresenta figuras e gráficos, mas os argumentos são algébricos ou analíticos para serem visualizados na figura.

3 - O texto quase não tem figuras ou não tem figura alguma.

Fig.33: Distribuição dos livros segundo o critério VISUALIZAÇÃO

A utilização de figuras, importantes para a construção do significado, é muitas vezes, em $33 \%$ dos casos, feita apenas para que o estudante verifique aquilo que foi estabelecido (2), embora $54 \%$ busquem o caminho mais frutífero, partindo da figura para extrair conclusões (1). No restante dos casos, 17\%, praticamente não há figuras ou mesmo não há figura alguma. 


\section{A - Argumentação}

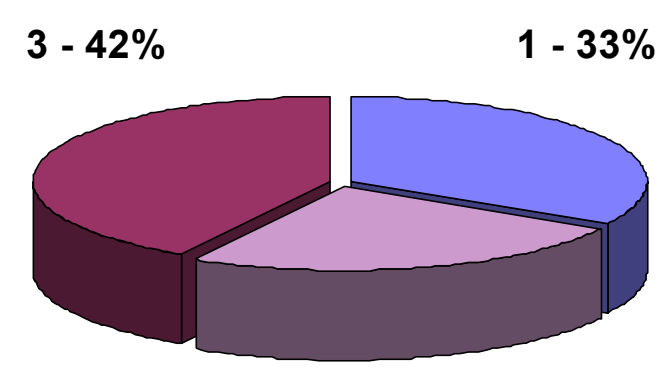

$2-25 \%$

1 - O autor busca a construção do conhecimento através de aproximações, retornando várias vezes, sem caráter definitivo, logo da primeira vez. Aproveita, às vezes, a intuição.

2 - Embora a argumentação não seja apenas internalista, podendo mesmo utilizar a intuição, o autor estabelece um caráter definitivo para o conhecimento construído.

3 - Os argumentos utilizados são provenientes apenas da lógica interna e o caráter do conhecimento construído é definitivo.

Fig.34: Distribuição dos livros segundo o critério ARGUMENTAÇÃO

Em relação à argumentação, observamos que $42 \%$ dos textos utilizam recursos provenientes da lógica interna (3), caracterizando a dedução e evitando ao máximo a intuição que poderia tornar mais razoáveis os raciocínios efetuados. Apenas 33\% dos livros busca a construção do conhecimento por aproximações, sem imprimir um caráter definitivo, logo da primeira vez. Em 25\% dos livros observados, a argumentação não é apenas internalista, mas é estabelecido um caráter definitivo (2). 


\section{F - Formalização}

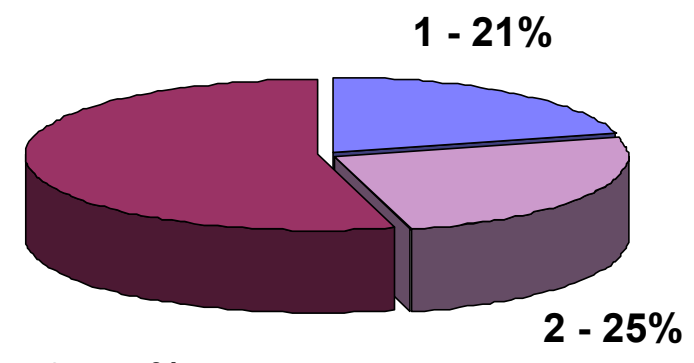

$3-54 \%$
1 - A organização do texto mostra o Cálculo em construção, não se constituindo numa apresentação logicamente estruturada; as generalizações e formalizações necessárias são naturalmente obtidas.

2 - A organização do texto apresenta, inicialmente, o Cálculo em construção, e, após a introdução do novo conceito, parte para um esquema revelador do Cálculo, logicamente estruturado.

3 - A organização do texto mostra uma revelação do Cálculo; tudo é demonstrado e sempre inserido num contexto logicamente estruturado.

Fig.35: Distribuição dos livros segundo o critério FORMALIZAÇÃO

Em praticamente todos os livros observados, percebemos a preocupação com a formalização e generalização dos resultados. Entretanto, a maioria, 54\% deles, pretende estabelecer um curso de Cálculo que, no final de contas, ainda é revelado, permanecendo a noção da transmissão de conhecimento, em lugar da construção (3). Apenas $21 \%$ dos autores apresenta o Cálculo em construção (1), enquanto que $25 \%$ deles parece, inicialmente, ter essa proposta, mas após a introdução de um novo conceito adota a postura de revelação do Cálculo logicamente estruturado. 


\subsection{Uma representação visual da análise}

A análise dos livros, a partir dos critérios definidos, permitiu-nos realizar uma representação gráfica que é interessante porque permite, rapidamente, perceber diferenças, semelhanças e proximidades entre as diversas propostas dos autores observados.

Considerando os seis critérios estabelecidos: idéias (I), problematização $(P)$, linguagem $(L)$, visualização $(V)$, argumentação $(A)$ e formalização $(F)$, construímos, para cada livro analisado, um polígono, cujos vértices correspondem aos resultados obtidos na análise. Dessa forma, o hexágono correspondente a cada livro situa-se entre dois hexágonos extremos, um de área mínima e outro de área máxima, possibilitando visualizar suas características com relação ao referencial estabelecido. Basicamente, o hexágono de maior área corresponde à apresentação do Cálculo em construção, e aquele de menor área representa a revelação do Cálculo, enquanto um todo sistematizado, logicamente estruturado, numa abordagem típica dos textos de Análise Real.

Assim sendo, em primeiro lugar, verificamos que os hexágonos obtidos têm maior área conforme a maior adequação ao curso introdutório de Cálculo Diferencial e Integral, segundo o paradigma elaborado a partir das idéias de Brousseau. Isto significa que suas propostas privilegiam a recontextualização e repersonalização, a negociação dos significados e, finalmente, a redescontextualização e a redespersonalização, buscando assim apresentar o Cálculo Diferencial e Integral em construção. É o caso, por exemplo de: 


\section{Bartkovich et alii}

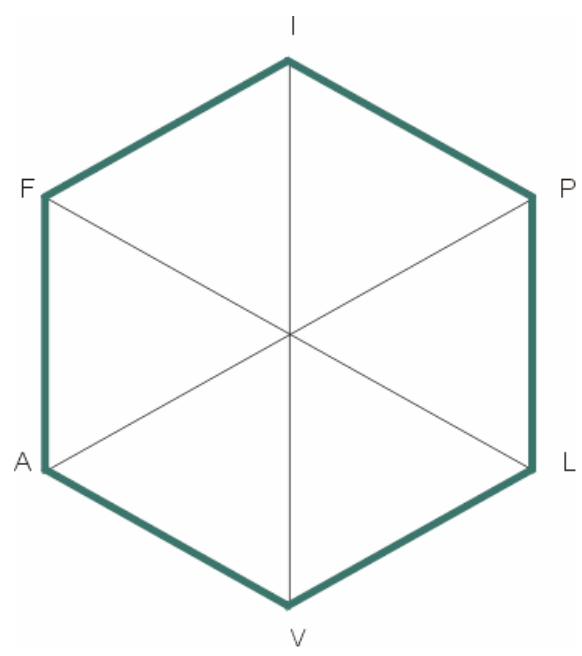

Figura 36: Representação hexagonal para Bartkovich et alii

\section{Bruckheimer et alii}

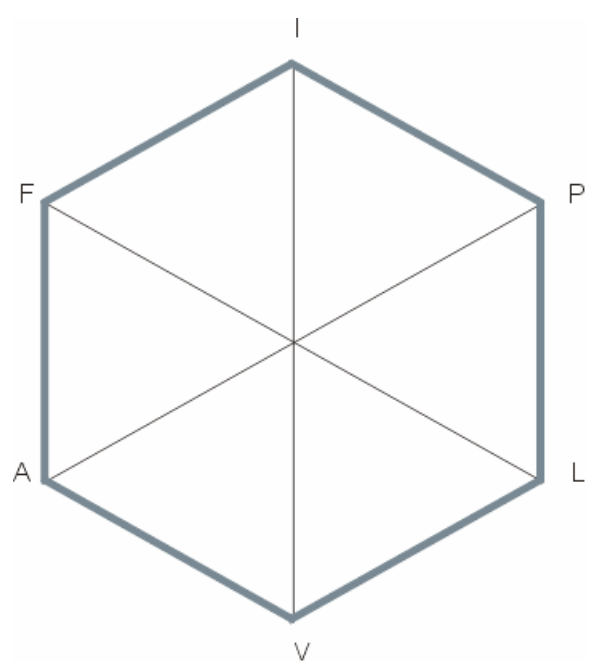

Figura 37: Representação hexagonal para Bruckheimer et alii 


\section{Greenspan / Benney}

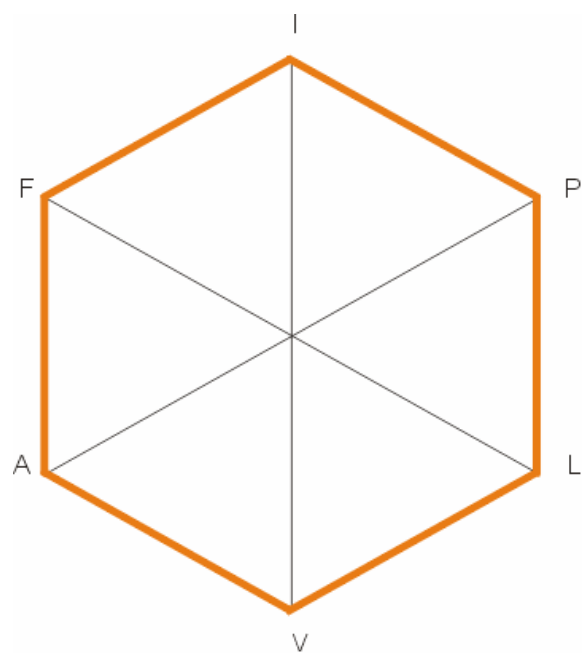

Figura 38: Representação hexagonal para Greenspan / Benney

Por outro lado, observamos que os hexágonos de área mínima correspondem aos livros escritos para um curso de Análise Real. É o caso, por exemplo, de:

\section{Apostol (Análise)}

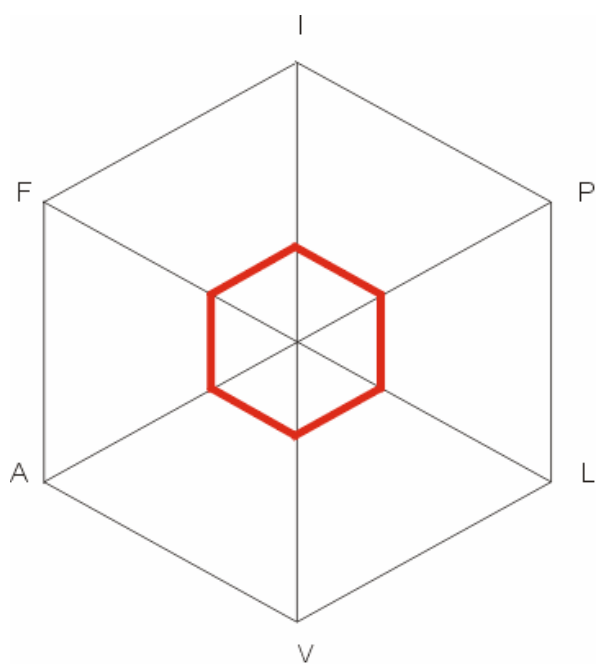

Figura 39: Representação hexagonal para Apostol (Análise) 


\section{Rudin}

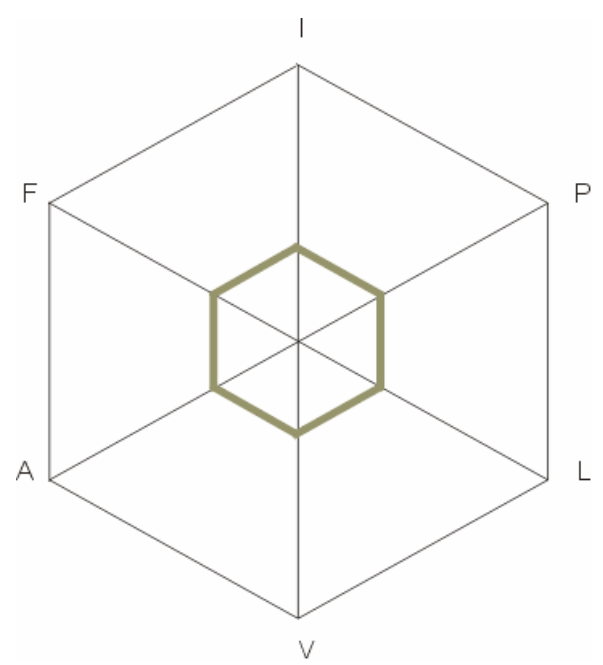

Figura 40: Representação hexagonal para Rudin

Nesse sentido, um hexágono com área pequena, próxima da área mínima, significa que a proposta do autor está mais próxima de uma revelação do Cálculo Diferencial e Integral sistematizado, logicamente estruturado.

Embora os livros sejam evidentemente interessantes, a configuração hexagonal obtida significa tão somente que a proposta dos autores não é muito adequada ao curso inicial de Cálculo segundo o paradigma elaborado, por estar mais próxima da configuração observada para um livro de Análise Real. É o caso, por exemplo de: 


\section{Spivak}

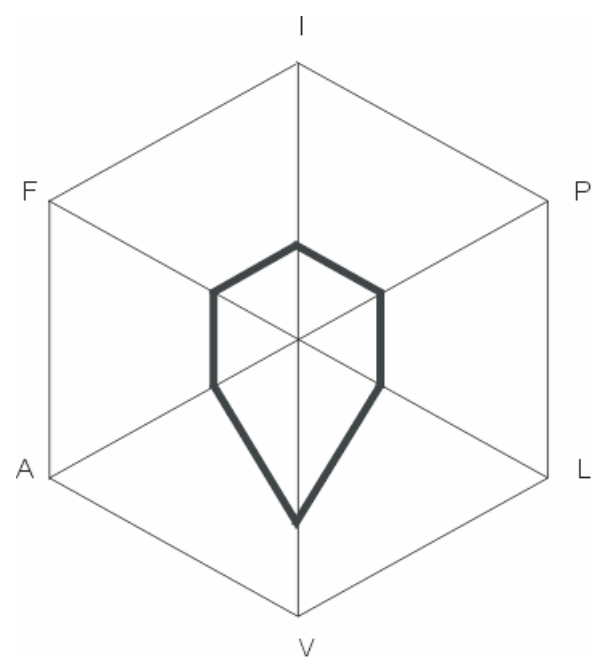

Figura 41: Representação hexagonal para Spivak

\section{White}

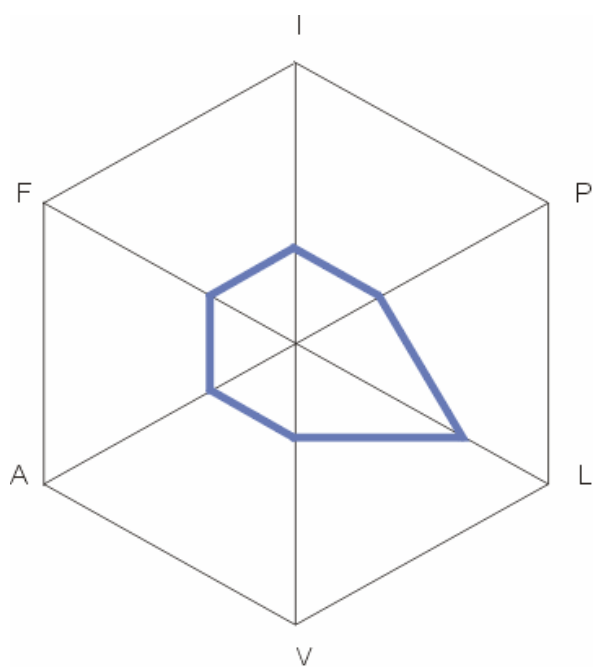

Figura 42: Representação hexagonal para White

Nestas duas representações verificamos que os hexágonos possuem mesma área, mas significam enfoques diferentes; no caso de Spivak, observamos que a visualização é privilegiada, enquanto que White demonstra maior preocupação com a linguagem. 
De modo geral, os hexágonos que não têm área mínima, nem máxima, apresentam vértices mais distantes do centro na região dos vértices $V$ e $L$, mostrando uma preocupação com a questão da negociação dos significados, no sentido da visualização e da linguagem. É o caso, por exemplo, dos textos de:

\section{Boulos}

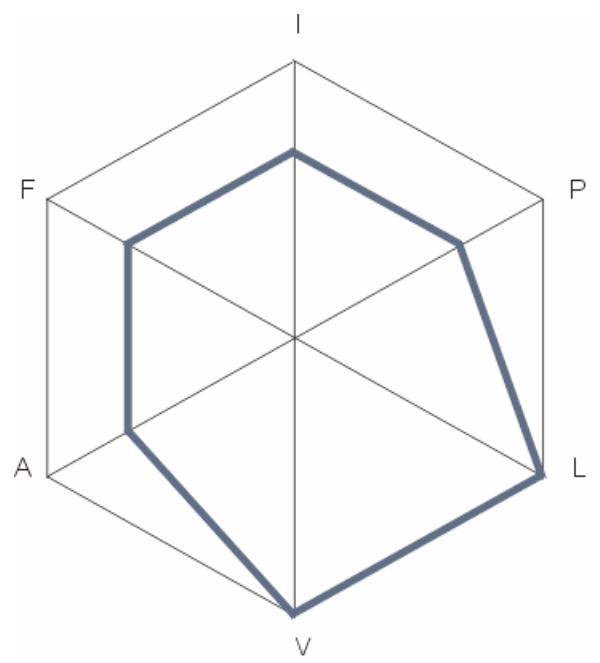

Figura 43: Representação hexagonal para Boulos

\section{Kaplan}

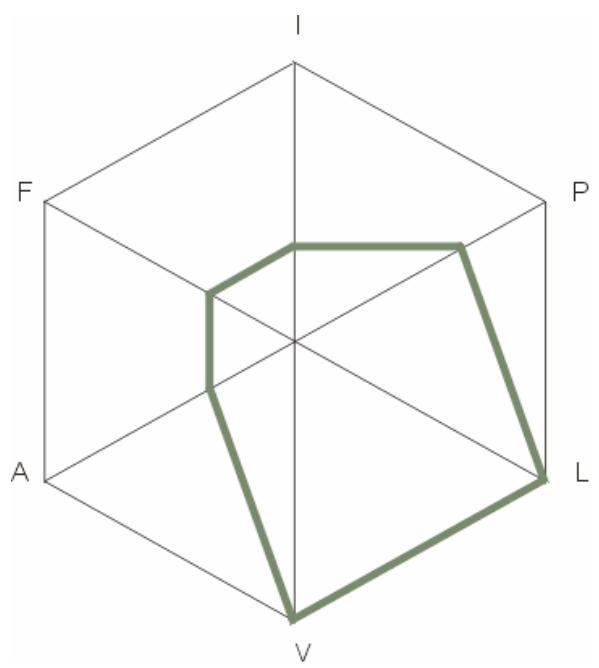

Figura 44: Representação hexagonal para Kaplan 


\section{Lang}

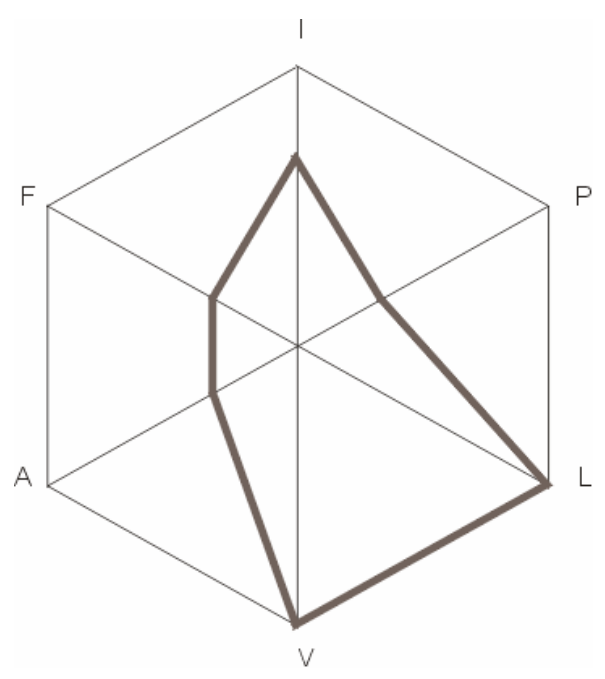

Figura 45: Representação hexagonal para Lang

Este fato, digno de nota, demonstra uma tendência desses autores, bem como de outros, para os quais a configuração hexagonal apresenta uma área inclusive maior. É o caso de:

\section{Apostol (Cálculo)}

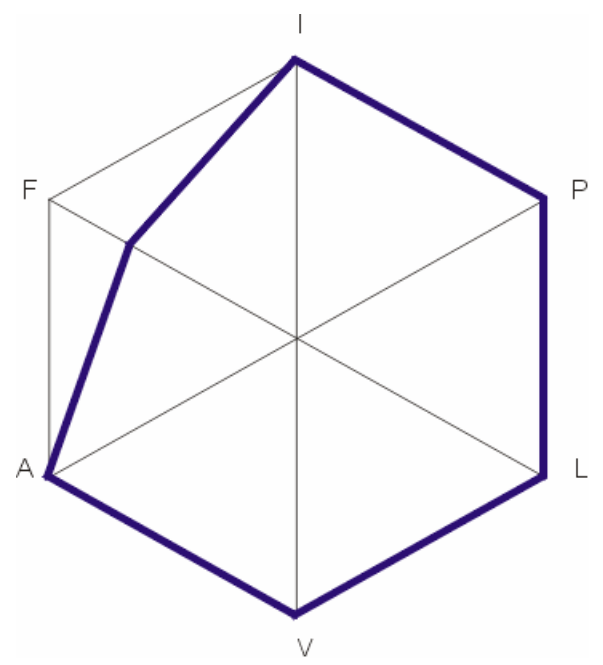

Figura 46: Representação hexagonal para Apostol (Cálculo) 


\section{Courant}

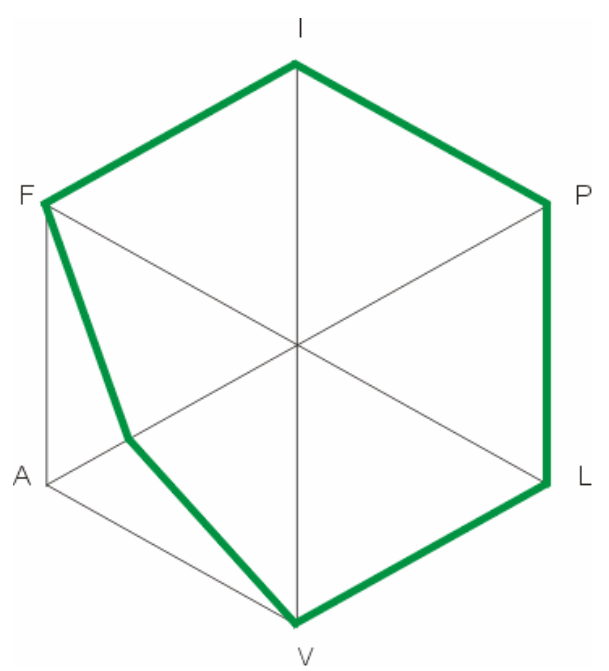

Figura 47: Representação hexagonal para Courant

\section{Courant / John}

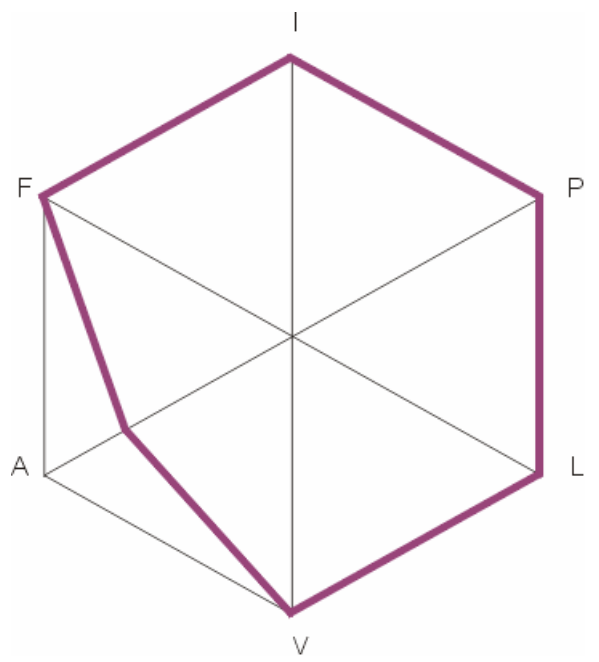

Figura 48: Representação hexagonal para Courant / John 


\section{Willcox et alii}

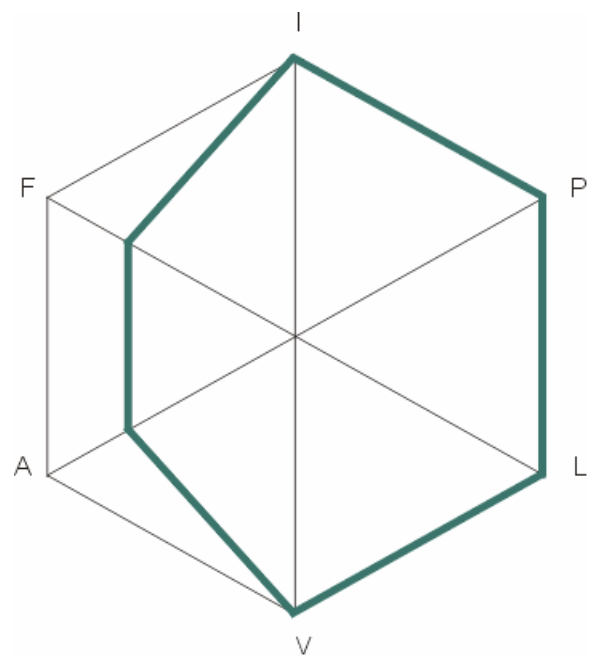

Figura 49: Representação hexagonal para Willcox et alii

A questão de privilegiar a negociação de significados mostrou ser uma preocupação marcante na grande maioria dos textos analisados. De fato, construindo os hexágonos correspondentes, observamos claramente esse fato:

\section{Kaplan / Lewis}

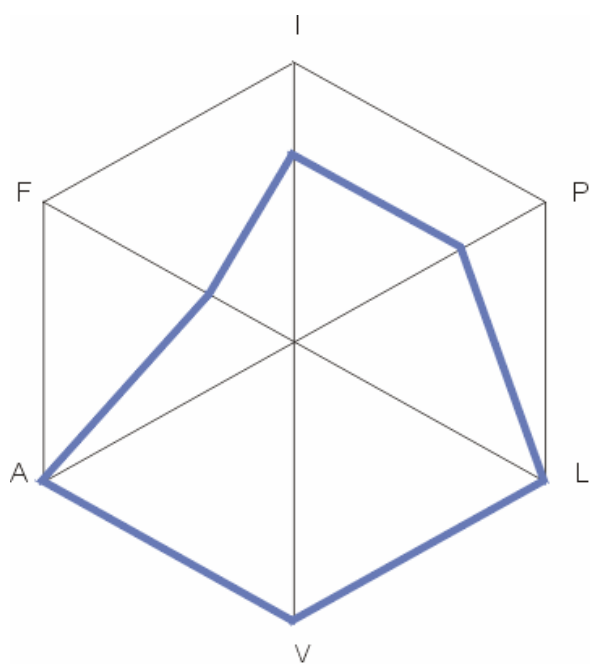

Figura 50: Representação hexagonal para Kaplan / Lewis 


\section{Alexander at alii}

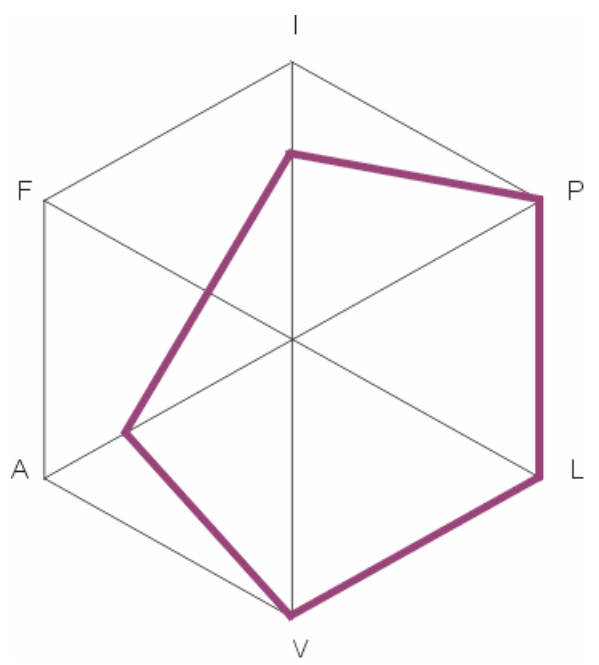

Figura 51: Representação hexagonal para Alexander at alii

\section{Simmons}

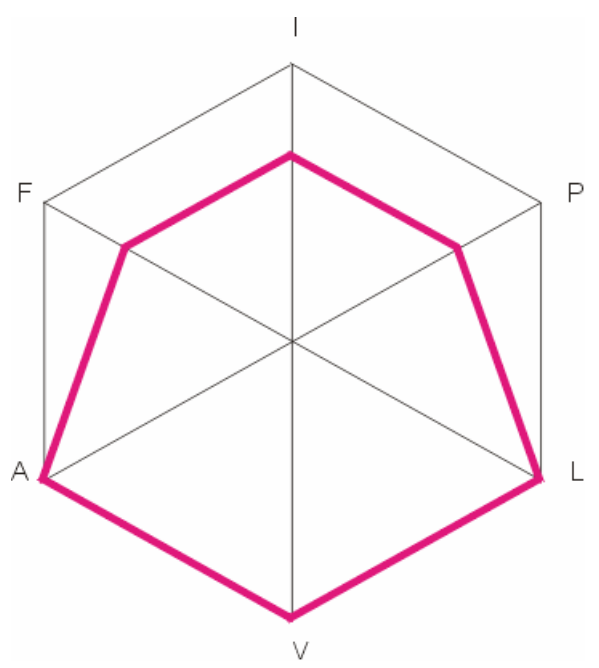

Figura 52: Representação hexagonal para Simmons 


\section{Swokowski}

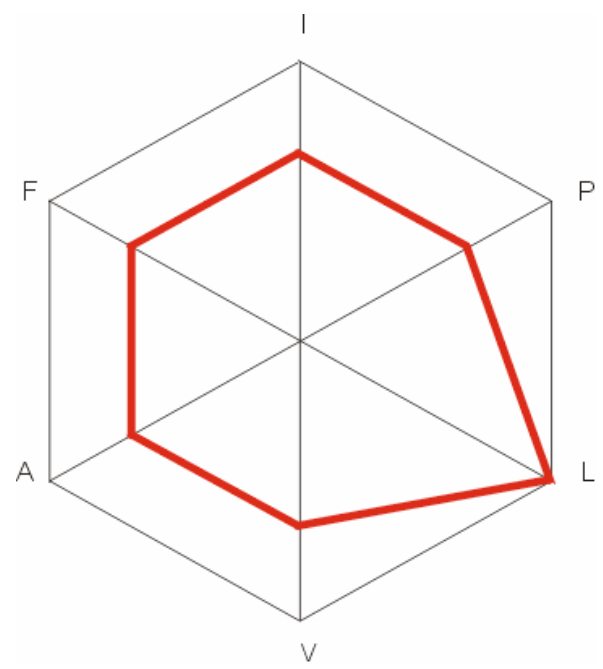

Figura 53: Representação hexagonal para Swokowski

\section{Ávila}

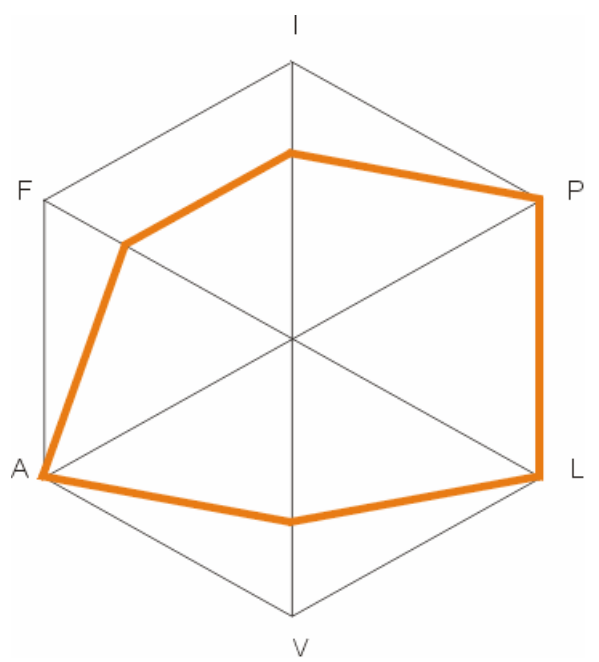

Figura 54: Representação hexagonal para Ávila 
Outra questão importante, que pode ser facilmente observada, é que os hexágonos, em geral, não apresentam vértices alternados mais distantes do centro, mostrando um certo equilíbrio em todas as propostas analisadas.

\section{Buck}

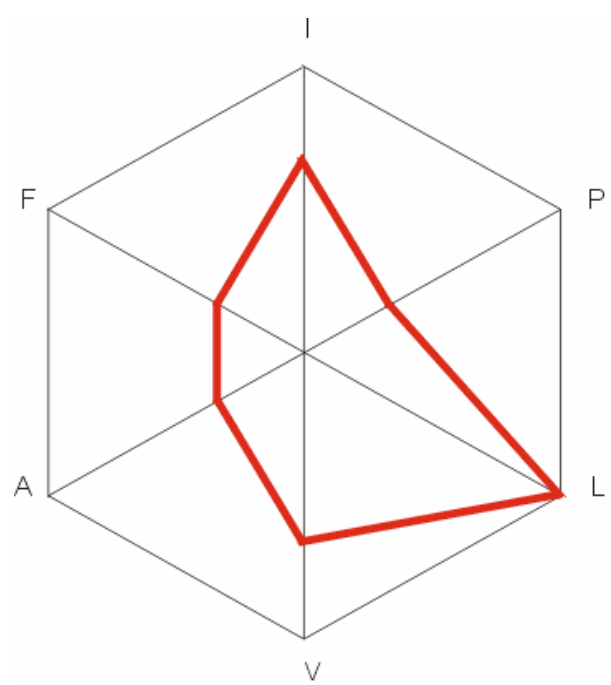

Figura 55: Representação hexagonal para Buck

\section{Guidorizzi}

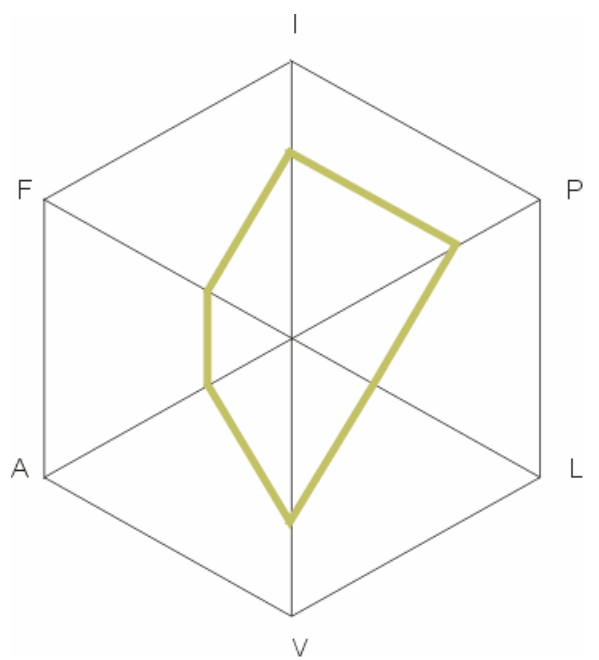

Figura 56: Representação hexagonal para Guidorizzi 


\section{Leithold}

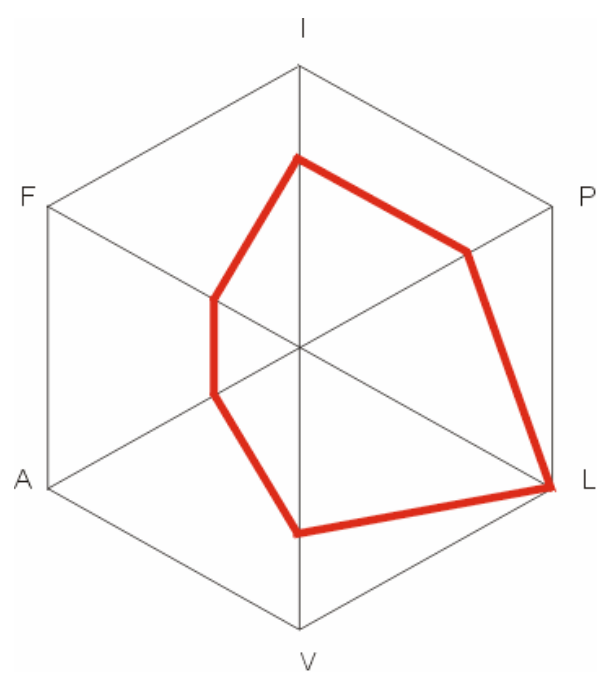

Figura 57: Representação hexagonal para Leithold

\section{Moise}

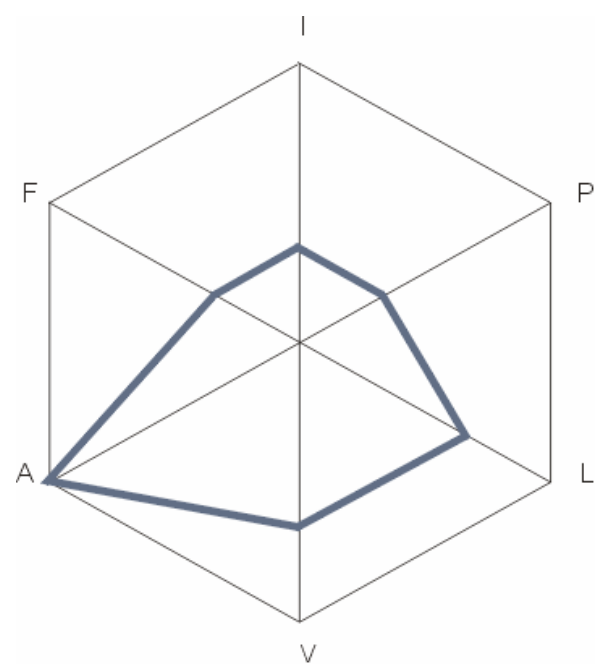

Figura 58: Representação hexagonal para Moise 
Por fim, encontramos um texto que não privilegiou nenhum dos critérios selecionados. É o caso de

\section{Piskounov}

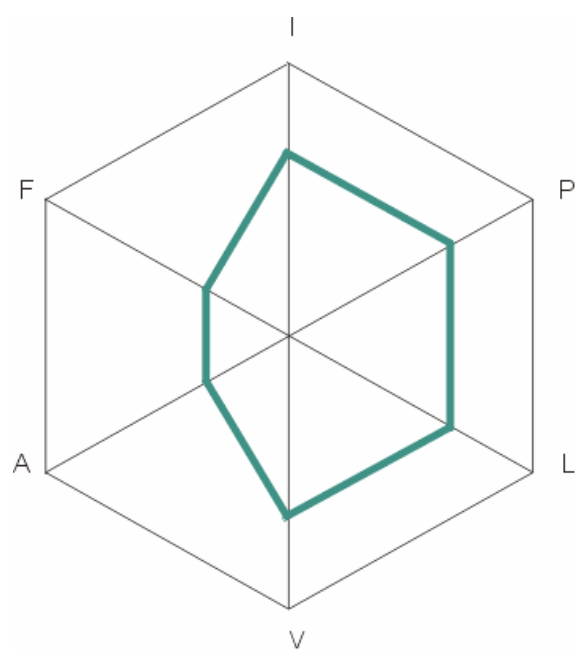

Figura 59: Representação hexagonal para Piskounov

Assim, o que podemos concluir é que os livros selecionados apresentam todos propostas que são válidas e que podem ser apreciadas dentro de determinado contexto. A utilização do livro didático, conforme os critérios do professor, poderá ser um instrumento mais ou menos facilitador do processo de ensino/aprendizagem do Cálculo, no sentido de propiciar maior ou menor vivência dos significados que podem otimizar a construção do conhecimento. 


\section{Capítulo 5. Comentários Finais e Perspectivas}

\subsection{0 conhecimento significativo}

Ao ingressar na Universidade, os alunos, em muitos cursos, defrontam-se com o Cálculo, como curso básico, pré-requisito para vários outros, e onde esperam conseguir integrar a matemática com a qual trabalharam na escola média. Mas, sendo Cálculo uma disciplina com tal importância e que, mesmo entre os alunos, possui um status elevado, por que razão gera tantos problemas e provoca tanta frustração, tanto do ponto de vista dos professores como dos estudantes?

Em primeiro lugar, é conveniente esclarecer que, embora alguns textos, dirigidos à escola média, apresentem tópicos relativos aos rudimentos do Cálculo, normalmente, o assunto não é tratado nesse período, sequer superficialmente.

$\mathrm{Na}$ escola média, os alunos trabalharam alguns conceitos matemáticos, muitas vezes de maneira isolada, com, na melhor das hipóteses, um enfoque significativo, e apesar dos professores da Universidade esperarem haver domínio de algumas técnicas operatórias, normalmente a linguagem lógicoformal não está satisfatoriamente estabelecida. A Matemática com a qual os estudantes trabalharam, na maioria das vezes, permaneceu no âmbito da intuição, com algum aspecto voltado, talvez, para o prazer da descoberta. Nesse sentido, o conhecimento matemático não foi estabelecido como um todo articulado, logicamente estruturado. 
De fato, não podemos esquecer, por exemplo, que o conteúdo da Geometria Euclidiana era trabalhado, durante alguns anos da escola fundamental, através de uma grande relação de postulados, definições, propriedades, lemas e teoremas. As demonstrações necessárias eram efetuadas, principalmente para tornar explícito o caráter dedutivo da Geometria, embora não houvesse garantia alguma de convencimento. Nesse contexto, os alunos começavam a formar algumas idéias, e, não muito mais do que isso, a respeito do que pudesse vir a ser uma teoria dedutiva, pois o trabalho com o conteúdo da Geometria, logicamente estruturado, constituía, normalmente, uma simples revelação. Aquilo que ficava claro para os estudantes era a existência de um certo tipo de linguagem e talvez de algumas propriedades das figuras geométricas. Nada disso, entretanto, garantia aprendizagem significativa e, por isso mesmo, precisou ser revisto. Uma vez que o esquema anterior era ineficiente, ao se pensar em conhecimento construído significativamente, a Geometria passou a ser tratada de maneira muito diferente. Normalmente, o tratamento lógico-formal dedutivo foi sendo atenuado, buscando mais o convencimento através de verificações, deixando, muitas vezes de lado, as demonstrações rigorosas.

A busca de um tratamento mais adequado certamente propiciou melhoria no ensino/aprendizagem daquele conteúdo específico, mas teve conseqüências importantes no ensino universitário. Enquanto no caso da Geometria percebeuse que a estrutura lógico-formal não era condição necessária, nem suficiente, para garantir a compreensão, o mesmo não aconteceu, por exemplo, no curso de Cálculo. De fato, em muitos cursos, observamos a estrutura logicamente sistematizada, com o intuito principal de apresentar uma teoria lógico-formal dedutiva; entretanto, dessa maneira, as idéias deixaram de ter o merecido destaque.

Para os alunos, essa perspectiva não tem sentido, ainda mais se pensarmos quantos deles, que freqüentam o curso de Cálculo, sequer 
enveredarão pelo caminho da matemática pura. Mesmo para esses, num curso inicial de Cálculo, não faz sentido centrar o enfoque num universo rigoroso e distante, onde não conseguem exercer qualquer tipo de crítica.

Nessa abordagem, a coerência e a justificação através de prova, apesar de perfeitas, não fornecem estímulo suficiente para a grande maioria dos alunos, pois para eles não fica de modo algum claro a razão pela qual certas afirmações são importantes, precisam ou não ser demonstradas, e assim por diante. Os recursos utilizados são internalistas; há uma coerência sintática, com pouca preocupação semântica. Por estarmos pensando em alunos recém-egressos da escola média, que, normalmente, nesse estágio, não trabalharam sequer os rudimentos do Cálculo, a rede conceitual, individual e coletivamente falando, não permite o estabelecimento de vínculos com um teoria que, primordialmente, busca articulação através da lógica interna.

Com efeito,

Every branch of knowledge is a collection of ideas described by means of words and symbols and one cannot understand these ideas unless one knows the exact meanings of the words and symbols that are used. (Apostol, 1962, p.8) ${ }^{39}$

Cada vez mais, o conhecimento a ser buscado precisa ser significativo e importante. Felizmente, não é mais suficiente a visão dogmática de que determinados assuntos são importantes para a formação dos indivíduos. Eles, os estudantes, precisam perceber a importância, na medida em que percebem a possibilidade de resolver problemas reais, importantes e seus!

Considerando a expectativa das teorias pedagógicas atuais, no sentido de que o conhecimento seja construído pelos estudantes, não podemos esperar que a apresentação do conhecimento estruturado, corretamente lógico, seja

\footnotetext{
39 Todo ramo de conhecimento é uma coleção de idéias descritas através de palavras e símbolos e alguém só pode compreender essas idéias se souber exatamente qual o significado das palavras e dos símbolos utilizados.
} 
suficiente para garantir a aprendizagem, no sentido de apropriação por parte do aluno.

Enfocando o Cálculo sistematizado, como um ramo do conhecimento, temos, diante de nós, uma sucessão de conceitos, propriedades, técnicas operatórias, com inúmeras aplicações práticas. Trata-se, sem dúvida, de um todo logicamente bem estruturado, formalmente correto. Entretanto, o quanto é importante para os estudantes, o quanto é significativo?

David M. Bressoud, do Department of Mathematics, Penn State University, referindo-se ao curso de Cálculo, afirma que:

(...) this course is not adequate as it stands. Our students approach calculus with a mixture of trepidation and anticipation. They know that it is going to be hard, but they also expect that this will be the course that draws together the mathematics that they have learned and transforms it into an instrument for comprehending the world around us. We know that this tool exists, but our students usually miss it. They leave disillusioned and disappointed. (Bressoud, 1991) ${ }^{40}$

O mesmo Professor Bressoud nos esclarece a respeito da importância do Cálculo, afirmando que:

The first is that Calculus is used in a variety of contexts by many disciplines. If we mathematicians did not teach it, others will have to. (...) Physicists, engineers, and biologists are being brought into our discussion of calculus reform. Textbooks are using real applications, and there is now rich source material. Our use of this material is often faulty - too frequently it is tacked on rather incorporated into the motivation for the concept it is to convey - but there is effort and progress in reforming calculus in this direction.

But the usefulness of Calculus is not a sufficient answer to my question. There are topics from discrete mathematics - statistical

\footnotetext{
${ }^{40}$ (...) este curso não é adequado, da maneira como se apresenta. Nossos estudantes aproximam-se do Cálculo com um misto de trepidação e antecipação. Eles sabem que será difícil, mas também esperam que será o curso que unificará a matemática que estudaram e a transformará num instrumento para explicar o mundo que nos rodeia. Sabemos que essa ferramenta existe, mas nossos estudantes normalmente não o percebem. Eles saem desiludidos e desapontados.
} 
analysis, linear programming - that are far more useful to most of our students. My second answer, the one that has radical consequences for the way we teach Calculus, is that Calculus lies at the foundation of our scientific world view. Modern scientific thought has been formed from the concepts of Calculus and is meaningless outside this context. When I speak of science, I do not restrict myself to other disciplines. In a very significant respect, mathematics it self came into being with the development of Calculus. (id., 1991) ${ }^{41}$

O fato de outras disciplinas e outros profissionais necessitarem das ferramentas do Cálculo, e existirem tantos problemas onde o Cálculo é indispensável, poderia ser o grande motor para propiciar uma integração real e interdisciplinar trazendo à tona toda a potência e grandeza do Cálculo. Sair-se-ia do contexto lógico-formal rigoroso, onde a matemática domina, e entrar-se-ia num contexto onde a realidade, com seus problemas fundamentais é o mais importante.

Como vimos, no contexto de rede de conhecimentos e significados, onde conhecer algo é conhecer seu significado, construindo nós e estabelecendo relações, percebemos o quão fundamental é a questão dos significados. O significado de algum objeto, indivíduo, entidade, e assim por diante, é o conjunto de tudo o que se diz ou se pode dizer a respeito desse objeto, indivíduo, entidade. Nesse sentido, negociar significados é falar sobre, mostrar representações de, exibir metáforas extremamente úteis para a transferência de relações que existem entre o conhecido e o novo. Para negociar significados e estabelecer relações não basta pois, apresentar uma sucessão de definições e

\footnotetext{
41 O primeiro motivo pelo qual ensinamos Cálculo é que ele é usado numa variedade de contextos e em várias disciplinas. Se nós matemáticos não o ensinarmos, outros o farão.(...) Físicos, engenheiros, biólogos têm sido admitidos nas discussões sobre as reformas do Cálculo. Os textos utilizam aplicações reais e existe atualmente uma fonte de material muito rica. A nossa utilização desse material, muitas vezes, é falha - com freqüência é postergada em lugar de ser incorporada na motivação para o conceito que se quer introduzir.

Entretanto, a utilidade do Cálculo não é um motivo suficiente para a minha questão. Existem tópicos da matemática discreta - análise estatística, programação linear, - que são muito mais úteis para nossos estudantes. Minha segunda resposta, aquela que tem conseqüências radicais sobre o porquê ensinamos Cálculo, é que o Cálculo se encontra nos fundamentos da nossa visão de mundo científico. O pensamento científico moderno foi formado a partir dos conceitos do Cálculo e não tem sentido fora desse contexto. Quando falo de ciência não me restrinjo a outras disciplinas. Numa maneira muito significativa a própria matemática passou a ser encarada dessa forma, com o desenvolvimento do Cálculo.
} 
propriedades, formalmente corretas, coerentemente articuladas, inseridas no contexto; muito mais é preciso.

É uma triste ilusão imaginar que os alunos ingressantes estão aptos a trabalhar num curso inicial de Cálculo estruturado como uma série de definições, propriedades, teoremas, e pretender que isso seja significativo. Nesse caso, lamentavelmente, muitos deles são apenas receptáculos de uma série de resultados nos quais acreditam porque alguém, detentor do conhecimento, afirmou. O máximo que poderão fazer é repetir conceitos que guardaram na memória episódica, procurando reproduzi-los da mesma maneira que lhes foram transmitidos, ou resolver problemas semelhantes aos que viram serem resolvidos, aplicando técnicas que, de tanto repetir, conseguiram razoavelmente memorizar.

Não há como tornar diferente o processo se não se perceber a importância do significado. Essa questão é fundamental, como já salientamos antes. Algo faz sentido ou tem sentido para o indivíduo se ele é capaz de articulá-lo à sua rede, caso contrário fica solto e se perde. O significado de alguma coisa existe para o sujeito não porque alguém assim o determinou ou desejou, mas porque é importante para ele, resolve um problema que é dele, e que o desafiou.

Voltando à citação de Apostol, à página 150, no caso do Cálculo, além da coleção de idéias, extremamente férteis, temos um conjunto de palavras específicas e símbolos correspondentes, sendo que o todo se constitui num mundo novo para os estudantes. Temerária é a redução, infelizmente comum, às palavras, símbolos e técnicas operatórias, imaginando que as idéias brotarão por si só.

A negociação de significados, para viabilizar a aprendizagem significativa por parte dos alunos, pode ocorrer de várias maneiras. O uso da língua materna tem a grande e evidente vantagem de estar mais próxima dos alunos do que a 
linguagem matemática, ainda mais se esta for utilizada de maneira predominante, o tempo todo. Através da linguagem corrente é possível falar muito mais sobre os objetos, estabelecer relações entre eles, construir metáforas e analogias, articulando o desconhecido com o já estabelecido. De fato,

\begin{abstract}
Os efeitos metafóricos - metáfora aqui entendida etimologicamente como "transferência" - são a base da constituição do significar já que este movimento (a transferência) é que permite que o sujeito, no deslizamento próprio dos sentidos, inscreva-se nos processos discursivos, filiando-se a redes de memória ao mesmo tempo em que se desloca. (Orlandi, 1997, p. 33)
\end{abstract}

As ilustrações sempre possibilitam melhor visibilidade e os argumentos geométricos normalmente são mais aceitos do que os argumentos puramente lógicos. Representações visuais são muito frutíferas, como é o caso do software canadense, de 1988: Le laboratoire mathématique: La dérivée et l'intégrale, de autoria de Wedad Antonius, que tem vantagens didáticas impressionantes. Não podemos esquecer que

A mensagem visual pode apresentar em seu aspecto global um forte grau de iconicidade sem por isso deixar de incluir em si relações lógicas mais ou menos sistematizáveis. (...) Freqüentemente, refletir sobre a imagem não consiste em produzir imagens, mas sim em produzir palavras. (Metz, 1974, p.16)

A colocação inicial de problemas interessantes e desafiadores é extremamente útil para poder semear as idéias sobre a fertilidade e utilidade do assunto, e, conseqüentemente, torná-lo significativo.

Assim, para possibilitar a construção compartilhada do conhecimento, fazse necessário recontextualizar o conhecimento desejável de tal modo que ele seja necessário para a solução de determinada situação-problema, que seja desafiadora e interessante. A figura do professor é, nesse instante, 
absolutamente necessária, pois apenas ele tem a capacidade de encontrar problemas adequados, pertinentes e compatíveis com o grupo de seus alunos. $\mathrm{O}$ professor precisa definir assim o seu projeto para viabilizar a construção do conhecimento desejado.

A elaboração de um projeto de resolução por parte dos alunos necessita certamente da orientação e da ajuda do professor. Essa capacidade de negociar, dirigir e propiciar a escolha dos caminhos mais consistentes e eficientes é algo que precisa ser uma característica pessoal do professor. Sua própria visão de como, historicamente, o conhecimento matemático foi sendo construído, através de quais avanços e recuos, é essencial. De fato, na sala de aula, o movimento dos pensamentos dos alunos, coletivamente falando, repete aquilo que foi, desde sempre, o processo de construção do conhecimento matemático cultural.

As diversas etapas de resolução para o sucesso do projeto elaborado, são respostas aos diferentes questionamentos formulados tanto pelo professor como pelos alunos. Normalmente, é interessante surgirem perguntas dos próprios alunos, mas a formulação de questões sempre é um instrumento que o professor pode utilizar para instigar a curiosidade e desafiar o grupo todo.

Cada problema resolvido, ou cada etapa de um problema maior, deve significar a construção de algum nó, isto é, a interseção de um feixe de relações estabelecidas entre nós já existentes na rede, individual ou coletivamente considerada.

A produção do novo conhecimento, entretanto, necessita passar por um novo processo de descontextualização e despersonalização para que os alunos percebam que, embora tenham resolvido um problema local, o novo conhecimento poderá ser utilizado em outras situações, para resolver novos problemas. Esse processo mostra a necessidade de formalização na matemática, e para tanto a ajuda do professor é novamente imprescindível. 
Nesse novo estágio, os alunos terão construído conhecimento matemático, num processo que, em certo sentido é comparável ao que o matemático profissional realiza normalmente.

\subsection{A abordagem que respeita a gênese das idéias e a abordagem lógico- formal}

Quando examinamos a história do Cálculo Diferencial e Integral percebemos que sua organização é fruto do trabalho de diversos pensadores, filósofos e matemáticos, e que a poderosa ferramenta sistematizada demandou mais de vinte séculos para chegar à formulação atual. As origens do Cálculo, e da Matemática, de modo geral, podem ser encontradas

\footnotetext{
(...) em três matemáticos que se destacaram a grande distância dos demais da época, assim como da maior parte de seus predecessores e sucessores. Esses homens foram Euclides, Arquimedes e Apolônio; é por causa da obra deles que o período de cerca de 300 a 200 A C foi denominado "Idade Áurea" da matemática grega. (Boyer, 1974, p.104)
}

Nos vinte séculos subseqüentes, pudemos constatar o enorme avanço realizado na compreensão de diversos fenômenos que regem o Universo, e, em particular, de muitos modelos matemáticos que explicam esses mesmos fenômenos. E, apesar das profícuas descobertas e explicações, a humanidade continua buscando respostas para um sem número de perguntas. Nestes tempos de desterritorialização, de inúmeras possibilidades e perspectivas, com o acesso cada vez mais rápido a uma quantidade de informações cada vez maior, os grandes objetivos ainda estão voltados para a busca da satisfação e compreensão plenas. Segundo Machado, 
(...) muitas transformações estruturais encontram-se em curso, (...) a transformação mais marcante, sem dúvida, é a emergência do conhecimento como o principal fator de produção. (Machado, 1997, p.16)

O fato, extremamente relevante, que pode ser observado desde os primórdios da história da humanidade, é que a existência de problemas, questionamentos vários, sempre estimularam a curiosidade e o pensamento humano, pois as soluções ou respostas eram importantes, muitas vezes essenciais. Conforme a concepção vigente, satisfatória, mas não definitiva, as preocupações se modificavam, se tornavam restritas ou ampliadas, mas nunca deixaram de existir.

O problema, sem dúvida, sempre foi um desafio e a sua solução podia demorar muito tempo. Entretanto, a forte motivação provocava o germinar das idéias que podiam desabrochar e frutificar séculos depois. A curiosidade humana e a necessidade de entender o funcionamento do Universo, respondendo a um número ilimitado de perguntas sempre se constituíram num motor que impulsionou um sem número de descobertas. Muitas vezes, ocorreram períodos de estagnação, onde as explicações encontradas eram satisfatórias, e assim permaneceram por um longo período. Entretanto, algum fato novo, sempre acaba gerando uma situação incômoda, não resolvida. Para Polya,

\footnotetext{
Uma grande descoberta resolve um grande problema, mas há sempre uma pitada de descoberta na resolução de qualquer problema. 0 problema pode ser modesto, mas se ele desafiar a curiosidade e puser em jogo as faculdades inventivas, quem o resolver por seus próprios meios, experimentará a tensão e gozará o triunfo da descoberta. (Polya, 1986, p.V)
}

Ao olhar para o Cálculo, numa perspectiva histórica, temos um caminho que nos revela a gênese das idéias e que nos estimula a propor ou criar problemas para buscar soluções. Não se trata, evidentemente, de começar tudo 
de novo, mas de perceber que a existência de problemas importantes é um fator ímpar de motivação e estímulo ao interesse. Através de problemas é possível semear as idéias do Cálculo, e tornar significativas as construções conceituais que se realizam no seu interior. Entretanto,

(...) a significação produzida requer do interlocutor uma espécie de raciocínio que, num caso, baseado no próprio enunciado, e no outro, baseado na fala do locutor, o leve a estes modos de compreensão dos enunciados. Neste sentido, porque para chegar a esta significação é preciso recorrer à situação de discurso em que se encontram os interlocutores, é que podemos, por oposição a formas de significação logicamente necessárias, falar em formas de significação historicamente necessárias. Em outras palavras, enquanto o sentido, a significação explícita, de um enunciado é dado por uma espécie de razão lógica, a sua significação implícita se produz a partir de uma espécie de razão histórica. (Vogt, 1977, p.30)

A metamorfose da rede é a porta aberta para justificar a abordagem histórica. As relações são historicamente situadas e a história mostra como as relações surgiram e, muitas vezes, caducaram.

A abordagem realizada pelos diferentes autores dos livros selecionados pode ser comparada com dois paradigmas existentes, quais sejam, a abordagem que respeita a seqüência na qual o Cálculo foi construído e aquela estabelecida no Cálculo organizado e sistematizado na perspectiva lógicoformal.

A abordagem que respeita a história organiza os assuntos numa seqüência onde encontramos a gênese das idéias, em como os conceitos foram significativamente construídos, como respostas a problemas enfrentados pelos homens ao longo de mais de vinte séculos. Nesse sentido, observamos a seguinte seqüência: 
- Integração através de problemas envolvendo área (quadratura), volume (cubatura), comprimento de arco (retificação)

- Diferenciação através de problemas de tangentes, valores extremos, normais e curvatura

- Unificação através do Teorema Fundamental do Cálculo

- Equações Diferenciais Ordinárias

- Desenvolvimento de notações e símbolos

- Conceito de função

- O conceito de quantidades infinitamente pequenas, indivisíveis e quantidades divisíveis ad infinitum

- O abandono eventual dos infinitésimos e a determinação do conceito de limite como conceito fundamental do Cálculo

- Os números reais

Segundo a perspectiva lógico-formal, a seqüência estabelecida é:

- Os números reais

- Funções elementares

- Limites

- Diferenciação

- Estudo detalhado de funções de uma variável real 
- Integração

- Teorema Fundamental do Cálculo

- Equações Diferenciais Ordinárias

No gráfico a seguir, representamos as duas diferentes abordagens, histórica e lógico-formal, e podemos observar como elas estão distantes.

$\mathrm{Na}$ legenda, a seqüência 1 representa a abordagem histórica e a seqüência 2 representa a abordagem lógico-formal. A seqüência de passos colocada é a da abordagem histórica.

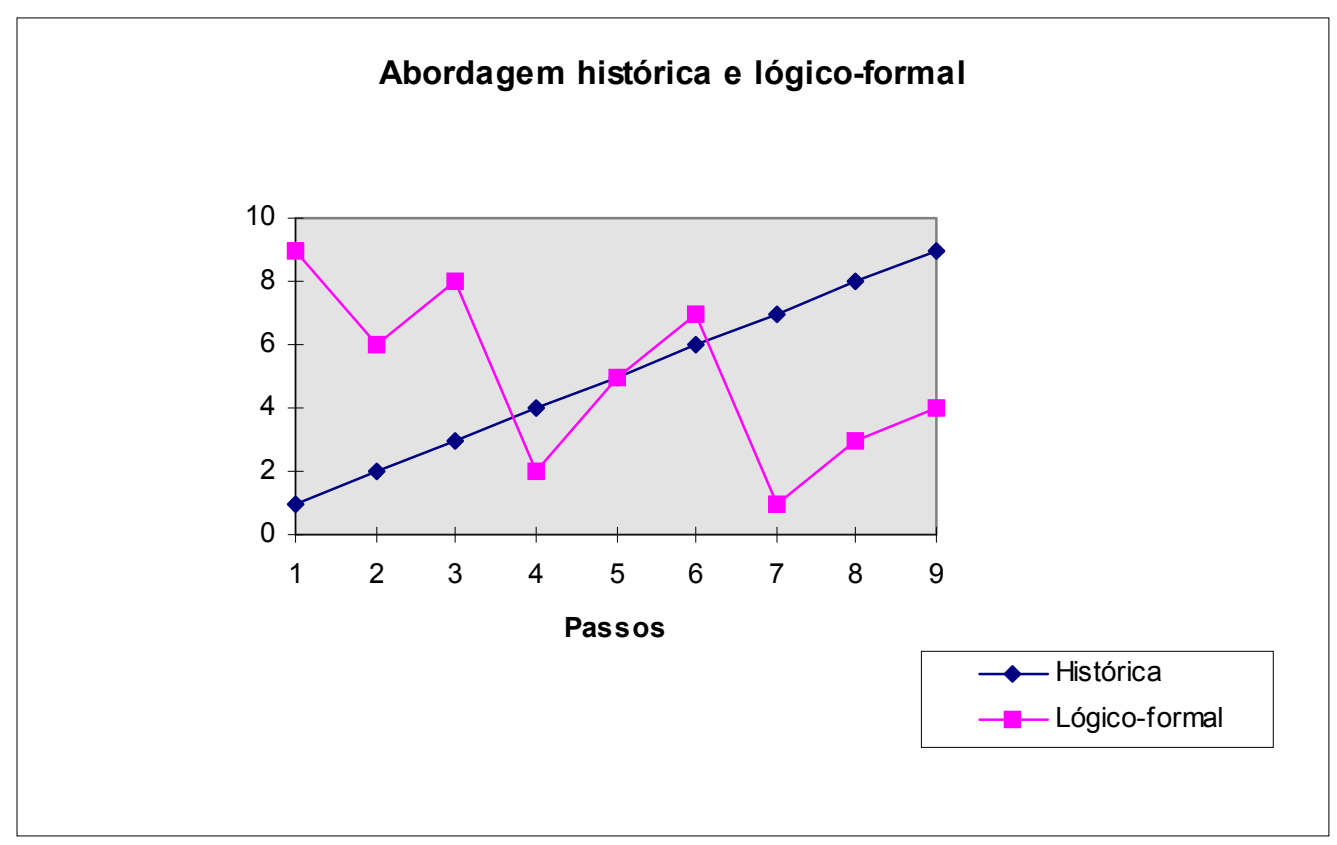

Figura 60: A abordagem que respeita a gênese das idéias e a abordagem lógico-formal 
As propostas de um curso de Cálculo, estabelecidas pelos diversos autores selecionados, se situam entre essas duas, que funcionam como paradigmas de concepções muito diferentes, no que se refere à construção do conhecimento.

\title{
5.3 Perspectivas
}

Um dos autores dos livros selecionados, coloca em seu Parágrafo, os seguintes questionamentos fundamentais:

\begin{abstract}
Some candid and critical questions must be raised concerning the present college mathematical curricula. Is calculus presented as an impressive and meaningful intellectual achievement? Can it be said that the subject matter selected meets the real needs of the engineering and scientific community? Or has calculus become almost exclusively an introduction to analysis for that small minority destined for pure mathematics? (Greenspan, 1973, p.x) ${ }^{42}$
\end{abstract}

Nossa pesquisa revela que suas perguntas são extremamente pertinentes, com o agravante considerável que um curso de Cálculo introdutório, que se constitua numa revelação, na qual as idéias ficam encobertas pelo brilho da lógica interna, sequer tem significado para os estudantes que pretendem se encaminhar para o estudo da matemática pura. De fato, as exigências de um curso revelador de Cálculo, onde a dedução e o formalismo são preponderantes, tornando-se um dos aspectos mais importantes

\footnotetext{
42 Algumas perguntas simples, porém cruciais, surgem quando examinamos os currículos universitários de matemática. Será que o cálculo é apresentado como uma realização intelectual imponente e significativa? Será que é possível afirmar que o conteúdo selecionado vai ao encontro das reais necessidades dos engenheiros e da comunidade científica? Ou será que o cálculo se tornou quase que exclusivamente uma introdução à análise para aquela minoria que se destina à matemática pura?
} 
da abordagem realizada, senão o mais importante, não condiz com o nível de maturidade matemática do aluno ingressante na Universidade.

A fim de minimizar o insucesso na construção do conhecimento significativo, a saída, muitas vezes adotada, é a de privilegiar a aplicação do Cálculo, apresentando um grande número de problemas e exercícios, muitas vezes repetitivos, onde o aluno acaba memorizando, de alguma forma, processos de resolução. Nesse sentido, reduz-se a idéia, o conceito, ao algoritmo, e sobra aquela eterna pergunta dos estudantes, não respondida e "odiada" pelos professores: Para que serve isso?

Diante dessa realidade, a pergunta que naturalmente nos fazemos: por que o professor realiza a escolha de determinado livro didático, para suporte de seu curso, quando as possibilidades são tantas?

Pela data da publicação dos textos, observamos que, muitos anos atrás, já existiam livros que apresentavam propostas diferenciadas, onde as idéias e os problemas eram privilegiados, e a lógica interna não era tão preponderante. Esses e outros livros, no mesmo estilo, continuam existindo.

Lembramos Brousseau, segundo quem, para o professor, é grande a tentação de apresentar o conhecimento estabelecido e estruturado, pronto e congelado, sendo que ao aluno cabe a responsabilidade de se apropriar do conhecimento como puder. Nesse sentido, infelizmente, uma abordagem reveladora do Cálculo resolve o problema.

Em contraposição, a Modelagem Matemática nos fornece um caminho para que, através da problematização das idéias, a potência do Cálculo seja exibida e as suas ferramentas se tornem significativas. Segundo Meyer,

(.. ) a inserção cultural e histórica da Matemática a faz especialmente mais rica quando os alunos podem vê-la não como uma região estanque de conhecimentos, mas como uma ferramenta eficiente e 
direta em todas as áreas. Além disso, as assim chamadas "Soluções" matemáticas nem sempre são obtidas ou eleitas com a precisão da teoria: números em forma decimal, raízes obtidas por processos iterativos, funções calculadas com suas expansões polinomiais, todos esse processos tornam as soluções aproximadas, mas suficientemente aproximadas como para garantir uma certa precisão dos resultados apresentados ao final do processo. Se é necessário conviver com essa inexatidão, também é necessário aprender a criticar cada procedimento - e isto os alunos aprendem a fazer. (Meyer, 1998, p.69)

Em Pedagogia do Oprimido, Paulo Freire nos esclarece com a fecundidade de suas palavras:

(...) os homens são seres da práxis. São seres do quefazer, diferentes, por isto mesmo, dos animais, seres do puro fazer. Os animais não "admiram" o mundo. Imergem nele. Os homens, pelo contrário, como seres do quefazer "emergem" dele e, objetivando-o, podem conhecê-lo e transformá-lo com seu trabalho.

(...) Mas se os homens são seres do quefazer é exatamente porque seu fazer é ação e reflexão. É práxis. É transformação do mundo. E, na razão mesma em que o quefazer é práxis, todo fazer do quefazer tem de ter uma teoria que necessariamente o ilumine. O quefazer é teoria e prática. É reflexão e ação. Não pode reduzir-se nem ao verbalismo, nem ao ativismo. (Freire, 1987, p.121)

Esta absoluta clareza da necessidade de ação/reflexão como par indissociável, presente no quefazer humano, nos faz, todo o tempo, pensar num outro par, também inseparável - professor/aluno - onde a existência de significado se constitui na base da própria ação/reflexão. Assim,

Essencialmente, estamos reconhecendo que entre ensinar e aprender não há uma relação de causa e efeito. (...) Sem dúvida, aquele professor que vê passar a informação, ensinar algo, repetir conhecimentos feitos e congelados está com os dias contados. O novo perfil do professor é fundamentalmente o de um facilitador da 
aprendizagem do aluno e de um companheiro na busca do novo.

(D’Ambrosio, 1998, p. 29)

Ao professor oferece-se um campo extremamente rico e diversificado, onde certamente poderá colher inquietações e semear o seu conhecimento. Os frutos que advirão dependem muito de sua sensibilidade e tolerância. Evidentemente, o solo para a semeadura deverá estar regado de questionamentos, e o cultivo adequado das plantas, por vezes rebeldes, irá depender e muito, de sua flexibilidade em variar os métodos para alcançar seus objetivos.

\subsection{As novas tecnologias}

As mudanças ocorridas na maneira de tratar a informação, nas últimas décadas, nos mostram a necessidade premente de tornar a interação com os computadores algo tão natural quanto o foi, em décadas passadas, a manipulação do lápis ou da caneta.

Ao alvorecer do terceiro milênio, as novas tecnologias da informação nos obrigam a olhar para o mundo com novos olhos. Não podemos mais continuar com o mesmo tipo de preocupações que tínhamos no limiar do século XIX.

Tudo ficou mais rápido, mais acessível, mais próximo. O real e o virtual se entrelaçam; nem sempre conseguimos fazer a distinção que, aliás, dependendo, pode mesmo deixar de ser necessária. A rede virtual, podendo interligar todas as pessoas, está se tornando cada vez mais real, presente no dia a dia: digitando alguns poucos símbolos, o acesso às informações pode ser instantâneo. E assim, 
A sociedade da informação coloca novas exigências à sabedoria humana. A sua emergência impõe como importante tarefa educativa tornar os alunos capazes de se mover à vontade no mundo da informação e tirar dele o melhor partido, apreciando a globalidade das suas implicações e intervindo nas grandes opções que terão que fazer a seu respeito.

As novas tecnologias da informação provocam o aparecimento de novos saberes e novas competências, ligadas ao tratamento de informação. É necessário saber onde esta pode ser procurada, e ser capaz de a interpretar, utilizar e avaliar. (Ponte e Canavarro, 1997, p. 23)

A sala de aula não pode ficar alheia a tudo o que está presente na atualidade. Torna-se, em certo sentido, paradoxal, viver no presente, esquecendo das coisas que existem no presente. Deste modo, não podemos mais fazer de conta que o computador não existe.

Para Alvin Toffler, no Seminário Brasil 500: Como se muda um País

\section{Através da Educação:}

Os computadores não podem assumir o lugar dos professores, mas os professores não poderão ensinar sem os computadores. $E$ não estamos falando dos computadores tal qual os conhecemos mas de equipamentos ainda mais complexos. A escola precisa preparar as crianças para realidades que serão muito diferentes do presente e precisa, portanto, simular melhor o futuro.

Utilizando as máquinas para efetuar cálculos muitas vezes maçantes, poderemos nos perceber em situações parecidas às que foram vividas no tempo das réguas de cálculo, quando o foco se situava fortemente na interpretação dos resultados apresentados e não no cálculo em si. A questão era a de entender como a régua funcionava; o trabalho do cálculo era deixado para ela. Em seguida, interpretar o resultado, perceber a coerência e o significado. 
Especificamente, no âmbito da Universidade, ainda parece ser consenso o fato de o Cálculo ser um curso básico, extremamente importante para a formação de muitos alunos ingressantes. Nesse ambiente, muitos cursos de Cálculo permanecem os mesmos, com a mesma abordagem que era realizada vinte, trinta ou quarenta anos atrás. Ainda podemos observar o deslumbre decorrente da sistematização lógica do Cálculo, quando o processo de limite foi finalmente formalizado e os números reais passaram a constituir um universo onde os matemáticos se movimentam bem.

O estabelecido tornou-se verdade absoluta, que passou a ser transmitido aos estudantes, os homens do futuro. E como vivem eles o presente? $\mathrm{Na}$ realidade, estão sendo preparados para serem homens do futuro ou do passado?

Nos cursos, ainda são feitas para eles as mesmas perguntas que foram feitas no passado, talvez porque, hoje em dia, os professores, eles próprios, muitas vezes, não tenham outras perguntas. Pretendem que os estudantes entendam o Cálculo a partir da lógica interna, ou a partir da sua potência enquanto ferramenta importante na resolução dos problemas?

O computador é capaz de realizar determinadas tarefas algoritmizáveis, e, nesse sentido, ele é muito competente e rápido, resolvendo, em geral, uma série de problemas. Por outro lado, como nem tudo é passível de ser transformado em algoritmo, isto parece diminuir a importância do computador, mas não é este o caso. Em Machado, encontramos que

\footnotetext{
Uma questão que já deu margem a muita discussão e que está no centro das atenções ainda hoje, quando se examinam as possibilidades e as competências dos computadores é a da distinção entre as tarefas que são algoritmizáveis, portanto realizáveis pelos computadores, e as tarefas que não são passíveis de algoritmização. Durante muito tempo, o debate a esse respeito concentrou-se em distinguir criteriosamente os dois tipos de tarefas.
} 
(...) Hoje, questões dessa estirpe não têm mais tanta importância quando se pensa o trabalho da escola. Há um razoável consenso com relação ao fato de que, mesmo as tarefas decididamente nãoalgoritmizáveis podem ter como referência próxima aquelas que o são.

(...) A questão fundamental não é a de classificar os fenômenos em geral em lineares ou não-lineares, mas sim a de como trabalhar com os fenômenos não-lineares aproximando-os por processos lineares. A grande questão é como pensar o não-linear através do linear, o que não significa, obviamente, reduzir tudo à linearidade. O Cálculo Diferencial e Integral trata precisamente disso, ou seja, da aproximação de curvas por retas, de representações de fenômenos não lineares por representações de fenômenos lineares. Metaforicamente, estamos precisando de um "cálculo" desses para tratar da aproximação do que é algoritmizável e o que não é. Sem dúvida, existem tarefas ou processos não-algoritmizáveis, que não são passíveis de realização pelo computador. Mas mesmo essas podem ser tratadas com o apoio de processos algorítmicos. A discussão, portanto, está longe de esgotar-se na simples rotulação de fenômenos ou processos. (Machado, 1995, p.248)

Dessa maneira, precisamos ter claro que o computador é extremamente útil em tarefas que podem ser transformadas em algoritmos, como também em outras que não podem. Em particular, no que diz respeito ao trabalho com o Cálculo, ele é uma ferramenta extremamente útil para propiciar a formulação de inúmeros questionamentos, reflexões e análises que fazem com que a sala de aula se torne visivelmente um ambiente onde relações podem ser estabelecidas, possibilitando articulações diversas e, portanto, a construção do conhecimento. 


\subsection{Novos tempos, novos instrumentos, novos olhares.}

Imaginemos o estudante diante da tela do computador onde aparece o gráfico de uma função.

Com a ajuda do cursor, controlado através do mouse, o estudante seleciona determinado ponto ou intervalo do domínio da função, que imediatamente muda de cor, enquanto aparece seu nome na tela. (por exemplo, ponto de inflexão). Em seguida, a um novo clicar do mouse, a tela inteira é ocupada com a seleção, através de um zoom poderoso.

O estudante escolhe no menu a opção “explicação”. Um filme didático, em câmera lenta, passa a mostrar várias propriedades de um ponto de inflexão. Ao mesmo tempo, uma voz vai fornecendo explicações, relacionando a derivada segunda da função com a concavidade do gráfico.

No menu, há uma opção "mais..." e, ao clicar do mouse, aparece uma nova tela onde a questão do ponto de inflexão é mais explorada, com outros exemplos, inferências verdadeiras ou falsas, questionando o estudante. Sempre no menu, o estudante tem a opção "voltar", que, se escolhida, faz voltar à tela anterior. Há também a opção "dados históricos”, que, se escolhida, mostrará na tela uma seqüência de gravuras referentes à época na qual o assunto foi estudado e uma voz vai falando sobre os matemáticos que trabalharam o assunto. Sucessivamente, a tela vai mudando, mostrando problemas por eles enfrentados.

Ao desejar, o estudante pode voltar ao início, e escolher outra opção, por exemplo, o intervalo onde a variável tende ao infinito. Selecionado esse intervalo, a tela mostrará esse intervalo ampliado com o comportamento da função. No menu, o estudante poderá escolher a opção "cálculo", "mais ...", “dados históricos”. Na opção "cálculo”, aparece uma nova tela com o cálculo 
do limite, possivelmente utilizando a Regra de L'Hospital, e enquanto os cálculos estão sendo efetuados, uma voz vai detalhando o que acontece. Na opção "mais...", um filme didático explora a questão da limite no infinito, com exploração da regra de L'Hospital e outros exemplos, tantos quantos o estudante achar interessante, podendo ele mesmo interagir e fazer perguntas pertinentes.

A elaboração de um tal hipertexto, é perfeitamente viável na atualidade. O professor é substituível? Sob alguns aspectos, sim, mas são exatamente aqueles aspectos onde o professor exerceria de maneira menos nobre as suas funções, ou seja onde ele se mostraria como um grande depósito de informações. A capacidade de questionar, de propor problemas, de buscar onde estão as informações, de estar próximo, de estar presente, de ser gente, de perceber onde estão as dificuldades, essas características a máquina não possui. A sensibilidade do professor, enquanto ser humano, não pode ser substituída. É ela que o torna tolerante e disponível, aberto para as necessidades e dificuldades de seus alunos, buscando sempre novas maneiras de concretizar seus objetivos. A sensibilidade possibilita ao professor observar o brilho nos olhos de seu aluno quando este conseguiu construir o significado.

No cruzamento de olhares é possível perceber todo o prazer propiciado pela compreensão, que, aliás, somente ocorre quando emerge a significação. 


\section{Apêndice}

Apresentamos algumas tabelas com dados referentes aos diferentes cursos de Cálculo Diferencial e Integral ministrados na Universidade de São Paulo, que fornecem fortes indícios a respeito da questão examinada no presente trabalho. As siglas mencionadas referem-se a:

MAT 111 - Cálculo Diferencial e Integral I

MAT 121 - Cálculo Diferencial e Integral II

MAT 104 - Cálculo para Arquitetos I

MAT 124 - Cálculo para Arquitetos II

MAT 132 - Cálculo para Arquitetura

MAT 103 - Complementos de Matemática para Contabilidade

MAT 113 - Complementos de Matemática I

MAT 125 - Complementos de Matemática II

MAT 128 - Complementos de Matemática para Economia I

MAT 129 - Complementos de Matemática para Economia II

MAT 106 - Cálculo para Biociências

MAT 118 - Matemática para Biociências

MAT 104 - Cálculo I para Licenciatura

MAT 133 - Cálculo II para Licenciatura

MAT 136 - Cálculo Diferencial e Integral para Geociências

MAT 131 - Cálculo Diferencial e Integral

MAT 135 - Cálculo para Funções de uma Variável Real

MAT 110 - Cálculo Diferencial e Integral I para Química

MAT 127 - Cálculo Diferencial e Integral II 
Escola Politécnica

MAT 111

Ano

Semestre Alunos Média Aprovados \% Aprovados

$\begin{array}{llllll}1990 & 1 \text { o. } & 808 & 5,1 & 610 & 75,5 \% \\ 1991 & \text { 1o. } & 791 & 5,3 & 608 & 76,9 \% \\ 1992 & \text { 1o. } & 825 & 5,3 & 637 & 77,2 \% \\ 1993 & 1 \text { o. } & 763 & 5,4 & 596 & 78,1 \% \\ 1994 & 10 . & 735 & 6,4 & 634 & 86,3 \% \\ 1995 & 10 . & 721 & 4,9 & 513 & 71,2 \%\end{array}$

MAT 111 (repetição)

Ano Semestre Alunos Média Aprovados \% Aprovados

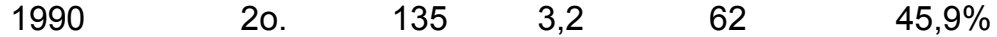

19912 2o. $100 \quad 2,2 \quad 21 \quad 21,0 \%$

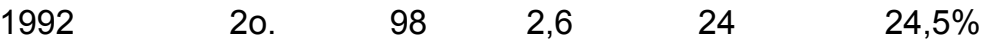

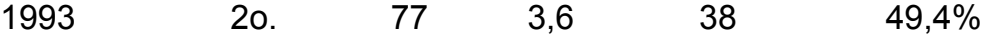

$199420 . \quad 49 \quad 3,6 \quad 26 \quad 53,1 \%$

$199520 . \quad 78 \quad 4,4 \quad 50 \quad 64,1 \%$

MAT 121

\section{Ano}

1990

1991

1992

1993

1994

1995

Semestre Alunos Média Aprovados \% Aprovados

$\begin{array}{lllll}\text { 2o. } & 823 & 4,5 & 532 & 64,6 \% \\ \text { 2o. } & 780 & 4,6 & 483 & 61,9 \% \\ \text { 2o. } & 853 & 5,2 & 642 & 75,3 \% \\ \text { 2o. } & 754 & 5,6 & 577 & 76,5 \% \\ \text { 2o. } & 758 & 4,9 & 506 & 66,8 \% \\ \text { 2o. } & 740 & 5,5 & 563 & 76,1 \%\end{array}$

MAT 121 (repetição)

Ano Semestre Alunos Média Aprovados \% Aprovados

1990

1991

1992

1993

1994

1995

\section{0.}

10.

10.

10.

10.

10.

298

306

124

94

84

78
2,8

3,3

98

123

60

3,6
5,5

4,6

3,2
$32,9 \%$

$40,2 \%$

$48,4 \%$

$78,7 \%$

$64,3 \%$

$35,9 \%$ 
Faculdade de Arquitetura e Urbanismo

MAT 114

Ano Semestre Alunos Média Aprovados \% Aprovados

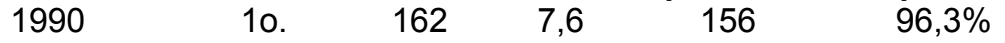

$1991 \quad 10 . \quad 154 \quad 6,2 \quad 136 \quad 88,3 \%$

$\begin{array}{llllll}1992 & 10 . & 164 & 3,6 & 39 & 23,8 \%\end{array}$

MAT 124

Ano

Média Aprovados \% Aprovados

$1990 \quad 20.0165 \quad 5,8 \quad 128 \quad 77,6 \%$

$\begin{array}{llllll}1991 & 20 . & 166 & 5,5 & 133 & 80,1 \%\end{array}$

$\begin{array}{llllll}1992 & 20 . & 70 & 4,0 & 38 & 54,3 \%\end{array}$

MAT 132

Ano

Semestre Alunos Média Aprovados \% Aprovados

1993

anual

$231 \quad 3,8$

123

anual $\quad 275 \quad 4,6 \quad 168$

$53,2 \%$

1994

anual

255

5,3

202

$61,1 \%$

$79,2 \%$ 
Faculdade de Economia e Administração

\begin{tabular}{|c|c|c|c|c|c|}
\hline \multicolumn{6}{|l|}{ MAT } \\
\hline Ano & Semestre & Alunos & Média & Aprovados & $\%$ Aprovado \\
\hline 1990 & 10. & 646 & 3,8 & 321 & $49,7 \%$ \\
\hline 1991 & 10. & 700 & 3,4 & 330 & $47,1 \%$ \\
\hline 1992 & 10. & 459 & 4,2 & 271 & $59,0 \%$ \\
\hline 1993 & 10. & 403 & 3,9 & 206 & $51,1 \%$ \\
\hline 1994 & 10. & 247 & 5,3 & 181 & $73,3 \%$ \\
\hline \multicolumn{6}{|l|}{ MAT 125} \\
\hline Ano & Semestre & Alunos & Média & Aprovados & $\%$ Aprovado \\
\hline 1990 & 20. & 554 & 2,7 & 253 & $45,7 \%$ \\
\hline 1991 & 20. & 622 & 4,2 & 371 & $59,6 \%$ \\
\hline 1992 & 20. & 440 & 4,8 & 293 & $66,6 \%$ \\
\hline 1993 & 20. & 343 & 4,8 & 238 & $69,4 \%$ \\
\hline 1994 & 20. & 226 & 4,1 & 118 & $52,2 \%$ \\
\hline
\end{tabular}

MAT 128

\section{Ano}

1992

1993

1994

Semestre Alunos

Média

Aprovados \% Aprovados

10. $274 \quad 3,9 \quad 147 \quad 53,6 \%$

10. $279 \quad 4,1 \quad 153 \quad 54,8 \%$

10. $274 \quad 4,8 \quad 180 \quad 65,7 \%$

MAT 129

Ano

1992

1993

1994

Semestre Alunos

$\begin{array}{lllll}\text { 2o. } & 201 & 4,8 & 118 & 58,7 \% \\ \text { 2o. } & 219 & 3,8 & 125 & 57,1 \% \\ \text { 2o. } & 271 & 5,2 & 199 & 73,4 \%\end{array}$

MAT 103

Ano

Semestre Alunos Média Aprovados \% Aprovados

1994

1995

$\begin{array}{lllll}\text { 1o. } & 181 & 4,5 & 112 & 61,9 \% \\ 1 \text { o. } & 378 & 5,1 & 271 & 71,7 \%\end{array}$

MAT 111

Ano

1995

Semestre Alunos

10.

236

Média

Aprovados \% Aprovados

MAT 121

Ano

1995

Semestre Alunos Média Aprovados \% Aprovados
20.
192
4,2
119
$62,0 \%$ 
Instituto de Biociências

MAT 118

Ano

Semestre Alunos Média Aprovados \% Aprovados

1990

1991

1992

1993

1994

1995

$10 . \quad 159$

4,8

$69,2 \%$

1o. $164 \quad 4,3 \quad 97 \quad 59,1 \%$

1o. $170 \quad 5,1 \quad 135 \quad 79,4 \%$

1o. $160 \quad 5,3 \quad 131 \quad 81,9 \%$

1o. $155 \quad 5,2 \quad 124 \quad 80,0 \%$

10. $151 \quad 5,6 \quad 124 \quad 82,1 \%$

MAT 106

Ano

1993

1994

1995

Semestre Alunos Média Aprovados \% Aprovados

$\begin{array}{lllll}\text { 2o. } & 56 & 1,9 & 15 & 26,8 \% \\ \text { 2o. } & 47 & 2,8 & 16 & 34,0 \% \\ 20 . & 67 & 4,1 & 40 & 59,7 \%\end{array}$


Instituto de Física

$\begin{array}{lccccc}\text { MAT 111 } & & & & & \\ \text { Ano } & \text { Semestre } & \text { Alunos } & \text { Média } & \text { Aprovados } \% \text { Aprovados } \\ 1990 & 10 . & 567 & 3,1 & 153 & 27,0 \% \\ 1991 & 10 . & 499 & 2,4 & 140 & 28,1 \% \\ 1992 & 10 . & 473 & 2,2 & 132 & 27,9 \% \\ 1993 & 10 . & 364 & 2,9 & 127 & 34,9 \% \\ 1994 & 10 . & 295 & 3,1 & 113 & 38,3 \% \\ 1995 & 10 . & 226 & 3,6 & 102 & 45,1 \%\end{array}$

MAT 111 (repetição)

Ano Semestre Alunos Média Aprovados \% Aprovados

$\begin{array}{llllll}1990 & 20 . & 304 & 2,4 & 95 & 31,3 \% \\ 1991 & 20 . & 242 & 2,2 & 66 & 27,3 \% \\ 1992 & 20 . & 169 & 2,2 & 40 & 23,7 \% \\ 1993 & 20 . & 116 & 3,0 & 46 & 39,7 \% \\ 1994 & 20 . & 99 & 2,7 & 34 & 34,3 \% \\ 1995 & 20 . & 88 & 2,6 & 26 & 29,5 \%\end{array}$

$\begin{array}{lccccc}\text { MAT 121 } & & & & & \\ \text { Ano } & \text { Semestre } & \text { Alunos } & \text { Média } & \text { Aprovados } & \text { Aprovados } \\ 1990 & 20 . & 309 & 3,2 & 121 & 39,2 \% \\ 1991 & 20 . & 276 & 3,2 & 117 & 42,4 \% \\ 1992 & 20 . & 383 & 3,0 & 146 & 38,1 \% \\ 1993 & 20 . & 261 & 4,0 & 144 & 55,2 \% \\ 1994 & 20 . & 198 & 3,8 & 99 & 50,0 \% \\ 1995 & 20 . & 168 & 4,1 & 92 & 54,8 \%\end{array}$

MAT 121 (repetição)

$\begin{array}{lccccc}\text { Ano } & \text { Semestre } & \text { Alunos } & \text { Média } & \text { Aprovados } \% \text { Aprovados } \\ 1990 & 10 . & 60 & 1,5 & 10 & 16,7 \% \\ 1991 & 10 . & 45 & 3,4 & 25 & 55,6 \% \\ 1992 & 10 . & 142 & 3,3 & 59 & 41,5 \% \\ 1993 & 10 . & 92 & 2,1 & 22 & 23,9 \% \\ 1994 & 10 . & 80 & 3,9 & 45 & 56,3 \% \\ 1995 & 10 . & 85 & 2,7 & 30 & 35,3 \%\end{array}$

MAT 104

Ano

1993

1994

1995

Semestre Alunos

$\begin{array}{lcccc}\text { 1o. } & 91 & 4,7 & 53 & 58,2 \% \\ \text { 1o. } & 111 & 2,8 & 39 & 35,1 \% \\ \text { 10. } & 119 & 3,8 & 69 & 58,0 \%\end{array}$

MAT 133

Ano

1993

1994

1995
Semestre Alunos Média Aprovados \% Aprovados

$\begin{array}{lllll}\text { 2o. } & 55 & 5,2 & 36 & 65,5 \% \\ \text { 2o. } & 63 & 4,0 & 39 & 61,9 \% \\ \text { 2o. } & 92 & 5,3 & 67 & 72,8 \%\end{array}$


Instituto de Geociências

MAT 111

Ano

Semestre Alunos Média Aprovados \% Aprovados

1990

1991

1992

1993

10. 67

1,4

11

10. $65 \quad 2,9 \quad 21$

1o. $68 \quad 3,1 \quad 25$

10. $69 \quad 2,7$

19

$16,4 \%$

$32,3 \%$

$36,8 \%$

$27,5 \%$

MAT 121

Ano

Semestre Alunos Média Aprovados \% Aprovados

1990

1991

1992

1993

3,6

11

$55,0 \%$

2o. $22 \quad 4,9 \quad 15 \quad 68,2 \%$

2o. $27 \quad 4,2 \quad 16 \quad 59,3 \%$

2o. $36 \quad 2,6 \quad 12 \quad 33,3 \%$

MAT 136

Ano

1994

Sem

emestre Alunos Média Aprovados \% Aprovados

1995

$\begin{array}{lllll}\text { anual } & 55 & 4,7 & 32 & 58,2 \% \\ \text { anual } & 57 & 3,2 & 20 & 35,1 \%\end{array}$


Instituto de Matemática e Estatística

$\begin{array}{lccccc}\text { MAT } 111 & & & & \\ \text { Ano } & \text { Semestre } & \text { Alunos } & \text { Média } & \text { Aprovados } & \text { \% Aprovados } \\ 1990 & 10 . & 360 & 2,9 & 100 & 27,8 \% \\ 1991 & 10 . & 406 & 2,6 & 113 & 27,8 \% \\ 1992 & 10 . & 399 & 3,3 & 149 & 37,3 \%\end{array}$

MAT 111 (repetição)

Ano Semestre Alunos Média Aprovados \% Aprovados

$\begin{array}{llllll}1990 & 20 . & 202 & 2,3 & 43 & 21,3 \% \\ 1991 & 20 . & 229 & 2,3 & 67 & 29,3 \% \\ 1992 & 20 . & 157 & 2,4 & 48 & 30,6 \%\end{array}$

MAT 121

Ano

Semestre Alunos Média Aprovados \% Aprovados

$\begin{array}{llllll}1990 & 20 & 196 & 3,3 & 80 & 40,8 \%\end{array}$

$\begin{array}{llllll}1991 & 20 & 178 & 3,1 & 68 & 38,2 \%\end{array}$

$\begin{array}{lllll}1992 & 20 & 262 & 3,9 & 126\end{array}$

MAT 121 (repetição)

Ano Semestre Alunos Média Aprovados \% Aprovados

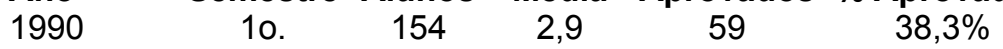

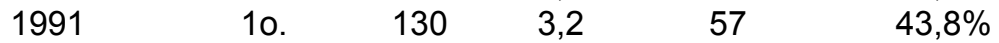

$\begin{array}{llllll}1992 & 10 & 147 & 2,6 & 43 & 29,3 \%\end{array}$

MAT 131

Ano Semestre Alunos Média Aprovados \% Aprovados

1993

1994

1995

anual

137

2,6

42

$30,7 \%$

anual $\quad \begin{array}{llll}160 & 4,4 & 93 & 58,1 \%\end{array}$

anual $130 \quad 4,4 \quad 73 \quad 56,2 \%$

MAT 135

Ano

1993

1994

1995

$\begin{array}{cc}\text { Semestre } & \text { Alunos } \\ \text { anual } & 235 \\ \text { anual } & 197 \\ \text { anual } & 254\end{array}$

Média

Aprovados \% Aprovados

2,2

64

$27,2 \%$

$4,5 \quad 109 \quad 55,3 \%$

anual 254

84

$33,1 \%$ 


\section{Instituto de Química}

\section{MAT 111}

Ano

1990

1991

1992

1993

1994

1995

MAT 127

Ano

1990

1991

1992

1993

1994

1995
Semestre Alunos Média Aprovados \% Aprovados

$\begin{array}{lllll}\text { 1o. } & 79 & 3,8 & 44 & 55,7 \% \\ \text { 1o. } & 89 & 4,3 & 52 & 58,4 \% \\ \text { 1o. } & 89 & 3,8 & 45 & 50,6 \% \\ \text { 10. } & 95 & 4,6 & 60 & 63,2 \% \\ \text { 10. } & 74 & 4,4 & 47 & 63,5 \% \\ \text { 10. } & 78 & 3,8 & 35 & 44,9 \%\end{array}$

Semestre Alunos Média Aprovados \% Aprovados

$\begin{array}{lllll}20 . & 80 & 4,4 & 50 & 62,5 \% \\ 20 . & 66 & 5,1 & 50 & 75,8 \% \\ 20 . & 60 & 3,7 & 32 & 53,3 \% \\ 20 . & 72 & 4,0 & 42 & 58,3 \% \\ 20 . & 85 & 4,1 & 48 & 56,5 \% \\ 20 . & 71 & 4,2 & 38 & 53,5 \%\end{array}$




\section{Bibliografia}

$\diamond$ ANTONIUS, W. Le laboratoire mathématique: la derivée et l'integrale. Ministère de l'Enseignement supérieur et de la Science, 1988.

$\diamond$ ÁVILA, G. O Ensino de Cálculo no $2^{\circ}$ grau. Revista do Professor de Matemática, $\mathrm{n}^{\circ}$ 18, Sociedade Brasileira de Matemática, 1991.

$\diamond$ BALDINO, R. R. Cálculo Infinitesimal: Passado ou Futuro. Temas \& Debates, Ano VIII, Edição n 6, 1995, Sociedade Brasileira de Educação Matemática.

$\diamond$ BARON, M. E. e BOS, H. J. M. Curso de História da Matemática: origens e desenvolvimento do Cálculo. Trad. de José Raimundo Braga Coelho, Rudolf Maier e Maria José M. M. Mendes, Brasília, Editora da Universidade de Brasília, 1985.

$\diamond$ BASS, H. Mathematicians as Educators. Notices of the AMS, vol. 44, n.1, 1997.

$\diamond$ BORDENAVE, J. D. e PEREIRA, A. M. Estratégias de Ensino-Aprendizagem. Petrópolis, Vozes, 1989.

$\diamond$ BOYER, C. B. História da Matemática. Trad. Elza F. Gomide, São Paulo, Edgard Blücher, 1974.

$\diamond$ BOYER, C. B. The History of the Calculus and its conceptual development. New York, Dover Publications, Inc., 1959.

$\diamond$ BRESSOUD, D. M. Why do we teach Calculus? MSC: 0035, 26A06, 1991.

$\diamond$ CALVINO, I. Seis Propostas para o próximo milênio. Trad. de Ivo Barroso, São Paulo, Companhia das Letras, 1990. 
$\checkmark$ D’AMBROSIO, U. Relações entre Matemática e Educação Matemática: Lições do Passado e Perspectivas para o Futuro. Anais do VI ENEM, 1998, Sociedade Brasileira de Educação Matemática.

$\checkmark$ DABAS E. y NAJMANOVICH D. (compiladoras), Redes - El lengage de los vínculos: Hacia la reconstrucción y el fortalecimiento de la sociedad civil. Paidós, Ideas \& Perspectivas, 1995.

$\checkmark$ DESCARTES, R. Discurso do Método. Trad. de João Cruz Costa, Rio de Janeiro, Edições de Ouro, 1969.

$\checkmark$ DOUADY, R., A Universidade e a Didática da Matemática: os IREM na França, Caderno 1 da Revista do Professor de Matemática, Sociedade Brasileira de Matemática, 1990.

$\diamond$ FREIRE, P. Pedagogia do Oprimido. São Paulo, Paz e Terra S/A, 1998.

$\diamond$ GRANGER, G. G. Filosofia do Estilo. Trad. de Scarlett Zerbetto Marton, São Paulo, Perspectiva-EDUSP, 1974.

$\diamond$ HARIKI, S. Analysis of Mathematical Discourse: Multiple Perspectives. Thesis for the degree of Doctor of Philosophy, University of Southhampton, 1992.

$\diamond$ LAKOFF, G. e JOHNSON, M. Metaforas de la Vida Cotidiana. Madrid, Ediciones Cátedra, S.A., 1986.

$\diamond$ LÉVY, P. As Tecnologias da Inteligência: o futuro do pensamento na era da informática. Trad. de Carlos Irineu da Costa, Rio de Janeiro, Editora 34, 1995.

$\diamond$ LÉVY, P. O que é virtual? Trad. de Paulo Neves, São Paulo, Editora 34, 1997.

$\diamond$ MACHADO, N. J. Cidadania e Educação. São Paulo, Escrituras, 1997. 
$\diamond$ MACHADO, N. J. Epistemologia e Didática. São Paulo, Cortez, 1995.

$\checkmark$ MACHADO, N. J. Matemática e Educação: Alegorias, tecnologias e temas afins. São Paulo, Cortez, 1992.

$\checkmark$ MACHADO, N. J. Matemática e Língua Materna (Análise de uma impregnação mútua). São Paulo, Cortez, 1990.

$\checkmark$ METZ, C. et alii. A Análise das Imagens. Trad. de Luís Costa Lima e Priscila V. de Siqueira, Petrópolis, Editora Vozes, 1973.

$\diamond$ MEYER, J. F. da C. A. Modelagem Matemática: do fazer ao pensar. Anais do VI ENEM, 1998, Sociedade Brasileira de Educação Matemática.

$\diamond$ MOLES, A. A Criação Científica. Trad. de Gita K. Guinsburg, São Paulo, Editora Perspectiva, 1998.

$\diamond$ ORLANDI, E. P. Discurso e Leitura. São Paulo, Cortez; Campinas, Editora da Universidade Estadual de Campinas, 1996.

$\diamond$ ORLANDI, E. P. Leitura e Discurso Científico. Cadernos Cedes 41, Ensino da Ciência, Leitura e Literatura, Campinas, Centro de Estudos Educação e Sociedade, 1997.

$\diamond$ PARRA, C e SAIZ, I., (compiladoras). Didáctica de Matemáticas: Aportes y Reflexiones. Buenos Aires, Paidós Educador, 1994.

$\diamond$ POLYA, G. A arte de resolver Problemas. Trad. de Heitor Lisboa de Araújo, Rio de Janeiro, Interciência, 1978.

$\diamond$ PONTE, J. P. da e CANAVARRO, A. P. Matemática e novas tecnologias. Lisboa, Universidade Aberta, 1997.

$\diamond$ PORLÁN, R. Constructivismo y Escuela: Hacia um modelo de enseñanzaaprendizaje basado en la investigación. Bogotá, Diada, 1995. 
$\diamond$ POSSENTI, S. Notas sobre Linguagem Científica e Linguagem Comum. Cadernos Cedes 41, Ensino da Ciência, Leitura e Literatura, Campinas, Centro de Estudos Educação e Sociedade, 1997.

$\diamond$ SCHUBAUER-LEONI, M. L. Le Contrat Didactique: un Cadre Interprétatif pour Comprendre les Savoirs Manifestés par les Elèves en Mathématique. European Journal of Psychology of Education, vol. I, $\mathrm{n}^{\circ} 2,1986$.

$\checkmark$ SNOW, C. P. As duas Culturas e uma segunda leitura. Trad. de Geraldo Gerson de Souza e Renato de Azevedo Rezende Neto, São Paulo, EDUSP, 1995.

$\diamond$ THURSTON, W. P. Sobre Prova e Progresso em Matemática. Trad. de Mário José Dias Carneiro, Michel Spira e Pedro Mendes, Matemática Universitária, n.17, dezembro de 1994.

$\diamond$ VOGT, C. O intervalo Semântico. São Paulo, Ática, 1977.

$\diamond$ VYGOTSKY, L. S. Pensamento e Linguagem. São Paulo, Martins Fontes, 1993.

Os livros didáticos analisados:

$\checkmark$ ALEXANDER H. W. et alii. A Programed Course In Calculus. Vol I, II, III, IV e $\mathrm{V}$, The Committee on Educational Media of the Mathematical Association of America, New York, W. A. Benjamin, Inc., 1968.

$\checkmark$ APOSTOL, T. M. Mathematical Analysis. Reading MA, Addison-Wesley Publishing Company, Inc., 1957. 
$\diamond$ APOSTOL, T. M. Calculus. Vol. I, New York, Blaisdell Publishing Company, 1962.

$\diamond$ ÁVILA, G. Cálculo Diferencial E Integral. Vol. 1, Rio de Janeiro, LTC, 1981.

$\diamond$ BARTKOVICH, K. G. et alii. Contemporary Calculus Through Applications. Dedham MA, Janson Publications Inc., 1995.

$\diamond$ BOULOS, P. Introdução Ao Cálculo. Vol I e II, São Paulo, Edgard Blücher, 1974.

$\diamond$ BRUCKHEIMER, M. et alii. Introducción Al Cálculo Y Al Álgebra. Vol. I e II (Texto de la Open University de Londres), Trad. Bartolomé Frontera Marqués, Barcelona, Editorial Reverté, S. A., 1976.

$\diamond$ BUCK, R. C., Advanced Calculus, New York, McGraw-Hill, Inc., 1965.

$\diamond$ COURANT, R. Differential And Integral Calculus. Vol. I, Trans. E. J. McShane, New York, Nordeman Publishing Company, Inc., 1945.

$\diamond$ COURANT, R. and JOHN, F. Introduction To Calculus And Analysis. Vol. I, New York, Interscience Publishers, 1965.

$\diamond$ GREENSPAN, H. P. and BENNEY, D. J. Calculus - An Introduction To Applied Mathematics. Tokyo, McGraw-Hill Kogakusha, Ltd., 1973.

$\diamond$ GUIDORIZZI, H. L. Um Curso De Cálculo. Vol. I, Rio de Janeiro, LTC Editora, 1997.

$\checkmark$ KAPLAN, W. Advanced Calculus. Reading, MA, Addison-Wesley Publishing Company, Inc., 1959.

$\diamond$ KAPLAN, W e LEWIS, D. J. Cálculo E Álgebra Linear. Vol. I, Trad. Marco Antônio Raupp (coordenador), Rio de Janeiro, LTC, 1972. 
$\diamond$ LANG, S. Cálculo. Vol. I, Trad. Roberto de Maria Nunes Mendes, Rio de Janeiro, Ao Livro Técnico S. A., 1969.

$\diamond$ LEITHOLD, L. O Cálculo Com Geometria Analítica. Vol. I, Trad. Cyro de Carvalho Patarra, São Paulo, Harbra, 1994.

$\diamond$ MOISE, E. E. Cálculo. Um Curso Universitário. Vol. I, Trad. Dorival A. Mello e Renate G. Watanabe, São Paulo, Edgard Blücher, 1970.

$\diamond$ PISKOUNOV, N. Calcul Différentiel Et Integral. Éditions de la Paix, Moscou, s.d.

$\diamond$ RUDIN, W. Principles of Mathematical Analysis. Tokyo, McGraw-Hill Kogakusha Company, Ltd., 1964.

$\diamond$ SIMMONS, G. F. Cálculo Com Geometria Analítica. Vol. I, Trad. Seiji Hariki, São Paulo, McGraw-Hill, 1987.

$\diamond$ SPIVAK, M. Cálculo Infinitesimal. Vol. I e II, Trad, Bartolomé Frontera Marqués, Barcelona, Editorial Reverté, S. A., 1975.

$\diamond$ SWOKOWSKI, E. W. Cálculo Com Geometria Analítica. Vol. I, Trad. Alfredo Alves de Faria, São Paulo, Makron Books, 1994.

$\diamond$ WHITE, A. J. Análise Real: Uma Introdução. Trad. Elza F. Gomide, São Paulo, Edgard Blücher, 1973.

$\diamond$ WILLCOX, A. B. et alii. Introduction To Calculus. Vol. I, New York, Houghton Mifflin Company, 1971. 